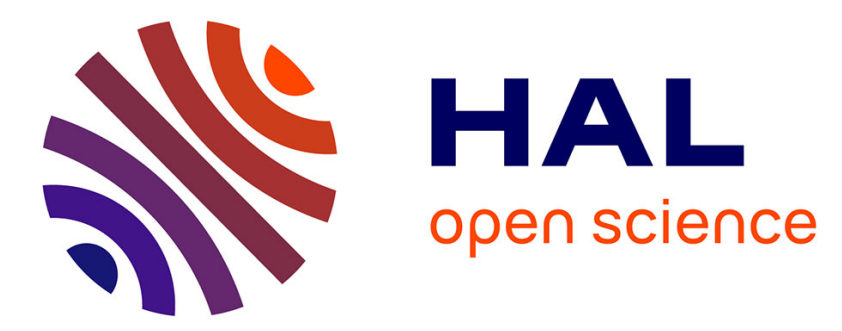

\title{
Comprehensive overview of biased pharmacology at the opioid receptors: biased ligands and bias factors
}

Jolien de Neve, Thomas M. A. Barlow, Dirk Tourwé, Frédéric Bihel, Frédéric Simonin, Steven Ballet

\section{- To cite this version:}

Jolien de Neve, Thomas M. A. Barlow, Dirk Tourwé, Frédéric Bihel, Frédéric Simonin, et al.. Comprehensive overview of biased pharmacology at the opioid receptors: biased ligands and bias factors. RSC Medicinal Chemistry, 2021, 12 (6), pp.828-870. 10.1039/D1MD00041A . hal-03442028

\section{HAL Id: hal-03442028 \\ https://hal.science/hal-03442028}

Submitted on 22 Nov 2021

HAL is a multi-disciplinary open access archive for the deposit and dissemination of scientific research documents, whether they are published or not. The documents may come from teaching and research institutions in France or abroad, or from public or private research centers.
L'archive ouverte pluridisciplinaire HAL, est destinée au dépôt et à la diffusion de documents scientifiques de niveau recherche, publiés ou non, émanant des établissements d'enseignement et de recherche français ou étrangers, des laboratoires publics ou privés. 


\section{Comprehensive overview of biased pharmacology at the opioid receptors: biased ligands and bias factors}

Jolien De Neve ${ }^{a}$, Thomas M. A. Barlow ${ }^{a}$, Dirk Tourwéa ${ }^{a}$ Frédéric Bihel ${ }^{b^{*}}$, Frédéric Simonin ${ }^{c^{*}}$, Steven Ballet $^{\mathrm{a}^{*}}$

a Research Group of Organic Chemistry, Departments of Chemistry and Bioengineering Sciences, Vrije Universiteit Brussel, Brussels, Belgium; ${ }^{b}$ Laboratoire d'Innovation Thérapeutique, Faculté de Pharmacie, UMR 7200, CNRS Université de Strasbourg, Illkrich, France; ' Biotechnologie et Signalisation Cellulaire, UMR 7242, CNRS, Université de Strasbourg, Illkirch, France

This work was financially supported by the Research Foundation Flanders (FWO) and the Flemish Government's Industrial Research Fund (IOF). 


\section{Abbreviations}

6'-GNTI, 6'-guanidinonaltrindole; 7-HMG, 7-hydroxymitragynine; AC, adenyl cyclase; Aib, 2aminoisobutyric acid; AIM, abnormal involuntary movement; ATP, adenosine-5'-triphosphate; BBB, blood-brain barrier; BNTX, 7-benzylidenenaltrexone; BRET, bioluminescence resonance energy transfer; cAMP, cyclic adenosine monophosphate; CBM, cyclobutylmethyl; CDP, chlordiazepoxide; $\mathrm{CHO}$, Chinese hamster ovary; $\mathrm{Cl}$, clearance; $\mathrm{CNS}$, central nervous system; CPA, conditioned place aversion; CPM, cyclopropylmethyl; CPP, conditioned place preference; DALCE, [D$\mathrm{Ala}^{2}, \mathrm{Leu}^{5}, \mathrm{Cys}^{6}$ ] ${ }^{2}$ kephalin; DADLE, [D-Ala ${ }^{2}, \mathrm{D}-$ Leu $^{5}$ ]-enkephalin; DAG, diacylglycerol; DAMGO, [D-Ala ${ }^{2}$, $\mathrm{N}$-MePhe ${ }^{4}$, Gly-ol]-enkephalin; DMSO, dimethylsulfoxide; Dmt, 2,6-dimethyl-tyrosine; DOR, $\delta$-opioid receptor; DPDPE, [D-Pen ${ }^{2}, \mathrm{D}-\mathrm{Pen}^{5}$ ]-enkephalin; Dyn, dynorphin; $\mathrm{ED}_{50}$, half maximal effective dose; $E_{50}$, half maximal effective concentration; ECG, electrocardiogram; $E F C$, enzyme fragment complementation; $E M$, endomorphin; $E_{\max }$, efficacy; ENS, enteric nervous system; ERK, extracellularsignaling regulated kinase; F, bioavailability; FDA, Food and Drug Administration; FRET, fluorescence resonance energy transfer; GDP, guanosine-5'-diphosphate; GEF, guanosine nucleotide exchange factor; GI, gastrointestinal tract; GPCR, G protein-coupled receptor; GPI, guinea pig ileum; GRK, G protein-coupled receptor kinase; GTP, guanosine-5'-triphosphate; GTP $\gamma \mathrm{S}$, guanosine-5'-O-[ $\gamma^{-}$ thio]triphosphate; HEK, human embryonic kidney; HTS, high throughput screening; i.c.v., intracerebroventricular; i.p., intraperitoneal i.t., intrathecal; i.v., intravenous; $\mathrm{IC}_{50}$, half maximal inhibitory concentration; $\mathrm{IP}_{3}$, inositol trisphosphate; KO, knock out; KOR, K-opioid receptor; MAPK, mitogen-activated protein kinase; MOR, $\mu$-opioid receptor; $M P E$, maximal possible effect; $M V$, minute volume; MVD, mouse vas deferens; N/OFQ, nociceptin; NalBzOH, benzoylhydrazone; NFEPP, $N$-(3-fluoro-1-phenethylpiperidin-4-yl)- $N$-phenylpropionamide; NMDA, $N$-methyl D-aspartate; NOP receptor, nociceptin/orphanin FQ peptide receptor; NSAIDs, nonsteroidal anti-inflammatory drugs; NTB, naltriben; NTII, 5'-cyanate-naltrindole; ORL1, opioid-like orphan receptor; PAG, periaqueductal gray; PAM, positive allosteric modulator; PCT, patent cooperation treaty; PD, pharmacodynamics; Pen, penicillamine; $P K$, pharmacokinetics; PNS, peripheral nervous system; PWT, peptide welding technology; s.c., subcutaneous; Sal A, salvinorin A; SAR, structure-activity relationship; SBDD, structure-based drug discovery; SUD, substance use disorder; Tic, tetrahydro-3-isoquinoline carboxylic acid; $\mathrm{V}_{c}$, volume of distribution 


\begin{abstract}
One of the main challenges in contemporary medicinal chemistry is the development of safer analgesics, used in the treatment of pain. Currently, moderate to severe pain is still treated with the "gold standard" opioids whose long-term often leads to severe side effects. With the discovery of biased agonism, the importance of this area of pharmacology has grown exponentially over the past decade. Of these side effects, tolerance, opioid misuse, physical dependence and substance use disorder (SUD) stand out, since these have led to many deaths over the past decades in both USA and Europe. New therapeutic molecules that induce a biased response at the opioid receptors (MOR, DOR, KOR and NOP receptor) are able to circumvent these side effects and, consequently, serve as more advantageous therapies with great promise. The concept of biased signaling extends far beyond the already sizeable field of GPCR pharmacology and covering everything would be vastly outside the scope of this review which consequently covers the biased ligands acting at the opioid family of receptors. The limitation of quantifying bias, however, makes this a controversial subject, where it is dependent on the reference ligand, the equation or the assay used for the quantification. Hence, the major issue in the field of biased ligands remains the translation of the in vitro profiles of biased signaling, with corresponding bias factors to in vivo profiles showing the presence or the lack of specific side effects. This review comprises a comprehensive overview of biased ligands in addition to their bias factors at individual members of the opioid family of receptors, as well as bifunctional ligands.
\end{abstract}




\section{Introduction}

Over the past decades, G protein-coupled receptors (GPCRs) have proven to be important in drug discovery, due to human pathophysiology and their pharmacological tractability. Not surprisingly, GPCRs comprise more than $30 \%$ of all prescription drugs and nearly $40 \%$ of all FDA-approved therapeutics. ${ }^{1}$ An important subfamily of GPCRs is the opioid receptor family (belonging to the GPCR family A: rhodopsin-like receptors). ${ }^{2-3}$ The opioid receptors were named after the opium poppy plant (Papaver somniferum), from which the first opioids, i.e. morphine (1803-1806) $)^{4-5}$ and codeine (1832), were extracted. ${ }^{4}$ The pharmacological actions of opioids are mediated through three 'true' opioid and one opioid-like receptors, with the former being composed of the $\mu-, \delta$ - and the $\mathrm{k}$-opioid receptors (MOR, DOR and KOR respectively) ${ }^{6-10}$ and the latter being the nociceptin/orphanin FQ peptide receptor (NOP), also sometimes referred to as the opioid receptor-like orphan receptor (ORL1). ${ }^{3,11}$ The high sequence homology of NOP receptor with the other opioid receptors $(>60 \%)$ places it within the 'opioid receptor family'. ${ }^{12-13}$

The opioid receptors are present and located in high quantity in the central nervous system (CNS), mostly expressed on prejunctional neurons. The CNS is responsible for the transmission and processing of pain-related nerve impulses, rather than mere participation in sensory perception of pain. ${ }^{14-15}$ Since the opioid receptors occur in the midbrain, limbic and cortical structures, they may be involved in the regulation of other functions, such as stress response and memory. ${ }^{16}$ Furthermore, they are involved in desensitization and internalization, which can account for the development of tolerance as a consequence of $\beta$-arrestin recruitment (vide infra), in addition to analgesic responses. ${ }^{17}$ Alongside their presence in the CNS, opioid receptors can also be found in the peripheral nervous system (PNS). The administration of centrally acting opioid analgesics and/or nonsteroidal anti-inflammatory drugs (NSAIDS) can provide pain relief, but also produces adverse effects. The avoidance of these adverse effects through a peripheral mode of action offers an attractive means to circumvent this, ${ }^{18}$ since peripheral opioids are not capable of crossing the bloodbrain barrier (BBB), thereby avoiding CNS side effects. ${ }^{19}$ As an example, the prevention of desensitization in the PNS, where recycling of the peripheral opioid receptors avoids the development of tolerance to opioids. This being one of the major side effects occurring with systemic administration of opioids, peripheral administration could prevent this problem. ${ }^{20}$ Opioid receptors and their ligands also play an important role in the gastrointestinal (GI) tract, since neuronal excitability is primarily affected by opioids through interaction with neurotransmitters in the enteric nervous system (ENS). ${ }^{16}$

\section{A. GPCR signaling}

We will briefly turn our attention to the mechanisms by which the opioid receptors carry out their signaling, i.e. GPCR signaling processes. GPCR signaling, in general, is constitutionally controlled by three protein families: $G$ proteins, $G$ protein-coupled receptor kinases (GRKs) and $\beta$-arrestins (Figure $1 A) .{ }^{21}$ The intracellular heterotrimeric $G$ protein consists of three subunits, $G_{\alpha}, G_{\beta}$, and $G_{\gamma}$, and is bound to GDP in a 'rest' state or inactive state of the heterotrimer. Upon extracellular agonist binding, the active conformation of the receptor is stabilized by intracellular binding of the $G$ protein, ${ }^{22-23}$ followed by the exchange of GDP for GTP, catalyzed by a GEF, ${ }^{21}$ leading to the dissociation of the $G_{\alpha}$ subunit, which is bound to GTP, and the $G_{\beta \nu}$ subunit. Both subunits are involved in the activation and formation of downstream second messengers, e.g. cyclic adenosine monophosphate (cAMP), inositol trisphosphate $\left(\mathrm{IP}_{3}\right)$, and diacylglycerol (DAG). ${ }^{21-24}$ Upon stimulation 
of the receptor, followed by $\mathrm{G}$ protein activation, the receptor can be phosphorylated by GRKs on the intracellular side of the receptor, most commonly at the $C$-terminus (Figure 1B). Phosphorylation brings about the recruitment of $\beta$-arrestins, which, in turn, is responsible for the desensitization and internalization of the receptor ${ }^{21-22} \beta$-arrestins induce internalization via interaction with clathrincoated pits, and signaling via downstream effectors, e.g. MAPKs. ${ }^{21-22,25}$ Initially, it was thought that G proteins were unable to interact with the receptor due to steric blocking by $\beta$-arrestins, but this was later countered by the fact that both $G$ protein and $\beta$-arrestin can bind simultaneously to the receptor. Cryo-EM and bioluminescence resonance energy transfer (BRET) demonstrated this latter fact in a "megaplex" conformation, capable of activating G protein-signaling. ${ }^{26}$

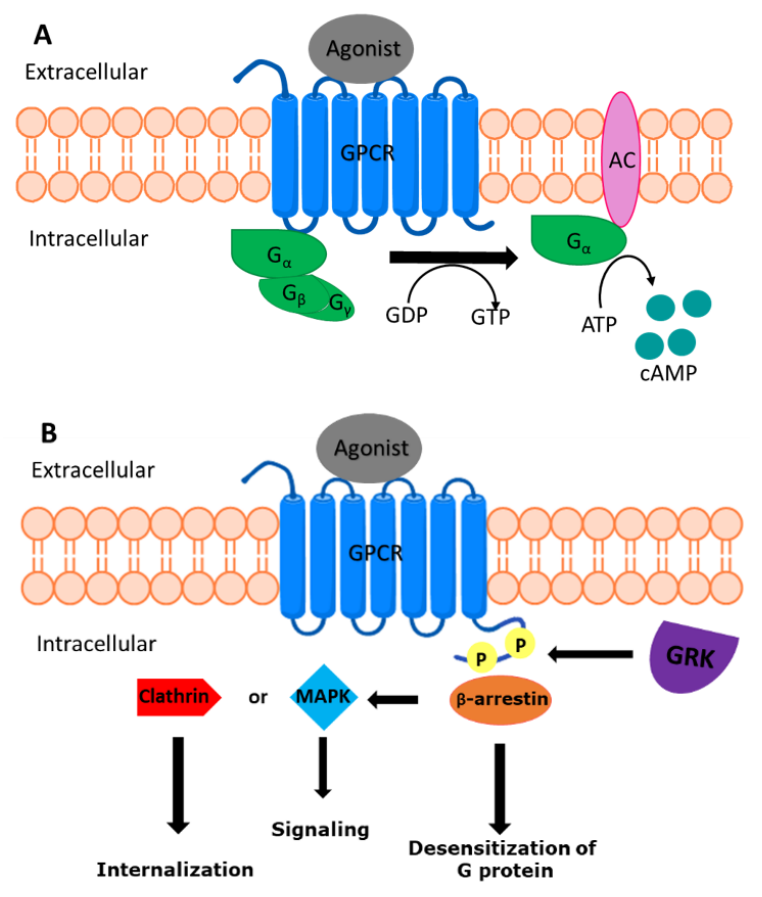

Figure 1: Signaling pathways of GPCRs. A) The G protein pathway B) The B-arrestin pathway

Within the opioid receptor subfamily, the desired analgesic effects are mediated through $\mathrm{G}$ proteinmediated signaling whereas adverse effects are linked to $\beta$-arrestin- 2 recruitment. ${ }^{27}$ The binding of a non-biased agonist at MOR results in an analgesic effect, along with detrimental effects such as respiratory depression, nausea, constipation, tolerance, and physical dependence. ${ }^{19,}{ }^{27}$ Analgesia is also induced at DOR, but to a lesser extent than for MOR, and DOR activation also causes severe side effects, e.g. respiratory depression, ${ }^{28}$ anxiety, ${ }^{29}$ convulsion, depressant effects, ${ }^{19,}{ }^{30}$ constipation and addictive liability. ${ }^{31}$ Stimulation of KOR leads to antinociceptive, antipruritic and antiaddictive effects, but also anhedonia/dysphoria, sedation ${ }^{19,32}$ and anxiety, ${ }^{27,33}$ as well as reduced motor skills and reduced motivation. ${ }^{34}$ NOP receptor has the most complex signaling profile and can either induce or block the analgesia depending on the method by which the ligand is administered, ${ }^{13,35}$ but it can also cause antidepressant-like effects. ${ }^{36}$ Non-biased MOR agonists give way to the strongest analgesic effect, when compared to the other opioid receptors, but also the strongest side effects.

\section{B. The $\mu$-opioid receptor (MOR)}

MOR was first cloned from rat brain cDNA by Chen et al. in $1993^{37-39}$ and can be classified into $\mu_{1}$, $\mu_{2}{ }^{40}$ and $\mu_{3}{ }^{41}$-subtypes. This classification, not only for MOR, but also for the other opioid receptors, essentially originate from classical pharmacology experiments. ${ }^{40}$ The $\mu_{1}$-subtypes are involved in 
various opioid effects, such as supraspinal analgesia, decrease in acetylcholine turnover, the induction of catalepsy and prolactin release. The other subtypes, $\mu_{2}$, are involved in respiratory depression, the delayed GI tract transit induced by opioids and decreased dopamine turnover. ${ }^{42-43}$ Additionally, the presence of $\mu_{3}$-subtypes in endothelial cells has been described by Stefano et al. who demonstrated the good binding affinities of this subtype for alkaloids $\left(K_{i}<50 n M\right)$, but not for peptide-based ligands $\left(K_{i}>1000 n M\right){ }^{41}$

MOR ligands, comprising mainly opioids, are used in the clinic to treat pain. One of the most commonly known MOR ligands is morphine, which is still currently used in clinic as a drug to treat pain, both acute and chronic pain. Unfortunately, morphine also leads to constipation, tolerance, and physical dependence. ${ }^{44} \mathrm{~A}$ milestone within the field of $\mathrm{G}$ protein-biased MOR ligands was the discovery of TRV130 (vide infra) which progressed as far as phase III clinical trials due to its $G$ protein-biased activity showing fewer side effects, e.g. respiratory depression ${ }^{45}$ and gastrointestinal inhibition, ${ }^{46}$ comparable to that of morphine. ${ }^{47}$ Ultimately, however, the FDA declined the compound owing to concerns about safety profiles, ${ }^{48}$ but subsequently in August 2020, TRV130 was approved marketed as OLINVYK ${ }^{\top M}$, for the treatment of severe acute pain through intravenous administration. Nevertheless, there is still a lack of better pain killers, especially for the treatment of chronic pain.

\section{The $\delta$-opioid receptor (DOR)}

DOR was the first opioid receptor to be cloned from mouse cDNA and monkey kidney COS cells (by Evans et al. and Kieffer et al. in 1992). ${ }^{38-39,49-50}$ As for MOR, so too can DOR be classified into different subtypes: $\delta_{1}$ and $\delta_{2}$. The $\delta_{1}$-subtypes is activated by DPDPE and blocked by DALCE and BNTX whereas the $\delta_{2}$-subtypes are activated by deltorphin II and blocked by NTB and NTII. It follows, then, that $\delta_{1}$ and $\delta_{2}$ differ not only in the signaling pathways to which they are coupled, but also in their structure. ${ }^{51}$ Both subtypes are capable of inducing analgesia, but the $\delta_{1}$-subtype is located in the brain and periphery, whereas the $\delta_{2}$-subtype is located in the brain and spinal cord. ${ }^{43}$ Furthermore, upon increase in DOR cell surface expression, an increase in DOR function was observed in periaqueductal gray (PAG), caudate and accumbens nuclei when testing physiologic stressor, e.g. stress-induced by forced swim test. ${ }^{51-52}$ For chronic stress, increased DOR function was observed in the ventral tegmental area. Additionally, DORs are located as such to modulate nociceptive transmission, since they are present on the dendrites and soma of intrinsic neurons as well as on primary afferent terminals of sensory neurons. Additionally, an improved antihyperalgesic effect increasing the DOR function was induced by chronic inflammation associated with tissue injury. Furthermore, it's unclear whether DOR activation does produce rewarding effects, considering many studies report conflicting results in outcome measurements of reward and additive behaviors. ${ }^{51} \mathrm{DOR}$ also plays an important role in modulating different types of memory processes and hippocampaland striatal-dependent learning, as well as motor function, motivation, and reward, with major implications for the control of cognitive performance and motor function under healthy and pathological conditions. ${ }^{53}$

In contrast to MOR, DOR ligands are involved in regulating anxiety and other mood disorders as well as analgesia. ${ }^{51}$ It has been shown that the anxiolytic and antidepressant-like effects can be separated from other behavioral effects, e.g. convulsions. ${ }^{30}$ This makes DOR ligands highly desirable for a number of therapeutic applications that differ significantly from $\mathrm{MOR}^{51}$ even though clinical 
candidates ADL5747 and ADL5859 failed in phase II, since the primary endpoint (pain reduction) was not met. For this reason, further investigation was aborted. ${ }^{54}$

\section{The k-opioid receptor (KOR)}

Another opioid receptor, KOR, was first cloned from mouse brain CDNA in the same year as MOR by Yasuda et al. ${ }^{38-39,55}$ As well as both MOR and DOR, different subtypes were also discovered for KOR based on receptor binding studies. Two variants, $\mathrm{K}_{1}$ and $\mathrm{K}_{2}$, were first described in rat and guinea pig

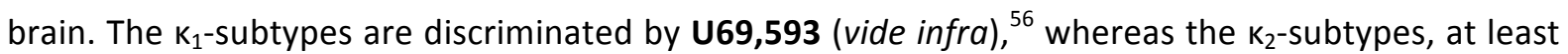
two in both rat and human brain, are differentiated via ligand selectivity, which differs from that observed in guinea pigs. ${ }^{57}$ In addition to $\mathrm{K}_{1}$ and $\mathrm{k}_{2}, \mathrm{~K}_{3}$-subtypes have been suggested by Clark et al., showing a high affinity towards naloxone benzoylhydrazone ( $\mathrm{NalBzOH})$, but no affinity towards U50,488 (vide infra). ${ }^{42-43,58}$ KOR is well distributed throughout the CNS, as well as the PNS. ${ }^{19}$ Furthermore, the presence of high levels of KOR in the nucleus accumbens shell and core, claustrum, ventral pallidum, medial habenula, caudate putamen, endoperiform nucleus, bed nucleus of the stria terminals, and amygdala was demonstrated by immunohistochemical and autoradiographic studies. ${ }^{59-60}$ After the production of KOR in the ventral tegmental area, the receptors are transported to the nucleus accumbens and caudate putamen. Here, they are expressed on presynaptic terminals and additionally control the release of dopamine ${ }^{61-62} \mathrm{KOR}$ agonists can induce antipruritic effects, due to their expression not only in the CNS, but also in the skin, since pruritus can be treated via peripherally-acting KOR agonists. Additionally, in the epidermis of atopic dermatitis and itchy psoriasis patients KOR immunostaining is downregulated. ${ }^{63}$ KOR is widely expressed in the PNS. ${ }^{19,64}$ The need to cross the BBB is therefore avoided, alongside any possible CNS side effects. ${ }^{19}$

KOR also seems to be involved in sedation and diuresis. Interestingly, upon administration of different KOR agonists, e.g. bremazocine, ethylketazocine, tifluadom, and U50,488 (vide infra) in rhesus monkeys, an increased urine output was observed, whereas this was not the case for morphine, but could be antagonized by naltrexone, MR2266, and quadazocine. ${ }^{65}$ Additionally, in the pathophysiology of depression and anxiety disorders, dynorphin and KOR are present throughout limbic brain areas. ${ }^{66}$ KOR agonists can exhibit hallucinogenic effects, as is the case with salvinorin $A$ (vide infra), ${ }^{67}$ in addition to antipruritic and analgesic effects. Furthermore, KOR agonists are able to induce anhedonia, dysphoria and anxiety. A well-known natural product still used today is menthol, an antipruritic/analgesic compound activated through the central $\mathrm{k}$-opioid system ${ }^{68}$ used in ointment form, to treat abrasions.

\section{E. The nociceptin/orphanin FQ peptide receptor (NOP receptor)}

The last opioid receptor, NOP receptor, was discovered many years after the three 'classical' opioid receptors. Mollereau et al. cloned the receptor with high homology towards the other opioid receptors. ${ }^{69}$ In mice CNS, NOP receptor transcripts are mainly expressed in the limbic areas, hypothalamus, brainstem and spinal cord, meaning they are potentially endowed in different central functions. Mollereau and coworkers suggested that NOP receptor could regulate neuroendocrine secretion in the hypothalamo-pituitary axis, together with regulation of nociception in the central gray and dorsal horn of the spinal cord in addition with emotions, behaviors and memory in the limbic areas. ${ }^{69}$ The effects of the administration of the endogenous peptide nociceptin (N/OFQ) on nociception were summarized by Mogil and Pasternak, who highlighted a number of different phenomena, e.g. anxiolytic effects, hypotension, induction of withdrawal symptoms, controversial 
pain effects, inhibition of bronchoconstriction, etc. Moreover, these effects suggest a wide range of application at NOP receptor. ${ }^{70}$

NOP receptor has some interesting properties of its own that, again, are very different from what is seen in the classical opioid receptors. NOP receptor agonists have been investigated for their activity against pain, abuse, anxiety and cough. ${ }^{71}$ NOP receptor can either induce or block analgesic effects depending on the route of administration of its agonists. ${ }^{13,35}$ Under conditions of opioid-induced analgesia, N/OFQ can block opioid-analgesic effects, or regulate the analgesic effect by antagonizing the $\mu$-opioid-induced analgesia resulting in a reduction of hyperalgesia. ${ }^{35,} 72$ The first clinical evidence for this was proven by the fact that increased nociceptin levels, N/OFQ at NOP receptor, were found in the cerebrospinal fluid of parkinsonian patients. ${ }^{73-74}$ Furthermore, administration of NOP receptor antagonists, just before administration of morphine, increased tail flick latency, which illustrated the blocking of tolerance. ${ }^{71}$ In mice, upon N/OFQ administration, tail flick latency was not decreased and blocked intracerebroventricular injection-induced analgesia. ${ }^{71}$ Sadly, upon chronic administration of NOP receptor agonists, attenuation of anti-allodynic and analgesic effects occured. ${ }^{75}$ On the other hand, NOP receptor antagonists have been examined for their activity towards depression, and additionally motor symptoms in Parkinson's disease. ${ }^{74}$

\section{F. Biased agonism}

As a result of these adverse effects, the search for better and safer opioid analgesics has been expanded over the past decades, in the form of biased agonists. ${ }^{21,} 26-27,76-78$ Nowadays, biased agonism has gained serious interest in modern drug discovery, as fine-tuned GPCR ligands have the potential to improve existing therapies through, for example, the exclusion of side effects. ${ }^{76}$ GPCR ligands have been classified based on their efficacies or potencies for activation of $G$ proteins dependent on their ability to provoke a receptor response. ${ }^{24}$ These ligands are able to engage distinct motifs in the GPCR structure to stabilize one of a number of discrete active conformations which favor the activation of one signaling pathway over the other. ${ }^{79}$ The word "bias" implies an inherent inequality and therefore needs to be applied to a pleiotropically linked receptor. ${ }^{80}$ The term "biased agonism" describes the ability to selectively activate one cell signaling pathway of the receptor over another (Figure 2) ${ }^{24,26,76-77}$ This can also be referred to as "functional selectivity". ${ }^{24}$

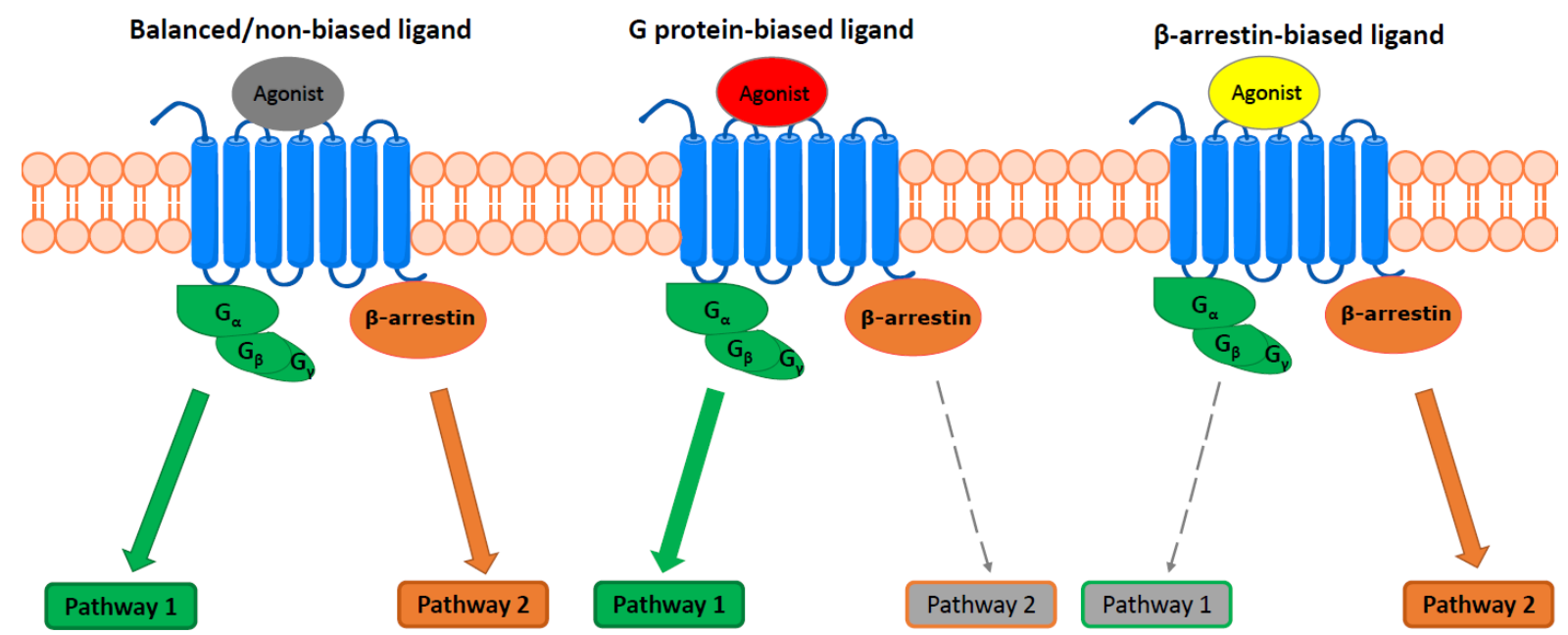


The very first arguments about biased signaling came from the idea of developing more effective and selective therapeutics, in particular antipsychotics. ${ }^{80}$ This led to the development of aripiprazole, an agonist of the dopamine $D_{2}$ receptor. While eliciting the desired response, aripiprazole did not promote internalization ${ }^{82}$ and was therefore classified as a biased agonist. ${ }^{80}$ Depending on the GPCR, a specific pathway - for instance the $G$ protein or the $\beta$-arrestin pathway (Figure 2 ) - is preferred for a biological response. For example, carvedilol is a non-selective $\beta_{1 / 2}$-adrenoceptor antagonist used for congestive heart failure. It stimulates phosphorylation and internalization of the receptor and $\beta$ arrestin translocation, while it fails to activate $G$ protein and thus serves as a $\beta$-arrestin-biased ligand, since this is the pathway with the wanted biological responses. ${ }^{83-84}$ The ability of biased ligands to discriminate between $G$ protein and $\beta$-arrestin-mediated responses at receptor level should ease selective commitment of a group of signals from a specific GPCR. To determine the therapeutic potential of the different pathways, i.e. $G$ protein and $\beta$-arrestin, the biggest obstacle is the lack of knowledge concerning the roles of the specific pathways in terms of signaling for both health and disease. ${ }^{85}$ For opioid receptors specifically, the $G$ protein pathway is preferred, since it leads to the analgesic responses, whereas the $\beta$-arrestin pathway leads to the undesired effects (vide supra). ${ }^{27}$ Despite many advantages, a number of questions remain: the first among these is whether the observed biased responses originate from the partial agonism of the ligand or from an actual inherent bias. Importantly, recent reports have questioned the importance of $\beta$-arrestin- 2 in the development of side effects associated with the administration of opioids. ${ }^{86-90}$ In one study, Kliewer et al. demonstrated an increase in analgesia, and decrease in tolerance, but at the same time worsening the other opioid side effects in phosphorylation-deficient $G$ protein-biased MOR. ${ }^{90}$ In addition, the authors were unable to replicate the original data regarding the results obtained in $\beta$ arrestin-2 KO mice with morphine. ${ }^{89}$ In 2020, Gillis et al. showed that opioids with improved side effect profiles can be obtained by low intrinsic efficacy for $G$ protein activation, rather than from a bias itself. ${ }^{86}$ Furthermore, the role of biased agonism in GPCR drug discovery is taking an increasingly prominent role, but is accompanied by additional complexities in the search for safer drugs. ${ }^{24}$ Importantly, to date, a major complication in this process has been the translation of in vitro profiles of biased signaling into in vivo systems, which is still lacking an efficient link. This is due, in part, to the many differences in physiological systems upon measuring bias. It remains an fundamental challenge to deconvolute in vivo biological responses towards the GPCR signaling pathways. ${ }^{24,80,91}$ Besides a bias towards $G$ protein and $\beta$-arrestin, and since opioid receptors can couple to multiple $G$ proteins, the possibility of an intra-G protein bias also exists. However, since a treatment of this topic goes beyond the scope of this review, no further details on this will be discussed. Interested readers are, however, directed to work of Tso and colleagues dealing with this issue. ${ }^{92}$

In recent years it has also become clear that alongside spatial and qualitative parameters at play in dynamic signaling events, there is also a temporal dimension to be considered. A number of discoveries have shown that cells are able to use ligand residence times, kinetic scaffolding and oscillatory phenomena (among others) to introduce a time-encoded dimension into their signaling. These dynamics are still being fully elucidated and will not feature in the present discussion. Interested readers are, however, referred to the illuminating review of Grundmann and Kostenis. ${ }^{93}$ In this review, biased ligands of all four opioid receptors, in addition to bifunctional biased opioid ligands, will be discussed. Even though $\mathrm{G}$ protein-biased ligands at the opioid receptors are favored, a number of $\beta$-arrestin-biased ligands are provided, all of which will be compared to a given reference ligand for the specific receptor. 


\section{Measuring bias in vitro and calculation of bias}

When considering biased agonism or biased responses, three components contribute to the overall effect, namely biased ligands, biased receptors, and system bias. Biased ligands are compounds that selectively enhance one signaling pathway versus others, compared to a reference ligand. Biased receptors, on the other hand, are capable of producing bias in their signaling profiles by differences in receptor structure or conformation compared with the 'wild-type' receptor. In contrast, a system bias means biased signaling directed by the relative expression of receptor transducers, such as increased expression of the $\mathrm{G}$ protein, GRKs or $\beta$-arrestins. ${ }^{21,94}$ Biased agonism can be determined via in vitro measurements of specific ligands. Via different read-outs, such as quantification of GTP $\mathrm{S}$ or cAMP levels, $G$ protein-signaling can be determined, while for $\beta$-arrestin signaling, the GRKs expression or $\beta$-arrestin recruitment is measurable. ${ }^{33}$ To assign in vitro bias, it is necessary to quantify the ligand bias which can be calculated with one of the following equations:

Equiactive comparison, analogous to the method of Furchgott (1966): ${ }^{24,95-96}$

1) $\beta=\log \left(\frac{R A_{12, \mathrm{lig}}}{R A_{12, \text { ref }}}\right)=\log \left(\left(\frac{E_{\max , 1}}{E C_{50,1}} \frac{E C_{50,2}}{E_{\max , 2}}\right)_{\text {lig }} x\left(\frac{E_{\max , 2}}{E C_{50,2}} \frac{E C_{50,1}}{E_{\max , 1}}\right)_{\text {ref }}\right)$

Equation 1: The equiactive comparison with B: bias factor; RA: relative activity; 1 \& 2 are pathways; $E_{\text {max }}$ efficacy; $E C_{50}$ : potency; lig: ligand; ref: reference ligand

Operational model based on Black and Leff model (1983): $:^{24,91,97-99}$

2) $\beta=\Delta \Delta \log \left(\frac{\tau}{K_{\mathrm{A}}}\right)=\left(\log \left(\frac{\tau}{K_{A}}\right)_{\text {lig }}-\left(\frac{\tau}{K_{A}}\right)_{\text {ref }}\right)_{\text {pathway } 1}-\left(\log \left(\frac{\tau}{K_{A}}\right)_{l i g}-\left(\frac{\tau}{K_{A}}\right)_{\text {ref }}\right)_{\text {pathway } 2}$

Equation 2: Operational model with B: bias factor; $\tau$ : efficacy; $K_{A}$ : equilibrium dissociation constant; $\left(\tau / K_{A}\right)$ : transduction coefficient; lig: ligand; ref: reference ligand

Of note, the antilog of the bias factor $\beta\left(10^{\beta}\right)$ of equation 2 has also been described as a measure of bias. ${ }^{98}$ In cases where the bias factor $\beta$ is greater than zero (Table 1 ), the ligand is biased towards pathway 1 . When $\beta$ is smaller than zero, on the other hand, the ligand is biased towards pathway 2 . In terms of the antilog, however, this either gives values greater than one or between zero and one respectively. For the purposes of this review, the biased values provided, correspond to the $\beta$ values for equations 1 or 2 .

Table 1: The bias towards a certain pathway is dependent on the sign of the bias factor $B$

\begin{tabular}{c|cc} 
Bias factor $\boldsymbol{\beta}$ & G protein pathway & $\boldsymbol{\beta}$-arrestin pathway \\
\hline Smaller than zero & $/$ & Unfavored bias \\
Greater than zero & Favored bias & $/$ \\
\hline
\end{tabular}

It should be noted that equation 1 is more accessible, since only $E_{\max }$ and $\mathrm{EC}_{50}$ values are needed, whereas in equation 2 a wider range of data (e.g. binding affinity data) is required. ${ }^{98}$ Importantly, bias factors can differ drastically when changing between the two equations, when switching reference ligand or when using a different assay. This will be shown throughout the review upon discussion of the various ligands as well as in the extensive table in the supporting information. 
In the next paragraphs, biased ligands with their bias factors will be discussed using equations 1 and 2. Additionally, an extensive overview of the bias factors of their discussed ligands are tabulated in the supporting information.

\section{Biased ligands}

\section{A. Biased $\mu$-opioid receptor ligands}

Though the $\mu$-opioid receptor induces the most and strongest adverse effects, it also induces the most powerful analgesic effects. The development of $\mathrm{G}$ protein-biased $\mu$-opioid receptor ligands is therefore of great therapeutic importance as the $G$ protein pathway is involved in antinociception, whereas the $\beta$-arrestin pathway is involved for the undesired side effects, e.g. tolerance, physical dependence, nausea, constipation and respiratory depression. ${ }^{19}$ To determine the biased activity of MOR ligands, reference ligands are used to compare functional activities. These reference ligands for MOR in the literature are generally morphine, oxycodone, fentanyl, and mainly DAMGO. Different biased $\mu$-opioid receptor ligands are listed and discussed briefly. 
<smiles>COc1ccsc1CNCC[C@@]1(c2ccccn2)CCOC2(CCCC2)C1</smiles>

TRV130

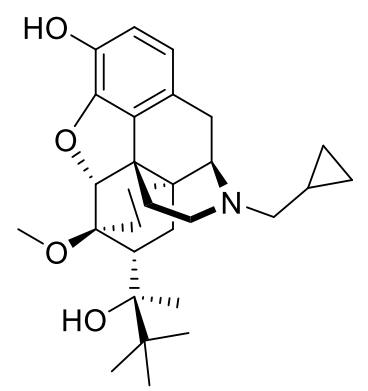

Buprenorphine<smiles>COC(=O)[C@H]1C=C(OC(=O)c2ccccc2)C(=O)[C@@H]2[C@@H]3C[C@H](c4ccoc4)OC(=O)C3CC[C@]12C</smiles>

Kurkinorin

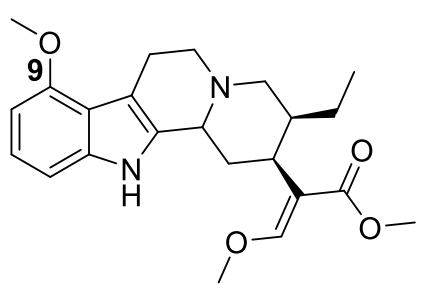

Mitragynine<smiles>C[C@H](Cc1ccsc1)NC(=O)NC[C@@H](Cc1ccc(O)cc1)N(C)C</smiles>

PZM21<smiles>COC(=O)[C@H]1C[C@@H](OC(C)=O)C(=O)[C@]2(C)[C@@H]3C[C@H](c4ccoc4)OC(=O)C3CC[C@]12C</smiles>

Salvinorin A<smiles>COC(=O)[C@H]1C[C@@H](NC(=O)c2ccccc2)C(=O)[C@@H]2[C@@H]3C[C@H](c4ccoc4)OC(=O)C3CC[C@]12C</smiles>

Herkamide

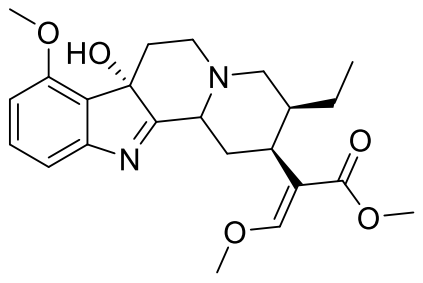

7-HMG

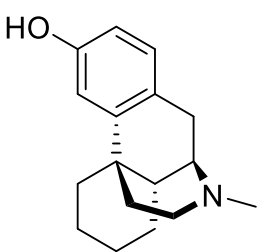

Levorphanol<smiles>CN1CC[C@H]2Cc3ccc(O)c4c3[C@@]2(CCN1C)[C@H](O)C4</smiles>

Morphine<smiles>COC(=O)[C@H]1C[C@@H](OC(=O)c2ccccc2)C(=O)[C@]2(C)[C@H]3C[C@H](c4ccoc4)OC(=O)C3CC[C@@H]12</smiles>

Herkinorin<smiles>COC(=O)[C@H]1C[C@@H](OC(=O)c2ccc(CO)cc2)C(=O)[C@]2(C)[C@H]3C[C@H](c4ccoc4)OC(=O)C3CC[C@@H]12</smiles>

25

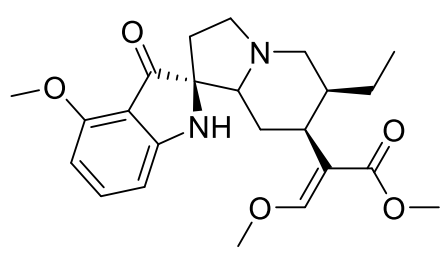

Mitragynine pseudoindoxyl

Figure 3: Structures of biased MOR ligands and reference ligands - part 1 


\section{Oliceridine (TRV130) and TRV734}

Oliceridine ( $(R)$-TRV130, Figure 3$)$ is a small molecule G protein-biased MOR agonist which induces very little $\beta$-arrestin-2 recruitment in rodent models. ${ }^{100}$ It was discovered by Chen and coworkers via structure-activity relationship (SAR) studies and later developed by Trevena. The S-enantiomer of TRV130 showed a strong bias towards $G$ protein-signaling, as it failed to recruit any of the $\beta$ arrestins, but unfortunately, the $\mathrm{G}$ protein activation by the $S$-isomer was also 90 -fold lower than for the $R$-enantiomer. The stereochemistry is therefore of great importance for the binding kinetics. ${ }^{101}$ In other studies, TRV130 showed an $\mathrm{EC}_{50}$ of $8 \mathrm{nM}$ and an $\mathrm{E}_{\max }$ of $83 \%$ for $\mathrm{G}$ protein coupling using a cAMP accumulation assay and an $E_{\max }$ of $14 \%$ for $\beta$-arrestin- 2 recruitment in hMOR compared to morphine $\left(\mathrm{EC}_{50} \approx 50 \mathrm{nM}\right.$ ). In vivo studies indicated that TRV130 reduced the effects of respiratory depression and constipation in rats relative to morphine, upon rat blood gas and glass bead colonic motility assays respectively. Furthermore, morphine caused a statistically significant increase in $\mathrm{pCO}_{2}$, whereas TRV130 did not induce this effect even at 8-fold higher equianalgesic doses. The quantification of bias was performed using the equiactive comparison equation (Equation 1) resulting in a bias factor of 3 for TRV130; that is to say, TRV130 is 3-fold more biased towards the G protein pathway than morphine. ${ }^{45}$ Later studies by Burgueno et al. calculated a bias factor using the operational model of Black \& Leff (Equation 2), providing a value of 1.64, when compared to morphine. ${ }^{102}$ From this can be concluded that using both equations can give a sizeable difference in bias factors, even when using the same reference ligand. Additionally, Altarifi and coworkers published further proof of reduced side effect profile of TRV130. The authors demonstrated antinociception upon repeated administration, along with gastrointestinal inhibition and an abuse liability similar to morphine. ${ }^{46}$ In the same study, the authors also demonstrated the inactivity of the (S)-isomer. ${ }^{46}$ Despite the promising in vitro and in vivo studies, ${ }^{45-46}$ the first clinical trials showing favorable pharmacokinetics (PK), pharmacodynamics (PD), safety, and tolerability results and favorable side effects profiles, ${ }^{103-104}$ and successfully completing phase Ila and $\mathrm{Ilb},{ }^{105-106}$ the results of phase III clinical studies with patients suffering from moderate-to-severe post-operative pain were less gratifying, as no statistical significance was obtained in terms of analgesia compared to morphine, but a safety and tolerability profile was observed with regard to respiratory and gastrointestinal adverse effects compared to morphine. ${ }^{47,107}$ However, due to concerns about potential cardiac side effects (QT interval prolongation on the electrocardiogram (ECG)), the FDA advisory committee did not approve TRV130. ${ }^{48}$ Supplementary safety data were then provided by Trevena, and in August 2020, TRV130 was approved by the FDA, marketed as OLINVYK ${ }^{\text {TM }}$, as a new chemical entity approved in adults for the management of acute pain severe enough to require an intravenous opioid administration.

TRV734, a close analog of TRV130, is an orally bioavailable G protein-biased $\mu$-opioid receptor agonist developed by Trevena and currently in Phase I trials. The results of the first-in-human trials were published in early 2020 by James et al. ${ }^{108}$ TRV734 was shown to be safe and well-tolerated at single doses of 2 to $250 \mathrm{mg}$. Within this range, acceptable PK were demonstrated with a minimal effect of food on its absorption. The preliminary PD data indicate that concentrations after single doses of $>80 \mathrm{mg}$ may be effective for pain relief. ${ }^{108}$

\section{PZM21}

PZM21 (Figure 3) is a small molecule, reported by Manglik et al from the authors' own structurebased drug discovery (SBDD) efforts. ${ }^{109} \mathrm{~A}$ docking campaign consisting of more than 3 million commercially available lead-like molecules from the ZINC database ${ }^{110}$ docked into the orthosteric 
pocket of the inactive MOR, led to a refined subset of 2500 compounds from which 23 highestscoring molecules were selected. The compound with the highest potency was then optimized, resulting, ultimately, in PZM21, which showed affinities towards MOR $\left(K_{i}=1.1 \mathrm{nM}\right), \operatorname{DOR}\left(K_{i}=506\right.$ $\mathrm{nM})$, and KOR $\left(\mathrm{K}_{\mathrm{i}}=18 \mathrm{nM}\right)$. In mice, PZM21 produced a level of analgesia with a maximal possible effect (MPE) of $87 \%$ in a hotplate test, reached $15 \mathrm{~min}$ after administration of $40 \mathrm{mg} / \mathrm{kg}$. This result was similar to TRV130 and morphine (but used at lower doses of $1.2 \mathrm{mg} / \mathrm{kg}$ and $10 \mathrm{mg} / \mathrm{kg}$ respectively). PZM21 showed no analgesia in the tail-flick assay compared to morphine, an unprecedented distinction among opioid analgesics. Respiratory depression was explored by measuring the respiration by whole-body mouse plethysmography, (which measures changes in the volume of the body due to differing amounts of air in the lungs). While the respiratory frequency decreased 20 min after administration of morphine, an equianalgesic dose of PZM21 led to no effect on the respiration versus the vehicle. Weak $\beta$-arrestin recruitment, which was not quantifiable, was observed using a BRET assay, even with overexpressed GRK2 which resulted in an $E_{\max }$ of $32 \%$ of $\beta$ arrestin recruitment. Additionally, a minimal level of the MOR internalization with an $E_{\max }$ of $8 \%$ was obtained relative to DAMGO and morphine ( $E_{\max }$ of $100 \%$ and $42 \%$ respectively) and comparable to TRV130 ( $E_{\max }$ of $\left.9 \%\right) .{ }^{109}$ However, these findings were countered by Hill et al. who reported that PZM21 had low efficacy on $G$ protein coupling $\left(E_{\max }\right.$ of $39 \%$ ) in comparison to DAMGO and morphine ( $E_{\max }$ of $100 \%$ and $55 \%$ respectively) using a BRET assay. ${ }^{111}$ Nevertheless, PZM21 did produce antinociception upon administration of a $40 \mathrm{mg} / \mathrm{kg}$ dose using a hot-plate test, but alongside prolonged respiratory depression was reached after 10-15 min upon subcutaneous (s.c.) administration by measuring minute volume (MV) of breathing air, in the same way as morphine at equianalgesic doses. Moreover, it was noted that tolerance to antinociception by PZM21 was developed in male mice upon receiving twice-daily doses for four days similar to morphine. After two days, the MPE was less than $40 \%$ and after the fourth day less than $10 \%{ }^{111}$ In addition, a more recent study demonstrated that PZM21, but also TRV130 and buprenorphine (vide infra), generate less respiratory depression at equiactive doses as compared to morphine and fentanyl, using the same test - i.e. the whole-body mouse plethysmography - as described by Manglik et al ${ }^{86}$ The discrepancies seen in the different studies above reflect the difficulties inherent to the interpretation of in vivo biased signaling profiles of in vivo profiles.

\section{Morphine and morphine-like compounds}

Morphine (Figure 3 ) is undoubtedly the most famous naturally occurring opioid, extracted from the opium poppy plant by Friedrich Sertürner at the beginning of the $19^{\text {th }}$ century $^{4-5}$ and is still ubiquitously found in clinical settings over the world. It is used to treat severe pain or for anesthetic purposes, even though its therapeutic use is accompanied by several severe side effects including respiratory depression and physical dependence. ${ }^{13}$ The role of $\beta$-arrestins in the occurrence of these side effects at MOR was first discovered in $\beta$-arrestin-2 knock out (KO) mice, which experienced less respiratory depression and constipation upon acute morphine administration. On the other hand, chronic administration of morphine to these KO-mice led to desensitization and tolerance as compared to wild-type mice. ${ }^{44,112-114}$ Two groups independently reported a contradictory bias of morphine towards both $G$ protein and $\beta$-arrestin-2 recruitment. ${ }^{76,99}$ Thompson and coworkers quantified a bias factor of -0.99 towards $\beta$-arrestin-2 recruitment using a GTP $Y$ S assay, whereas the group of Schmid et al. quantified a bias factor of 0.11 towards $G$ protein using the same type of assay, but a bias factor of -0.21 towards $\beta$-arrestin- 2 recruitment was obtained when adopting the 
CAMP assay. These bias factors were each determined on hMOR, with DAMGO as control and each using the operational model of Black and Leff (Equation 2) for the calculation. ${ }^{76,99}$

Buprenorphine (Figure 3 ) is a semi-synthetic derivative of the naturally occurring alkaloids thebaine and morphine, and it serves as a mixed opioid acting at both MOR and NOP receptor, ${ }^{115}$ but it also shows affinity towards KOR and DOR. ${ }^{116}$ Buprenorphine is currently used in the clinic to treat opioid dependence. ${ }^{117}$ The pharmacology of buprenorphine continues to be widely discussed within the research community, with some of the opinion that buprenorphine acts as a partial MOR agonist compared to morphine, ${ }^{45}$ or describing buprenorphine as a mixed MOR/NOP receptor partial agonist, ${ }^{118}$ whilst others report buprenorphine-mediated biased agonism. Burgueno and coworkers have demonstrated the $\mathrm{G}$ protein-biased agonism at MOR, relative to morphine, with subsequent quantification of the bias factor of 1.84, using the operational model (Equation 2). ${ }^{102}$ More recently, buprenorphine was also defined as a $G$ protein-biased agonist as it failed to recruit a significant amount of $\beta$-arrestins. ${ }^{101}$ As a result of this, no bias factor could be calculated. ${ }^{101}$ With no clear view on whether buprenorphine is a biased or a mixed partial agonist, it is difficult to understand whether the pharmacologic profile derives from the partial agonism or from an actual bias. ${ }^{81}$

Levorphanol (Figure 3 ) is a potent analgesic with agonist activity not only at MOR but also at DOR and KOR. Levorphanol shows NMDA antagonism, and because of its underutilization has been called 'the forgotten opioid'. ${ }^{119-120}$ It was first approved for clinical use in the USA in 1953 as a treatment for moderate to severe pain. ${ }^{121}$ This morphine-like compound was reported as a G protein-biased agonist for two 6 transmembrane MOR splice variants of mice, relative to DAMGO, together with reduced respiratory depression and incomplete cross-tolerance with both morphine and oxycodone. These splice variants were obtained by $5^{\prime}$ splicing of the Oprm1 gene, the gene that encodes the synthesis of the MOR protein. The bias factors obtained for splice variants MOR-1E and MOR-1O were 1.2 and 9.4 respectively, using the operational model (Equation 2). More importantly, levorphanol acts also as a $\beta$-arrestin-biased agonist at the normal 7 transmembrane MOR with a bias factor of $-2.6 .^{122}$

Consideration of the structures of the compounds mentioned above shows quite clearly that even small structural changes can lead to ligands with preferred signaling, i.e. $\beta$-arrestin-biased or unpreferred ligands. Additionally, even previously described MOR ligands ultimately appear as biased ligands, hence their pharmacology has to be reinvestigated at the light of this information.

\section{Herkinorin and herkinorin-like compounds}

Herkinorin (Figure 3) is derived from the selective KOR Salvinorin A (Sal A), which is a naturally occurring active ingredient from the hallucinogenic plant Salvia divinorum. ${ }^{67,123-125}$ Herkinorin was the first non-nitrogenous $\mu$-opioid agonist discovered and has a greater affinity for MOR than KOR $(\mu / k=0.13$-fold $) .{ }^{124}$ In 2007, Groer et al. reported the biased activity of herkinorin. The fact that herkinorin causes activation of $\mathrm{G}$ protein coupling and ERK1/2 phosphorylation in a naloxonereversible manner yet does not cause $\beta$-arrestin recruitment and internalization suggests that herkinorin is a G protein-biased MOR agonist. ${ }^{123,}{ }^{126}$ Previous in vivo studies by Lamb et al. showed that upon treatment with herkinorin in morphine-tolerant rats, antinociceptive efficacy was still observed. ${ }^{127}$ Another study demonstrated that herkinorin activated MOR receptor without recruiting $\beta$-arrestin-2 in primary sensory neurons. ${ }^{128}$ Nevertheless, Manglik et al. have more recently reported the $\beta$-arrestin recruitment of herkinorin in a set of studies in which it and TRV130 are compared to the effects of PZM21, DAMGO, and morphine. The results of these studies ( $E_{\max }$ of $112 \%$ and $104 \%$ 
in overexpressing GRK2 BRET assay) pointed to full agonistic activity of herkinorin with similar efficacy as DAMGO ( $E_{\max }$ of $100 \%$ in both cases). ${ }^{109}$ On the other hand, another study has shown that herkinorin is a partial agonist of MOR. ${ }^{129}$ As the latter authors themselves point out, the most likely explanation for the different result is that the different assays used to assess $G$ protein activity have different sensitivities and dynamic ranges.

Kurkinorin (Figure 3 ) is a herkinorin analog, also derived from the KOR-selective ligand Sal A, with only a double bond of differing in their structures. It showed high potency $\left(E_{50}=1.2 \mathrm{nM}\right)$ and was reported as a selective MOR agonist over DOR and KOR $(\delta / \mu=63$-fold and $k / \mu>8000$-fold). In addition to this selectivity, kurkinorin was described as a $G$ protein-biased ligand for MOR with a corresponding bias factor of 0.57 compared to DAMGO using the equiactive equation (Equation 1 ). From in vivo experiments, it was demonstrated that kurkinorin exhibited reduced tolerance, sedation and rewarding effects compared to morphine. These observations are interesting and counterintuitive, since kurkinorin recruited more $\beta$-arrestin-2 than morphine. ${ }^{130}$

Herkamide (Figure 3 ) is the benzamido-derivative of herkinorin, synthesized by Tidgewell et al. in 2008. They reported the high affinity of herkamide $\left(K_{i}=3.1 \mathrm{nM}\right)$ towards MOR over DOR and KOR $(\delta / \mu=261$-fold and $k / \mu=2397$-fold $)$, in addition with a 4-fold higher affinity towards MOR than herkinorin. ${ }^{131}$ The bias factor of herkamide was calculated using the equiactive equation (Equation 1 ) with kurkinorin, also compared to DAMGO and led to the corresponding value of 0.32 , making herkamide a $\mathrm{G}$ protein-biased ligand for MOR. ${ }^{130}$

Recently, Crowley et al. reported a series of kurkinorin derived compounds. The most promising compound developed was 25 (Figure 3), containing a 4-hydroxymethyl benzoate group. 25 demonstrated the best potency of all analogs $\left(\mathrm{EC}_{50}=0.03 \mathrm{nM}\right)$ for $\mathrm{MOR}$, being 100 times more potent than for KOR. Additionally, it proved to be five times more potent to MOR than fentanyl (vide infra). When compared to DAMGO, 25 displayed a bias towards the $G$ protein pathway, represented with a bias factor of 0.14 , calculated using the equiactive equation (Equation 1). Consequently, in vivo studies proved the potent analgesic effects, as well as the lack of significant tolerance. ${ }^{132}$

It is noteworthy that all of the herkinorin-like compounds described above lack a basic nitrogen which is present in many other opioid ligand classes.

\section{Mitragynine and mitragynine-like compounds}

Mitragynine (Figure 3) was the first isolated alkaloid from the medicinal plant Mitragyna (also known as kratom). ${ }^{133}$ Kratom can be used as a stimulant and produces opioid-like analgesic effects. ${ }^{134} \mathrm{~A}$ total of 25 different alkaloids have been found in kratom leaves, all of which are analogs of mitragynine, which itself is the most abundant (comprising around $60 \%$ of the isolate) ${ }^{135}$ A number of pharmacological studies showed that mitragynine exhibits mixed $\mu$-agonist/ $\delta$-antagonist activity. ${ }^{136-137}$ Murine models showed slow development of tolerance and a marked decrease of physical dependence as well as the inability to recruit $\beta$-arrestin-2 (in fact, because of the weak response during $\beta$-arrestin recruitment experiments, the authors were not able to calculate the bias factor ${ }^{138}$ ). These results are particularly noteworthy because the authors undertook more rigorous testing of tolerance than is commonly seen in the literature i.e. over a much-extended timeframe, yet still found significant reduction in antinociceptive tolerance. How exactly this mixed receptor activity contributes to the beneficial pharmacological profile of the molecule is not fully elucidated and remains under investigation. 
Mitragynine's chemical structure represents an excellent springboard for further diversification efforts, and, to this end, the authors' own SAR studies revealed that substitution at the C-9 position has the most dramatic effects being able to switch between the partial-agonistic and antagonistic activities at MOR but also being able to module activity at DOR.

The second most abundant alkaloid extracted from the kratom plant is 7-hydroxymitragynine (7HMG; Figure 3) - a selective and full agonist at MOR. ${ }^{135}$ It showed a 46- and 13-fold higher potency than mitragynine and morphine respectively. ${ }^{134}$ Similar to mitragynine, 7-HMG demonstrated slow tolerance development, a decrease of physical dependence, and did not recruit $\beta$-arrestin- $2 .{ }^{138}$ Compared to morphine, 7-HMG was 5-fold more potent in the antinociceptive effect. ${ }^{136}$ In addition, this study focused on an oxidized rearrangement product of mitragynine, viz. mitragynine pseudoindoxyl (Figure 3). Complementary to mitragynine and 7-HMG, mitragynine pseudoindoxyl failed to recruit $\beta$-arrestin-2, produced tolerance in a slower rate than morphine, together with limited respiratory depression, constipation and physical dependence, while still showing potency in a GTPYS assay at MOR with an $\mathrm{EC}_{50}$ of $1.7 \mathrm{nM}$ and $\mathrm{E}_{\max }$ of $122 \%$ compared to DAMGO. ${ }^{136}$ 
<smiles>CC(c1ccc2c(c1)OCCO2)N1CCC(n2c(=O)[nH]c3cc(Cl)c(Cl)cc32)CC1</smiles>

SR-11501<smiles>O=c1[nH]c2cc(Cl)c(Cl)cc2n1C1CCN(Cc2ccc(Cl)cc2F)CC1</smiles>

SR-15098<smiles>CC(c1ccc(Br)cc1)N1CCC(n2c(=O)[nH]c3cc(Cl)c(Cl)cc32)CC1</smiles>

SR-14968<smiles>O=c1[nH]c2cc(Cl)c(Cl)cc2n1C1CCN(Cc2ccc(Br)cc2)CC1</smiles>

SR-15099<smiles>CC(c1ccc(Cl)cc1F)N1CCC(n2c(=O)[nH]c3cc(Cl)c(Cl)cc32)CC1</smiles>

SR-14969<smiles>O=c1[nH]c2cc(Cl)c(Cl)cc2n1C1CCN(Cc2ccc(Cl)cc2)CC1</smiles>

SR-17018<smiles>O=c1[nH]c2cc(Cl)ccc2n1C1CCN(Cc2ccc(Br)cc2F)CC1</smiles>

41<smiles>O=c1[nH]c2cc(Cl)c(Cl)cc2n1C1CCN(Cc2ccc(Br)cc2F)CC1</smiles>

44

Figure 4: Structures of biased MOR ligands: SR-compounds- part 2

\section{SR-compounds}

The SR-compounds (Figure 4), developed by Schmid et al., are a series of piperidine-based molecules, ${ }^{99}$ bearing a slight relation to bezitramide, itself an opioid analgesic used to treat severe, chronic pain. ${ }^{139}$ The SR-compounds, with the exception of SR-11501, were described as G proteinbiased ligands. Notably they show reduced respiratory depression whilst still inducing antinociception in rodent models relative to DAMGO, fentanyl, and morphine. The authors quantified the bias factor of these compounds using the operational model (Equation 2) both on hMOR and mMOR using GTPYS and CAMP assays, which are reproduced in 
Table 2. ${ }^{99}$

From 
Table 2, a dramatic change can be seen in bias factor upon switching from hMOR to mMOR, or from GTPYS to CAMP cellular assays. Additionally, the bias factor increased in favor of the biased pathway when performing the cellular assay on a different cell type; in this case, the switch from Chinese hamster ovary $(\mathrm{CHO})$ to mice brainstem cells. SR-17018 showed the highest bias factor and consequently has the highest preference for the $G$ protein-signaling pathway. It should be noted that one compound, SR-11501, is biased with favored $\beta$-arrestin-2 recruitment, resulting in a negative bias factor. This compound showed a decrease in plasma levels over time, whilst the plasma levels of the other SR-compounds remained elevated up to 6 hours after intraperitoneal (i.p.) injection. Additionally, SR-11501 proved to be the least potent with an $\mathrm{EC}_{50}$ of $396 \pm 68 \mathrm{nM}$ in a GTP $\mathrm{SS}$ (brain) assay on mMOR. ${ }^{99}$ Based on their chemical structures, SR-11501 is the only compound lacking a halogen at the para-position of the phenyl group and is it the only ligand among the authors' compounds that acts as a $\beta$-arrestin-biased ligand. The authors ascribe this to favorable conformations imposed on MOR by halogen substitution at a number of positions - such as is seen in SR-11501 - that promote the binding of GTP $\gamma$ S thereby limiting signaling through $\beta$-arrestin-2. Later, a chronic study on the most promising compound SR-17018 was performed. This study demonstrated less antinociceptive tolerance in a hot plate test on mice relative to morphine and oxycodone. Interestingly, morphine sensitivity was restored within three days when morphinetolerant mice were treated with SR-17018. Furthermore, upon chronic administration of SR-17018, no MOR desensitization was produced in periaqueductal gray (PAG). The authors suggest that SR17018 can stabilize MOR in a way where it could restore G protein signaling and could serve as a ligand to reestablish efficacy in tolerant systems. ${ }^{140}$ This latter suggestion was countered in the authors' latest publication. In a warm water tail immersion test, SR-17018 demonstrates tolerance which is in contrast with the hot plate test. Even though SR-17018 showed G protein-biased signaling in vitro, the authors claim that the lack of $\beta$-arrestin-2 is directly linked to a decrease in tolerance. ${ }^{141}$ Nevertheless, whether or not the in vitro biased profiles can be linked to in vivo systems remains to be fully elucidated. 
Table 2: Bias factors of SR-compounds at hMOR and MMOR in CHO and brain cells using DAMGO as a reference ligand

\begin{tabular}{c|cc|cc}
\multirow{2}{*}{ Agonist } & \multicolumn{2}{|c|}{ hMOR } & \multicolumn{2}{c}{ mMOR } \\
\cline { 2 - 5 } & $\begin{array}{c}\text { (GTPYS (CHO)/ } \\
\text { B-arr-2) }\end{array}$ & $\begin{array}{c}\text { (cAMP (CHO)/ } \\
\boldsymbol{\beta} \text {-arr-2) }\end{array}$ & $\begin{array}{c}\text { (GTPYS (CHO)/ } \\
\boldsymbol{\beta} \text {-arr-2) }\end{array}$ & $\begin{array}{c}\text { (GTPYS (brain)/ } \\
\boldsymbol{\beta} \text {-arr-2) }\end{array}$ \\
\hline SR-11501 & -0.39 & -0.09 & -0.91 & -0.64 \\
SR-14968 & 1.55 & 0.71 & 0.83 & 1.54 \\
SR-14969 & 1.03 & 0.40 & 0.46 & 0.93 \\
SR-15098 & 1.47 & 1.28 & 1.03 & 1.74 \\
SR-15099 & 1.68 & 1.44 & 1.07 & 1.74 \\
SR-17018 & 1.93 & 1.60 & 1.47 & 2.01 \\
\hline
\end{tabular}

In addition to the previous results, the same research group published another series of SRcompounds. They screened for other and more halogens on the phenyl ring, and pendant groups such as halogens, - $\mathrm{OMe},-\mathrm{OCF}_{3},-\mathrm{SO}_{2} \mathrm{Me},-\mathrm{CN}$ and $-\mathrm{Me}$ on the benzimidazolone as relates the calculation of their bias factors. The two best compounds obtained from this, were $\mathbf{4 1}$ and $\mathbf{4 4}$ (Figure 4), with a corresponding bias factors of 1.36 and 1.75 using the operational model (Equation 2), making them both biased towards the $G$ protein pathway compared to DAMGO. Interestingly, the BBB penetration was determined after i.p. administration of $6 \mathrm{mg} / \mathrm{kg}$ in mice and brain levels were measured after $1 \mathrm{~h}$. Both $\mathbf{4 1}$ and $\mathbf{4 4}$ were still present in the brain with a concentration of $17 \mu \mathrm{M}$ and 4.6 $\mu \mathrm{M}$ respectively. ${ }^{142}$ This latter fact makes both compounds very interesting as a consequence of MOR's brain localization. 
<smiles>NC(=O)[C@H](Cc1ccccc1)NC(=O)C(C[Al])NC(=O)[C@@H]1CCCN1C(=O)C(N)Cc1ccc(O)cc1</smiles>

EM-1: $A r=3$-indolyl

EM-2: $A r=$ phenyl<smiles>[R]C(=O)C([Y19])NC(=O)[C@H](Cc1ccccc1)NC(=O)[C@H](Cc1c[nH]c2ccccc12)NC(=O)[C@H](CCCCNC(=O)[C@H](N)Cc1ccc(O)cc1)NC(=O)[C@H](N)Cc1ccccc1</smiles>

ZH809: $\mathrm{n}=1, \mathrm{R}=\mathrm{NH}_{2}$

ZH850: $n=2, \mathrm{R}=\mathrm{NH}_{2}$

ZH853: $n=2, \mathrm{R}=$ Gly-NH<smiles>C=C(C(N)=O)[C@H](NC(=O)[C@H](Cc1c[nH]c2ccccc12)NC(=O)[C@H](C)N(C)C(=O)[C@H](N)Cc1c(C)cc(O)cc1C)c1ccco1</smiles>

MEL-N1606

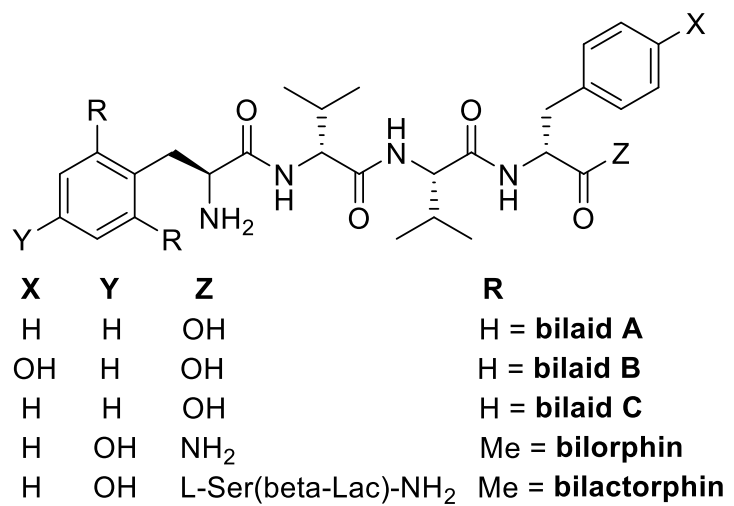<smiles>[CH][C@H](N)C(=O)N[C@@H](Cc1c[nH]c2ccccc12)C(=O)N[C@@H](Cc1ccccc1)C(=O)NCCCC[C@@H](Cc1ccccc1)NC(=O)[C@@H](N)Cc1ccc(O)cc1</smiles>

$\mathrm{HO}$<smiles>NC(=O)[C@H](CCCCNC(=O)CC[C@@H](Cc1ccccc1)NC(=O)[C@H](Cc1ccccc1)NC(=O)[C@H](Cc1ccccc1)NC(=O)[C@H](N)Cc1ccc(F)cc1)C(=O)NC(Cc1ccccc1)Cc1ccccc1</smiles>

ZH831<smiles>C=C(C(N)=O)[C@H](NC(=O)[C@H](Cc1ccccc1)NC(=O)[C@H](C)N(C)C(=O)[C@H](N)Cc1c(C)cc(O)cc1C)c1ccco1</smiles>

MEL-N1608

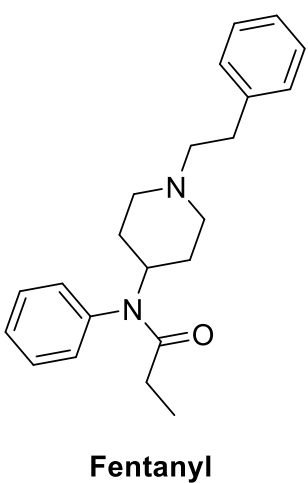

Sufentanil 


\section{Endomorphin-1 \& 2 and derivatives}

Endomorphin-1 \& 2 (EM1 \& EM2) (Figure 5) are endogenous tetrapeptides ${ }^{5,40}$ displaying high affinities towards MOR ( $\mathrm{K}_{\mathrm{i}}=0.36$ and $0.69 \mathrm{nM}$ respectively) and a great binding selectivity over DOR and KOR $(\delta / \mu=4183$-fold and $\mathrm{k} / \mu=15077$-fold for EM1 and $\delta / \mu=13381$-fold and $\mathrm{k} / \mu=7594$-fold for EM2). ${ }^{143}$ Goldberg et al. reported the affinity of EM1 and EM2 on two splice variants of MOR in mouse brain homogenates resulting in $\mathrm{K}_{\mathrm{i}}$ values of 0.67 and $3.2 \mathrm{nM}$ for EM1 and 0.43 and $4.0 \mathrm{nM}$ for EM2 respectively. ${ }^{144}$ Both peptides have been reported as $\beta$-arrestin-biased ligands in different studies in contrast to most of the MOR ligands described above, ${ }^{76,102,145-146}$ being the unfavored bias for MOR. The quantified bias for both EM1 and EM2 was reported by Thompson and coworkers using the operational model (Equation 2) with a GTPYS cellular assay for the G protein pathway versus $\beta$-arrestin-2 recruitment, which resulted in bias factors of -1.22 and -0.563 relative to DAMGO for EM1 and EM2 respectively. ${ }^{76}$

CYT-1010 (Figure 5) is a synthetic analogue of endomorphin-1 containing a D-Lys in the second position which is cyclized through the $C$-terminus of the peptide. It has a higher affinity for hMOR ( $\mathrm{K}_{\mathrm{i}}$ $=0.25 \mathrm{nM})$ than both EM1 and EM2 ( $\mathrm{K}_{\mathrm{i}}=13.9$ and $12.5 \mathrm{nM}$ respectively). ${ }^{147}$ The latter affinities of EM1 and EM2 for hMOR were found not as good as those described initially. ${ }^{143}$ Preclinical data showed a reduced abuse potential, since it lacked rewarding behavior in rodents models in conditioned place preference (CPP) test, in addition with higher analgesic potency in a tail-flick test after both intravenous (i.v.) and oral administration relative to morphine. Results of phase I clinical trials showed that CYT-1010 gave way to significant analgesia and no respiratory depression since over the first three hours after dosing, no significant decrease in plasma oxygen saturation or change in respiratory rate was observed. In light of this latter fact, CYT-1010 has progressed to phase II clinical trials. ${ }^{147}$

In 2016, Zadina et al. described four cyclic endomorphin analogs (Figure 5): three of EM1 (ZH809, ZH850, ZH853) and one of EM2 (ZH831). They have all demonstrated a higher receptor selectivity for MOR over DOR and KOR (Table 3). All four showed drastically improved antinociception-vs-side effect ratios. Relative to morphine, in rodent models the analogs demonstrated a reduction of the most common side effects associated with opioids (vide supra), a profile potentially linked to a bias towards the $\mathrm{G}$ protein pathway, although this has not been validated experimentally. ZH853 reduced or showed absence of six critical side effects, e.g. tolerance, hyperalgesia, respiratory depression, abuse liability, motor impairment, and glial activation, making it the most promising drug candidate of the four. ${ }^{148}$

Table 3: Selectivity of the ZH compounds at MOR

\begin{tabular}{c|c|c} 
Ligand & $\boldsymbol{\delta} / \boldsymbol{\mu}$ & $\mathbf{\kappa} / \boldsymbol{\mu}$ \\
\hline ZH809 & 169 & 102 \\
ZH850 & 132 & 453 \\
ZH853 & 188 & 7584 \\
ZH831 & 86 & 253 \\
\hline
\end{tabular}

Another series of novel endomorphin analogs - the MEL-N16 series - were developed in 2017 to find compounds with a biased activity, and thus a more favorable side effect profile. The whole series showed an great affinity and selectivity for the MOR. On top of that, the authors observed an 
increase in stability and BBB permeability. Of these analogs, however, only two, MEL-N1606 and MEL-N1608 (Figure 5) were reported to be biased agonists towards the $G$ protein-signaling pathway. More specifically, MEL-N1606 produced less constipation, motor impairment, and drug-seeking behavior, as compared with morphine. Additionally, upon repeated administration, no significant decrease in analgesic effect was found, indicating the lack of tolerance development. ${ }^{149}$

\section{Bilactorphin}

Recently, three tetrapeptides, bilaids A, B, and C (Figure 5), were extracted from the Australian estuarine-derived Penicillium sp. MST-MF667. ${ }^{150}$ Notably, they all contain the L,D,L,D stereochemical pattern. SAR studies proved that this L,D-alternation at positions 1 and 2 is necessary to maintain opioid activity. Following optimization studies, the authors obtained bilorphin (Figure 5), which showed a bias towards $\mathrm{G}$ protein-signaling to a similar extent as TRV130 ${ }^{150}$ Contrary to the results obtained from intrathecal (i.t.) administration, studies demonstrated no antinociception after s.c. or i.v. administration. Further optimization led to the development of bilactorphin (Figure 5), a pentapeptide, with enhanced BBB permeability, still biased towards G protein-signaling. Interestingly, bilactorphin is orally available with similar potency to morphine in vivo. ${ }^{150}$

\section{Fentanyl \& Sufentanil}

Fentanyl (Figure 5) is a synthetically developed potent MOR agonist, first synthesized by Janssen in $1960,{ }^{151}$ and followed by the discovery of sufentanil (Figure 5) in $1974 .{ }^{152}$ Schmid et al. have previously described both fentanyl and sufentanil as ligands biased towards $\beta$-arrestin-2 recruitment, in comparison with DAMGO, with bias factors of -0.75 and -0.78 respectively using the operational model (Equation 2) with GTPyS assay at hMOR. ${ }^{99}$ However, when comparing fentanyl to morphine, a bias towards $G$ protein recruitment was observed (bias factor of 0.96 using the operational model with CAMP assay at hMOR). ${ }^{102}$ Hence, the bias of a ligand is dependent upon the reference ligand and the type of assay employed.

\section{B. Biased $\delta$-opioid receptor ligands}

Even though the $\mu$-opioid receptor is the most common target in clinical research for new and/or improved opioid analgesics, the $\delta$-opioid receptor (DOR) still has proven itself capable of exerting strong antinociception with fewer side effects. ${ }^{153}$ Since these side effects could be respiratory depression, ${ }^{28}$ anxiety, ${ }^{29}$ convulsion, depressive effects, ${ }^{19,}{ }^{30}$ constipation, and addictive liability, ${ }^{31}$ the development of $\mathrm{G}$ protein-biased $\delta$-opioid receptor ligands are still profitable. In fact, DOR agonists can induce anxiolytic- and antidepressant-like effects, together with effective analgesia, which makes them significantly different from MOR and highly desirable in therapeutic applications. Additionally, this latter fact is also important on account of its relation to chronic pain, which in turn is associated with anxiety and mood disorders, ${ }^{51}$ though it's worth pointing out that the clinical candidates ADL5747 and ADL5859 failed in phase II due to lack of efficacy. ${ }^{54}$ Biased DOR agonists could offer an approach to by-pass the adverse effects, such as convulsion, seen during the administration of normal DOR agonists. ${ }^{154}$ To determine the biased activity of DOR ligands, reference ligands are used to compare its activity, namely Leu-enkephalin, BW373U86, DPDPE, and DADLE but mostly SNC-80. Several different biased $\delta$-opioid receptor ligands are listed and discussed here. 
<smiles>[R]C(=O)C(CC(=O)O)NC(=O)C(CC(C)C)NC(=O)C1CCCN1C(=O)C(N)Cc1ccc(O)cc1</smiles>

Rubiscolin-5: $\mathrm{R}=\mathrm{OH}$

Rubiscolin-6: $\mathrm{R}=\mathrm{Phe}-\mathrm{OH}$<smiles>C=CCN1C[C@H](C)N([C@@H](c2ccc(C(=O)N(CC)CC)cc2)c2cccc(O)c2)C[C@H]1C</smiles>

BW373U86<smiles>C=CCN1C[C@H](C)N([C@H](c2ccc(C(=O)N(CC)CC)cc2)c2cccc(OC)c2)C[C@H]1C</smiles>

SNC-80<smiles>[CH][C@@H]1CC/C(=C2\c3ccccc3Oc3cc(C(=O)N(CC)CC)ccc32)N1</smiles>

JNJ-20788560

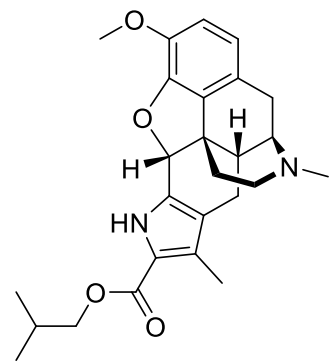

SB-235863 (c)

DADLE<smiles>Cc1cc(O)cc(C)c1CC(N)C(=O)N1Cc2ccccc2C[C@H]1C(=O)N[C@H](CC(=O)O)c1nc2ccccc2[nH]1</smiles>

UFP-512<smiles>CN(C)C(=O)c1ccc(C(=C2CCN(Cc3cncs3)CC2)c2cccc(C(N)=O)c2)cc1</smiles>

PN6047<smiles>[Z10]C(C)(C)OC(C)(C)C</smiles><smiles>CN1CC[C@]2(c3cccc(O)c3)Cc3nc4ccccc4cc3C[C@H]2C1</smiles>

TAN-67

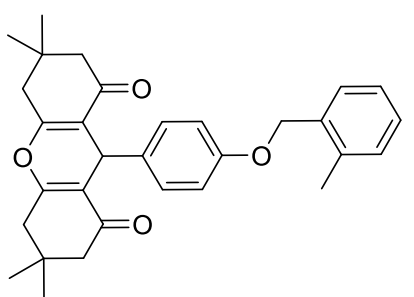

BMS-986187

Figure 6: Structure of biased DOR ligands and reference ligands<smiles>CN[C@H](C(=O)NCC(=O)N[C@@H](Cc1ccccc1)C(=O)N[C@H](C(=O)O)C(C)(C)S)C(C)(C)SSC</smiles>

DPDPE<smiles>CCN(CC)C(=O)c1ccc(C(=C2CCNCC2)c2ccccc2)cc1</smiles>

ARM390<smiles>CCN(CC)C(=O)c1ccc(C2=CC3(CCNCC3)Oc3cccc(O)c32)cc1</smiles>

ADL5859<smiles>CN1C[C@@]2(O)Cc3cc4ccccc4nc3C[C@]2(O)CN1C</smiles>

KNT-127 


\section{Rubiscolin-5 \& rubiscolin-6 (rubixyl)}

Rubiscolin-5 and rubiscolin-6 (Figure 6) are hexapeptides first isolated from the spinach Rubisco plant. ${ }^{155}$ Both demonstrated opioid activity with a high selectivity for DOR over MOR $(\mu / \delta=>500$ fold and $>2000$-fold respectively), inducing antinociception even by oral administration. ${ }^{155}$ In later studies, rubiscolin-6 was found to inhibit the internalization of DOR. ${ }^{156}$ Additionally, Cassell et al. reported that both rubiscolin- 5 and rubiscolin- 6 are $G$ protein-biased agonists, since they could not induce $\beta$-arrestin-1 recruitment. As a result of this latter fact, no bias factor could be calculated. As regards $G$ protein-signaling vs. $\beta$-arrestin- 2 recruitment, the bias factors were 0.31 and -0.28 for rubiscolin-5 and rubiscolin-6 respectively (which is in comparison to Leu-enkephalin in a cAMP assay), making rubiscolin-5 more $G$ protein-biased than Leu-enkephalin, and rubiscolin- 6 less $G$ protein-biased or $\beta$-arrestin-2-biased. ${ }^{157}$ This suggests that the addition of only one amino acid can make a huge difference to the extent to which signaling pathways can be biased. The additional phenylalanine, which contains a bulky phenyl-group, could interact in the binding pocket of DOR, potentially involving $\pi-\pi$ stacking interactions, which, in turn, could be capable of switching its biased activity towards the unfavored pathway.

\section{DADLE ([D-Ala², D-Leu $\left.{ }^{5}\right]$-enkephalin)}

DADLE (Figure 6) is a DOR-selective pentapeptide reported by Conibear et al. as a $\mathrm{G}$ protein-biased agonist over the recruitment of both $\beta$-arrestin- 1 and $\beta$-arrestin- 2 relative to SNC-80 (vide infra). The bias factors were calculated at 1.5 and 1.15 respectively, using the operational model (Equation 2). ${ }^{158}$ Upon mutation of DOR, DADLE was shown to be biased towards $G$ protein-signaling compared to BW373U86 (Figure 6), which is a selective DOR agonist. Mutation of $\mathrm{Arg}^{314}$ to Ala, led to no $\beta$ arrestin activation, whereas the $G$ protein activation only decreased a bit ( $E_{\max }$ of $\left.79 \%\right)$ as compared to the wild-type DOR ( $E_{\max }$ of $42 \%$ for $\beta$-arrestin activation and $102 \%$ for $G$ protein activation) taking BW373U86 as a reference ligand with $E_{\max }$ of $100 \%$ in all cases. ${ }^{159}$

\section{UFP-512}

UFP-512 (Figure 6) was developed in 2002 as a potent peptide-based DOR agonist, ${ }^{160}$ and was proven to prevent tolerance when studying the antidepressant-like effects. After 7 days of daily administration of UFP-512, similar antidepressant-like effects as obtained after acute administration were observed. ${ }^{161}$ Another study also demonstrated the antidepressive effects in addition to anxiolytic-like effects in vivo. ${ }^{162}$ Furthermore, Charfi et al. demonstrated the biased behavior of UFP512 when comparing CAMP inhibition assay with internalization assay (an indication of $\beta$-arrestin recruitment). The authors obtained a bias factor of 2.12 using the operational model (Equation 2), relative to DPDPE (Figure 6). ${ }^{163-164}$

\section{SNC-80 and derivatives}

SNC-80 (Figure 6) is a non-peptidic DOR agonist, chemically derived from BW373U86 ${ }^{165}$ and capable of selectively activating the heteromeric $\mu-\delta$ opioid receptor. ${ }^{166}$ Prior studies showed that SNC-80 interacts with the $\delta$-protomer, activating the complex in vivo. ${ }^{166}$ In HEK293 cells stably expressing Flag-DOR, SNC-80 demonstrated, in the same way as UFP-512, a biased character, when looking at cAMP inhibition versus internalization, displaying a bias factor of 1.70 , relative to DPDPE as a reference ligand and using the operational model (Equation 2). ${ }^{163-164}$ In rodent models, Saitoh et al. have reported the antidepressant- and anxiolytic-like effects of SNC-80 upon activation of DOR, ${ }^{167}$ whereas in a nitroglycerin-induced thermal hyperalgesia assay in 'wild-type' mice, as described by Dripps and coworkers, SNC-80 did produce antihyperalgesia. ${ }^{30,168}$ As described above, DADLE was 
reported to be $\mathrm{G}$ protein-biased as compared to SNC-80, thereby making SNC-80 less $\mathrm{G}$ proteinbiased, i.e. recruiting more $\beta$-arrestin than DADLE, ${ }^{158}$ though SNC-80 is more $\mathrm{G}$ protein-biased as compared to DPDPE. ${ }^{163-164}$ As a consequence, the bias of SNC-80 or of any other ligand is wholly dependent on the reference ligand. ${ }^{21}$

PN6047 (Figure 6) is a compound developed by PharmNovo AB in 2012. PN6047 is a potent and selective DOR agonist, chemically derived from SNC-80. During the second half of 2018, the preclinical studies on PN6047 were completed, showing high potency and efficacy in chronic pain models and no indications of undesired side effects. The first in-human clinical trials are planned between 2019 and 2021. ${ }^{169-170}$ The bias factor of PN6047 for G protein over $\beta$-arrestin-1 and for G protein over $\beta$-arrestin-2 signaling was quantified by Conibear et al. in 2020 , using SNC-80 as a reference ligand, giving values of 1.17 and 0.89 respectively using the operational model (Equation 2). This means that PN6047 is a G protein-biased DOR agonist, with an additional layer of selectivity being a high selectivity for DOR over MOR and KOR. ${ }^{158}$

ARM390 (Figure 6) is a DOR-selective agonist, also chemically derived from SNC-80 and developed by Wei et al. in 2000. ${ }^{171}$ It exhibited very high selectivity over MOR and KOR $(\mu / \delta=4370$-fold and $\mathrm{k} / \delta$ $=8590$-fold), with an IC 50 of $0.87 \mathrm{nM}$. ARM390 also showed excellent oral bioavailability (F $=90-100$ $\%)$ in rats. ${ }^{171}$ While SNC-80 caused DOR internalization, this was not significant in in vivo studies with ARM390 when analyzing tolerance. ${ }^{172-173}$ In addition, no behavioral desensitization after acute administration of ARM390 was observed. Whereas chronic SNC-80 administration led to complete loss of all DOR behavioral responses, including analgesia, ARM390 did neither change the receptor number, the receptor internalization, cell membrane localization and $G$ protein coupling. Although tolerance was developed to the analgesic effects of DOR agonists, other behavioral responses remained intact. ${ }^{154,174}$ Noteworthy, the potency and efficacy for $\mathrm{G}$ protein activation and analgesic ability are similar for both SNC-80 and ARM390. ${ }^{31}$ More recently, a bias factor of 0.55 was calculated for ARM390 towards G protein-signaling with SNC-80 as a reference ligand using the operational model (Equation 2). Consequently, ARM390 is a G protein-biased ligand for DOR. ${ }^{158}$

JNJ-20788560 (Figure 6) is an orally bioavailable DOR-selective agonist, structurally derived from SNC-80 and synthesized by Johnson \& Johnson. ${ }^{175}$ It showed a high affinity and potency towards $\operatorname{DOR}\left(\mathrm{K}_{\mathrm{i}}=2.0 \mathrm{nM}\right.$ and $\mathrm{EC}_{50}$ of $\left.5.6 \mathrm{nM}\right)$, in addition to a high selectivity over MOR and KOR, e.g. 600fold and 500-fold respectively. In preclinical models, JNJ-20788560 demonstrated antihyperalgesia and produced a similar level of analgesia as SNC-80, ARM390 (vide supra), ADL5859, TAN-67, and SB-235863 (vide infra). In rodent models, no tolerance was observed towards antinociceptive effects and antihyperalgesia. Moreover, in contrast to the NSAID ibuprofen, JNJ-2075560 did not induce GI erosion and it also did not display respiratory depression compared to morphine. Subsequently, JNJ20788560 provides a useful profile for the treatment of different types of pain. ${ }^{175}$

ADL5747 (Figure 6) is a compound resulting from SAR exploration and optimization of the potent, selective and orally bioavailable DOR agonist ADL5859 (Figure 6), which is 50-fold less potent than ADL5747. Both are chemically derived from SNC80 and the synthesis of ADL5747 was previously described by Le Bourdonnec et al.. The authors determined the half-life of both ADL-compounds, which were respectively $12.2 \mathrm{~h}$ and $5.1 \mathrm{~h}$ in canine models. ${ }^{176}$ Later studies performed by Nozaki et al. described the analgesic, locomotive and receptor internalization effects of ADL5747 and ADL5859. Neither compound induced receptor internalization or hyperlocomotion in vivo (relative to SNC-80), suggesting its biased activity for $\mathrm{G}$ protein-signaling at the receptor. In addition, both 
ADL5747 and ADL5859 reduced chronic pain in mice after nerve injury and tissue inflammation and displayed a longer mode of action. ${ }^{177}$ The promising preclinical data justified the entry of both compounds into clinical development. ADL5859 was well tolerated and showed good oral absorption and was subsequently investigated in phase II trials. A single dose administration of $200 \mathrm{mg}$ of ADL5859 demonstrated no analgesic effect. Sadly, after advancing to phase II, administration of ADL5747 showed no difference compared to placebo. For these latter reasons, further investigation on both compounds was cancelled. ${ }^{54}$

All SNC-80 derivatives provide a $G$ protein-biased signaling pathway. Despite their structural similarity, all of the pharmacological data provided are different and different tests were performed, making it difficult to compare them.

\section{TRV250}

TRV250 ${ }^{178}$, which currently finished phase I clinical trials, is a G protein-biased DOR agonist that preferentially activates the $\mathrm{G}$ protein pathway showing reduced hyperalgesia in rodent models. In these studies, TRV250 is developed for the treatment of acute migraine and was shown to have a quick absorption of 0.5 to 2 hours upon s.c. administration, which increased by up to 3 hours upon oral administration and by up to 6 hours in conjunction with a high-fat meal. The relative bioavailability of TRV250 in the fed state was 19\%, which was higher than in the fasted state (14\%). TRV250 showed mild side effects, such as headache and injection-site reactions, which were not dose-related and was proven to be well tolerated by the lack of serious adverse effects, like nausea. ${ }^{179}$

\section{SB-235863}

SB-235863 (Figure 6) is a morphine-like compound, developed by Petrillo et al., demonstrating a high affinity for DOR $\left(\mathrm{K}_{\mathrm{i}}=4.81 \mathrm{nM}\right)$ and selectivity over MOR and KOR (189-fold and 52-fold respectively). ${ }^{180}$ Even though SB-235863 was inactive in tail-flick and hot-plate tests in rodent models for acute pain, it exhibited potent thermal antihyperalgesia upon oral administration. Additionally, SB-235863 lacked some opioid side effects, like slowing the Gl tract and motor incoordination, up to $70 \mathrm{mg} / \mathrm{kg}$ after oral administration. SR-235863 is therefore a DOR ligand with a favorable side effect profile. ${ }^{180}$

\section{TAN-67}

TAN-67 (Figure 6) was discovered in 1998 by Nagase et al. based on the 'message-address' concept as a DOR agonist. The morphinan moiety (message part) interacts with the anionic part of the receptor, in addition with $\pi-\pi$ stacking and hydrogen bonding with the 3-hydroxy group. It has a high affinity for DOR over MOR and KOR $\left(\mu / \delta=2070\right.$-fold and $\mathrm{k} / \delta=1600$-fold) ${ }^{181}$ TAN-67 was capable of stimulating $\mathrm{G}$ protein binding, but it also gave way to a reduced rate of phosphorylation at DOR, leading to less $\beta$-arrestin-2 recruitment and less internalization. ${ }^{182}$ Additionally, van Rijn and Whistler suggested that TAN-67 acted on DOR/MOR heterodimers. ${ }^{183}$ Moreover, TAN-67 showed anxiolyticlike effects in ethanol-withdrawn mice, yet no decrease in anxiety-like behavior was observed in native mice. ${ }^{184}$ Subsequently, TAN-67 was found to be G protein-biased compared to DPDPE, since it recruits less $\beta$-arrestin-2 $\left(E_{\max }=41 \%\right) .{ }^{185}$ The bias factor of TAN-67 was calculated by Robins et al. using the equiactive comparison (Equation 1), resulting in a value of -1.4 relative to Leu-enkephalin, thereby showing a bias in favor of $\mathrm{G}$ protein-signaling. The authors opined that a negative bias factor 
indicates a bias towards CAMP activity - i.e. G protein-signaling - and not towards $\beta$-arrestin recruitment, which is adopted in most papers. ${ }^{186}$

\section{KNT-127}

KNT-127 (Figure 6) was synthesized by Nagase et al. in 2010 as a constrained version of TAN-67 with the addition of a hydroxyl group. KNT-127 displayed a high affinity for DOR ( $\mathrm{K}_{\mathrm{i}}=0.16 \mathrm{nM}$ ) over MOR and KOR $\left(\mu / \delta=134\right.$-fold, $\mathrm{K} / \delta=961$-fold) ${ }^{187}$ Subsequent studies proved a marked decrease in the side-effects seen with its use; compared to SNC-80, KNT-127 produced no convulsions up to doses of $100 \mathrm{mg} / \mathrm{kg}$ in mice upon s.c. administration, in addition to antidepressant-like effects, as determined via a forced swim test at mice. Furthermore, antinociceptive effects were observed in both a writhing and formalin test. ${ }^{188}$ Also, Nozaki et al. described the reduced side effects of KNT-127. Inflammatory hyperalgesia was reversed by KNT-127 upon acute treatment, together with the production of antidepressant-like effects. However, upon chronic administration of KNT-127, analgesic tolerance and cross-tolerance with SNC-80 was detected. Nevertheless, KNT-127 did not induce DOR internalization in vivo, in contrast to SNC-80. ${ }^{189}$

\section{BMS-986187}

BMS-986187 (Figure 6) is a biased allosteric DOR agonist discovered via high-throughput screening (HTS), showing no direct agonist activity, but did produce positive allosteric modulator (PAM) activity. It demonstrated an increase in potency to orthosteric agonists. ${ }^{190}$ Later studies based on free-energy interfaces identified specific binding sites and conformational states for BMS-986187. ${ }^{191}$ Subsequently, BMS-986187 was identified as a G protein-biased allosteric agonist, albeit less potent, but showing no significant level of $\beta$-arrestin-2 recruitment. This is a result of reduced phosphorylation, internalization and desensitization of the receptor, which consequently generates a bias factor of 1.53 towards $\mathrm{G}$ protein-signaling using the operational model (Equation 2) with SNC80 as a reference ligand. Additionally, through the use of orthosteric antagonists such as naltrindole and naxolone, it was shown that BMS-986187 could mediate agonism on other sites than just the orthosteric site. $^{192}$

\section{Biased K-opioid receptor ligands}

The third opioid receptor that we consider here is the k-opioid receptor (KOR). Since KOR is widely described in, not only the CNS, but also the PNS, potent analgesic effects can be produced without CNS-based side effects; as a result KOR is often considered as the 'safest' of the three classical receptors. ${ }^{13}$. Alongside their antinociceptive effects, KOR agonists have antiaddictive and antipruritic properties, in addition to effects on anhedonia, dysphoria, sedation, ${ }^{19,32,193}$ anxiety. ${ }^{27,33,193}$ Importantly, in $\beta$-arrestin KO mice both antinociceptive and antipruritic efficacies at KOR are retained. $^{33} \mathrm{G}$ protein-biased KOR agonists are capable of inducing analgesic effects, without producing dysphoria, ${ }^{194}$ sedation, abuse potential, ${ }^{195}$ anxiety, stress, and depression. ${ }^{34}$ To determine the biased activity of KOR ligands, salvinorin A, U50,488, and $\mathbf{U 6 9 , 5 9 3}$ are employed as reference ligands. Different biased k-opioid receptor ligands are listed and discussed here. These ligands can vary from morphine-like compounds, to peptides, to small molecules derived from KOR agonists. 


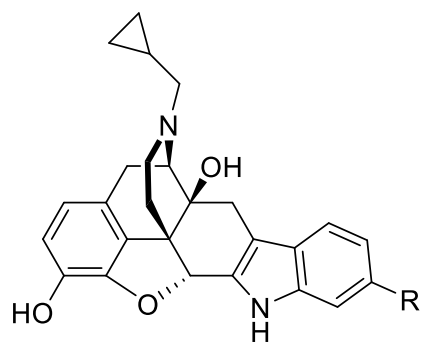

Naltrindole: $\mathrm{R}=\mathrm{H}$

6'-GNTI: $\mathrm{R}$ = guanidyl<smiles></smiles>

Noribogaine

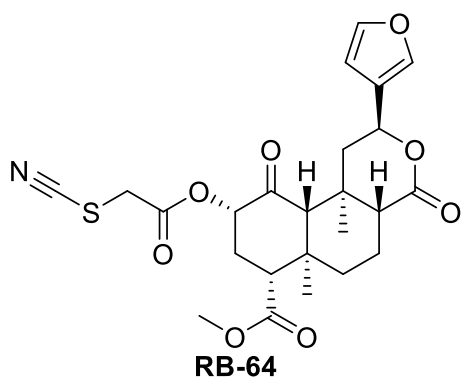<smiles>CN(C(=O)Cc1ccc(Cl)c(Cl)c1)[C@@H]1CCCC[C@H]1N1CCCC1</smiles>

$(+)-U 50,488$

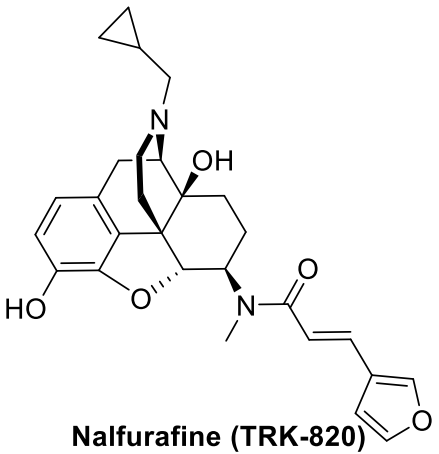<smiles></smiles>

Triazole probe: $X=O, \mathrm{R}^{1}=\mathrm{Cl}, \mathrm{R}^{2}=\mathrm{Cl}, \mathrm{R}^{3}=\mathrm{H}$ Triazole 1.1: $X=O, R^{1}=M e, R^{2}=C F_{3}, R^{3}=H$ Triazole 1.5: $X=S, R^{1}=C l, R^{2}=C_{3}, R^{3}=H$ 1.2: $X=S, R^{1}=H, R^{2}=C F_{3}, R^{3}=C l$<smiles>C[C@@]12C(=O)OC[C@@H]3C[C@]1(C)[C@H](c1ccoc1)OC[C@H]2[C@@H]3C(=O)c1ccccc1</smiles>

Collybolide<smiles>[R]N(CCc1ccccc1)CCc1cccc(O)c1</smiles>

HS665: $R$ = cyclobutylmethyl HS666 (MCBPHA): R = cyclopropylmethyl BPHA: $R=$ butyl MCPPHA: $R$ = cyclopentylmethyl<smiles>CC(NCc1nccn1C)c1cccc(O)c1</smiles>

compound 81

Dyn A: H-Tyr-Gly-Gly-Phe-Leu-Arg-Arg-lle-Arg-Pro-Lys-Leu-Lys-Trp-Asp-Asn-GIn-OH Dyn B: H-Tyr-Gly-Gly-Phe-Leu-Arg-Arg-Gln-Phe-Lys-Val-Val-Thr-OH Dyn 1-13: H-Tyr-Gly-Gly-Phe-Leu-Arg-Arg-lle-Arg-Pro-Lys-Leu-Lys-OH Dyn 1-11: H-Tyr-Gly-Gly-Phe-Leu-Arg-Arg-lle-Arg-Pro-Lys-OH

Dyn 1-9: H-Tyr-Gly-Gly-Phe-Leu-Arg-Arg-lle-Arg-OH Dyn 1-8: H-Tyr-Gly-Gly-Phe-Leu-Arg-Arg-lle-OH<smiles>CN(C(=O)Cc1ccccc1)[C@H]1CC[C@]2(CCCO2)C[C@H]1N1CCCC1</smiles>

U69,593<smiles>COC(=O)[C@H]1C[C@H](OC(=O)S(C)(=O)=O)C(=O)[C@@]2(C)[C@H]1CC[C@@H]1C(=O)O[C@H](c3ccoc3)C[C@H]12</smiles><smiles>COC(=O)N1CCN(C(=O)Cc2ccc(Cl)c(Cl)c2)C(CN2CCCC2)C1</smiles>

GR89696<smiles>[R]c1ccc(NC(=O)[C@@H]2CC=C[C@H]3CCN([R2])C(=O)[C@@]32[CH])cc1C(F)(F)F</smiles>

Lead compound: $\mathrm{R}^{1}=\mathrm{Cl}, \mathrm{R}^{2}=$ benzyl

2.1: $R^{1}=M e, R^{2}=2$-fluorobenzyl 2.2: $R^{1}=B r, R^{2}=$ phenyl

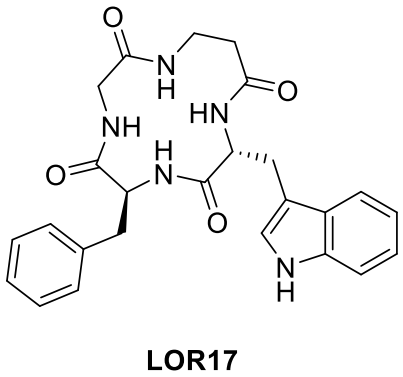

Figure 7: Structures of biased KOR ligands and reference ligands 


\section{Morphine-like compounds}

6'-guanidinonaltrindole (6'-GNTI; Figure 7) is a morphine-like compound developed by Sharma et al. in 2001. A shift of the guanidium group from the $5^{\prime}$ - to $6^{\prime}$-position transformed the antagonist naltrindole into the potent KOR-agonist, 6'-GNTI. ${ }^{196}$ This last one is able to selectively activate $G$ proteins, without recruiting $\beta$-arrestins. It thus serves as an antagonist to the undesired pathway by blocking internalization and $\beta$-arrestin recruitment in general. Generally, this is called biased agonism. 6'-GNTI produced antinociceptive effects in rodent models of thermal allodynia. ${ }^{197}$ In previous studies, $\mathbf{6}^{\prime}$-GNTI had been described as a DOR/KOR heterodimer-selective ligand, ${ }^{198}$ but when assessed using the radiant heat tail-flick assay in DOR KO mice, only a small decrease in nociception was observed, pointing to the maintained activation of KOR without the presence of DOR. ${ }^{197}$ In striatal neurons, $6^{\prime}$-GNTI did not activate ERK1/2 (linked to $\beta$-arrestin recruitment) but was able to activate Akt (linked to $G$ protein-signaling) whereas U69,593, a KOR agonist (Figure 7) activates both kinases. ${ }^{199}$ A bias factor for 6'-GNTI was determined using the operational model (Equation 2), with Sal A (vide supra) as a reference ligand, resulting in a value of 0.76 towards $G$ protein-signaling. ${ }^{200}$

Nalfurafine (TRK-820; Figure 7) is a morphinan-like compound derived from 4,5-epoxymorphinan, developed by Nagase et al., that is a highly potent and selective KOR agonist. ${ }^{201}$ Later studies demonstrated the antipruritic activity of nalfurafine. ${ }^{202}$ After successful results from clinical trials, nalfurafine hydrochloride subsequently entered the market (trade name Remitch ${ }^{\circledR}$ ) in Japan as an antipruritic agent. ${ }^{203}$ More recently, Lui et al. provided data on nalfurafine where it displayed analgesic and antipruritic effects without causing sedation, anhedonia, reduced motor coordination or conditioned place aversion (CPA), with a potency of $0.11 \mathrm{nM}$ in a GTP $\gamma \mathrm{S}$ assay in mouse neuro2A cells. ${ }^{204}$ In earlier studies, nalfurafine had been reported to produce only sedation (with $\mathrm{ED}_{50}=27$ $\mu \mathrm{g} / \mathrm{kg}$ ) when dosing the drug at levels much higher than required for producing antinociception $\left(\mathrm{ED}_{50}\right.$ $=3.3 \mathrm{\mu g} / \mathrm{kg}$ ). ${ }^{205}$ Nalfurafine also ensured a potent attenuation of i.t. morphine-induced itch/scratching responses in primates. ${ }^{206}$ The nalfurafine bias factor was calculated by Schattauer et al. for both rKOR and hKOR. Comparing ERK1/2 phosphorylation, linked to $G$ protein-signaling, with p38 phosphorylation, linked to $\beta$-arrestin-signaling, resulted in biased factors of 1.15 for rKOR and 3.2 for hKOR using the equiactive model relative to $\mathbf{U 5 0 , 4 8 8}$ (Equation 1). Hence, nalfurafine is a $G$ protein-biased KOR agonist both in rat and human receptor types. ${ }^{207}$

\section{Noribogaine}

Noribogaine (Figure 7) is the principal active metabolite from the drug ibogaine; a psychoactive alkaloid extracted from the African shrub Tabernanthe iboga. ${ }^{208-210}$ Noribogaine is, alongside ibogaine, both a KOR agonist and a NMDA receptor antagonist ${ }^{211}$ and was later found to be a G protein-biased KOR agonist, as well as a moderately potent MOR antagonist. This latter fact makes noribogaine a dual $\mathrm{k}-\mu$ agonist/antagonist. This is in contrast with ibogaine, which is a more potent MOR antagonist and a weaker KOR agonist than noribogaine. Relative to U69,593, noribogaine showed partial KOR agonism $\left(E_{\max }=72 \%\right.$ ) in a GTPYS assay, but displayed much lower levels of $\beta$ arrestin-2 recruitment $\left(E_{\max }=13 \%\right)$. Noribogaine can also be considered to be a $G$ protein-biased KOR agonist, since it is more effective at inhibiting $\beta$-arrestin agonist signaling as compared to the $G$ protein pathway. ${ }^{209}$

Noribogaine is structurally similar to mitragynine (vide supra, Figure 3); both contain an indole attached to an azepine or a piperidine ring. In addition, they both act as $G$ protein-biased ligands, 
but each at different receptors. More specifically, noribogaine is a MOR antagonist, suggesting the big impact on agonism when modifying the structure of the ligand. Noribogaine is more constrained compared to mitragynine and lacks the ester and enol ether function.

\section{Triazole 1.1 and derived compounds}

The triazole probe (Figure 7) was discovered in 2012 from HTS screening studies of the Molecular Libraries Probe Production Centers Network. ${ }^{212}$ This triazole probe displayed a high selectivity for KOR over MOR and DOR ( $\mathrm{k} / \mu=792$-fold and $\delta / \mathrm{K}=2230$-fold). Optimization of the triazole probe by substitution of the chlorine atoms on the aromatic ring afforded a series of potent $\mathrm{G}$ protein-biased agonists relative to $\mathbf{U 6 9 , 5 9 3}$ called triazole 1.1 to 1.5 (Figure 7). The bias factor was the highest for triazole 1.1 and $\mathbf{1 . 5}$ (1.79 and 2.05 respectively using the operational model; Equation 2). Triazole 1.1 and 1.5 were obtained by substitution of the two chlorine atoms by a methyl and a trifluoromethyl group for triazole $\mathbf{1 . 1}$ and the substitution of a chlorine atom by a trifluoromethyl group and replacing the pendant furan ring with a thiophene for triazole 1.5. After further investigation, triazole 1.1 was shown to be the most suitable analog since it displayed much less ERK1/2 phosphorylation than triazole $\mathbf{1 . 5}$ and in vivo tests proved the brain-penetrability of triazole 1.1. ${ }^{213}$ Subsequently, antinociception in murine tail flick tests was observed after systemic administration, showing triazole 1.1 to be a potent G protein-biased KOR agonist, since it displayed less ERK1/2 phosphorylation linked to $\beta$-arrestin recruitment, but still able to induce antinociception. ${ }^{213}$ In later studies, triazole 1.1 demonstrated neither aversion nor sedation upon doses resulting in analgesia and antinociception as compared to U50,488 (vide infra) ${ }^{195}$ Furthermore, triazole $\mathbf{1 . 1}$ did not change the ambulatory behavior in mice, whereas $\mathbf{U 5 0 , 4 8 8}$ led to dramatically lowered movement. ${ }^{214}$ In another study, other analogs of the triazole probe were developed, showing a bias towards $G$ protein-signaling. The compound with the highest biased factor of 1.9 (comparing $G$ protein with $\beta$ arrestin-2 and relative to $\mathbf{U 6 9 , 5 9 3 )}$ was compound 1.2 (Figure 7). Here, the 2-furanyl-ring was substituted with a 2-thiophenyl-ring and the 3,4-dichlorophenyl was substituted with a $1^{\prime}-\mathrm{Cl}, 5^{\prime}$ trifluoro-phenyl ring. Compound $\mathbf{1 . 2}$ showed a greater potency towards $\mathrm{G}$ protein-signaling, but a much lower potency towards $\beta$-arrestin when compared to $\mathbf{U 6 9 , 5 9 3}$. $^{215}$

\section{Salvinorin A derivatives}

Mesyl Sal B (Figure 7) is a neoclerodane diterpene analog, derived from Salvinorin A; a nonnitrogenous diterpene isolated from a hallucinogenic plant that acts as a potent selective KOR agonist. ${ }^{125}$ Mesyl Sal B was synthesized by Harding et al. by substitution of the acetate of Sal A by a methanesulfonyl group. Furthermore, Mesyl Sal B had similar potency and affinity as Sal A $\left(K_{i}=2.3\right.$ $\mathrm{nM}$ and $1.9 \mathrm{nM}, \mathrm{EC}_{50}$ of $30 \mathrm{nM}$ and $40 \mathrm{nM}$ respectively), but Mesyl Sal B showed a higher selectively towards KOR as compared to Sal A. ${ }^{124}$ Later, Simonson et al. described the antiaddictive properties of Mesyl Sal B and it was longer lasting than Sal A tested in the antinociception hot water tailwithdrawal assay in mice. Additionally, without altering cell-surface expression of dopamine transporters, Mesyl Sal B increased dopamine uptake in rat nucleus. ${ }^{216}$ The bias factor of Mesyl Sal B was later calculated by Kivell et al., as compared to U50,488 (vide infra), resulting is a bias factor of 0.61 meaning that Mesyl Sal B is biased towards the G protein pathway, since they compared cAMP inhibition vs $\beta$-arrestin recruitment. For these reasons, Mesyl Sal $B$ is considered as a $G$ proteinbiased ligand for KOR. Besides its antinociceptive effect, Mesyl Sal B did cause neither aversion, sedation, anxiety, nor learning and memory impairment in rats. ${ }^{217}$ 
RB-64 (Figure 7) is a semi-synthetic structural derivative of Sal A. RB-64 was developed by Yan et al., is more potent than Sal A, ${ }^{218}$ and was found to be a G protein-biased agonist for KOR. ${ }^{200} \operatorname{In} 2015$, RB64 was described as a biased agonist for $G$ protein-signaling without sedative and anhedonia-like effects. Additionally, RB-64 was the only KOR agonist that did not reduce motor coordination. Its bias factor, calculated in mice, was 1.98 towards $\mathrm{G}$ protein as compared to Sal A, using the operational model. ${ }^{219}$ The bias factor was later quantified in hKOR leading to a value of 1.55 , again using the operational model (Equation 2) relative to Sal $\mathbf{A} .{ }^{200}$

Collybolide (Figure 7) is a non-nitrogenous sesquiterpene, first extracted in 1974 from the fungus Collybia maculata. ${ }^{220}$ Collybolide shares a furyl- $\delta$-lactone core with Sal A and was shown to be a G protein-biased KOR agonist. It produced antinociception in a tail-flick assay in male mice together with a reduction of pruritus and was aversive. Additionally, upon doses where antinociception was observed, no sedation was detected. Moreover, it induced higher levels of anxiety than Sal A. Interestingly, at higher concentrations, collybolide can bind to a second site in hKOR behaving as a allosteric modulator. 221

\section{GR89696}

GR89696 (Figure 7) is a highly potent and selective KOR agonist, developed by Naylor et al. in 1993, showing well-defined antinociceptive effects $\left(E_{50}=0.52 \mathrm{ng} / \mathrm{kg} \text { upon s.c. administration }\right)^{222}$ GR89696 ensured a potent attenuation of i.t. morphine-induced itch/scratching responses in primates. ${ }^{206}$ It had also been suggested that GR89696 could interact with KOR/DOR heterodimers to mediate antinociception. ${ }^{223} \mathrm{~A}$ bias factor for $\mathbf{G R 8 9 6 9 6}$ of 0.67 towards $\beta$-arrestin- 2 was calculated by White et al. (Sal A as a reference ligand, using the operational model for quantification; Equation 2) which produces an unfavorable bias for GR89696, ${ }^{200}$ which was also reported by Kenakin et al. ${ }^{224}$

\section{6. $\mathrm{U} 50,488$}

U50,488 is a compound developed by Van Voigtlander et al. in the search for opioid analgesics. ${ }^{225}$ It is a highly selective KOR agonist and exhibited antitussive effects in rats. ${ }^{226}$ The authors made a distinction between (+)-U50,488 and (-)-U50,488, since a shift in biased signaling occurred between the enantiomers. Taking Sal A as a reference ligand, (+)-U50,488 (Figure 7) was a slightly G proteinbiased KOR agonist with a bias factor of 0.91 , whereas (-)-U50,488 proved to be a modestly $\beta$ arrestin-biased KOR agonist with a bias factor of 0.31 towards $\beta$-arrestin recruitment. These bias factors were both calculated using the operational model (Equation 2), ${ }^{200}$ which makes (+)-U50,488 the better biased KOR ligand. Compared to U69,593, (+)-U50,488 was also a KOR agonist slightly biased towards $\mathrm{G}$ protein-signaling (bias factor of 0.60 , calculated with the operational model). ${ }^{227}$

\section{Diphenethylamines}

The design and synthesis of different compounds with a diphenethylamine structure backbone has previously been described by Spetea et $a l^{228}$ The most favorable $N$-substitution of the diphenethylamines were cyclopropylmethyl (CPM) and cyclobutylmethyl (CBM) over $N$-alkyl groups for an increase in affinity and selectivity towards the KOR. The N-CBM analog, HS665, demonstrated a remarkable selectivity for KOR over MOR ( $>1100$-fold) and DOR ( $>20000$-fold) and displayed potent antinociceptive effects after s.c. administration in mice. The $\mathrm{N}$-CPM analog, HS666, showed lower but still significant selectivity for KOR over MOR (140-fold) and DOR (>1700-fold), and revealed itself to be a partial KOR agonist. ${ }^{228}$ Later investigations into those two compounds showed antinociceptive responses in murine models of acute thermal nociception. HS665 (Figure 7) was 
reported to be more potent than HS666 in the generation of antinociception upon intracerebroventricular (i.c.v.) ( $\mathrm{ED}_{50}$ of $3.74 \mathrm{nmol}$ and $6.02 \mathrm{nmol}$, respectively). When comparing to U50,488 (vide supra), HS665 was also more potent and HS666 showed a similar level of potency. However, HS666 showed reduced liability for aversive effects after i.c.v. administration in mice. ${ }^{229}$ More recently, Dunn et al. have described three of these diphenethylamine analogs as biased agonists: BPHA, MCBPHA (viz. HS665) and MCPPHA. MCBPHA was validated as equally potent as U50,488 in peripheral analgesia. Upon quantification of the bias, BPHA, MCBPHA, and MCPPHA (Figure 7) were all found to be biased towards $\mathrm{G}$ protein-signaling (bias factors of 1.8, 1.6 and 1.3 respectively all compared to U69,593, using the operational model of Black and Leff; Equation 2). Hence, BPHA was proven to be a full agonist with full efficacy in GTP $\gamma S$ assay without $\beta$-arrestin-2 recruitment, which makes it a highly G protein-biased KOR agonist. MCBPHA and MCPPHA have a lower bias factor than BPHA, since they showed partial efficacy towards $\beta$-arrestin-2 recruitment. ${ }^{227}$

\section{Isoquinolinone analogs}

Isoquinolinone lead compounds were discovered by Frankowski et al. using a 72-member library synthesized by Diels-Alder acylations and followed by screening of these compounds for binding at potential GPCR targets. The isoquinolinone lead compound (Figure 7) was found to be highly selective for KOR over both MOR and DOR. ${ }^{230-231}$ Later, this isoquinolinone lead compound was optimized by substituting the chlorine on the aromatic ring and the benzyl-group on the nitrogen of the isoquinolinone moiety by a methyl and 2-fluorobenzyl respectively, affording 2.1, and by a bromide and phenyl, giving $\mathbf{2 . 2}$ (Figure 7). The bias factors of these analogs were calculated using the operational model (Equation 2) with U69,593 as a comparison, resulting in factors of 1.50 and 1.67 respectively for $\mathbf{2 . 1}$ and $\mathbf{2 . 2}$ towards G protein-signaling. Analog $\mathbf{2 . 1}$ demonstrated the best potency ( $\mathrm{EC}_{50}$ of $84.7 \mathrm{nM}$ vs $264.5 \mathrm{nM}$ for 2.2) in vitro and was for this reason more extensively investigated in vivo, showing antinociceptive responses in the mouse tail flick test. Additionally, $\mathbf{2 . 1}$ proved to be brain-penetrating in vivo by taking brain samples after 30 and 60 min from C57BI-6 mice. ${ }^{213}$

\section{Compound 81}

In 2017, Zheng et al. reported the discovery of compound $\mathbf{8 1}$ (Figure 7), a potent G protein-biased KOR agonist with little $\beta$-arrestin recruitment. It was discovered by a multi-template screening using the KOR crystal structure with the corresponding ligand-optimized atomistic models to discover new KOR chemotypes with distinct functional features and submicromolar activities, followed by SAR, resulting in 11 hits. Compound $\mathbf{8 1}$ showed a high affinity towards $K O R\left(K_{i}=0.16 n M\right)$ and had a bias factor of 0.78 towards $G$ protein-signaling over $\beta$-arrestin recruitment relative to Sal $A$. Subsequent docking of compound $\mathbf{8 1}$ demonstrated $\mathbf{H}$-bonding between the amine moiety of the ligand with Asp $^{138}$ of KOR. ${ }^{64}$

\section{Dynorphins}

Dynorphin $A$ and $B$ are endogenous opioid peptides with a high selectivity for KOR over MOR and DOR. ${ }^{5}$ White et al. screened different dynorphin sequences for their propensity for biased signaling. The sequences tested were Dyn A, Dyn 1-8, Dyn 1-9, Dyn 1-11 and Dyn 1-13 (Figure 7). Dyn A is a 17-mer from which the other sequences are truncated derivatives; Dyn 1-8, Dyn 1-9, Dyn 1-11 and Dyn 1-13 represents the first eight, nine, eleven and thirteen amino acids from Dyn A respectively (starting from the $\mathrm{N}$-terminus). From their studies, the authors arrived at bias factors of 1.56, 0.68, 1.22, 1.67 and 1.56 (operational model; Equation 2) respectively, pointing clearly towards the $G$ protein pathway with Sal A as a reference ligand. This suggests that Dyn 1-8 and Dyn 1-9 are 
moderately biased towards G protein-signaling with Dyn A, Dyn 1-11 and Dyn 1-13 showing a higher level of bias towards $\mathrm{G}$ protein-signaling. ${ }^{200}$

\section{LOR17}

A recently discovered KOR agonist, LOR17, was shown to exhibit biased signaling. LOR17 (Figure 7) is a cyclized form of the tetrapeptide H-Gly-B-Ala-D-Trp-Phe-OH, inhibiting adenylyl cyclase in a similar way to U50,488, but without significant $\beta$-arrestin-2 recruitment at KOR. This was quantified by the calculation of the bias factor (operational model; Equation 2) using $\mathbf{U 5 0 , 4 8 8}$ as a reference ligand, revealing a bias factor of 2.93 towards $\mathrm{G}$ protein-signaling. Additional in vivo experiments showed LOR17 to be effective for acute nociception, together with a reduced thermal hypersensitivity of induced neuropathic pain, as determined in murine models. ${ }^{232}$

\section{Biased nociceptin-opioid receptor ligands}

Alongside the three classical opioid receptors, we will also consider the nociceptin-opioid receptor (NOP receptor) for discussion. NOP receptor was discovered many years after the classical opioid receptors MOR, DOR and KOR and was first characterized by Mollereau et al. as a result of cloning experiments. It was found to be structurally and functionally related to the classical opioid receptors, with a $49-50 \%$ sequence identity to the murine MOR, DOR and KOR. ${ }^{69}$ NOP receptor can either induce or block analgesic effects depending on the route of administration of its agonists. ${ }^{13,35}$ More specifically, nociceptin (N/OFQ) (Figure 9), the endogenous peptide at NOP receptor, can induce either hyperalgesia, by blocking the MOR-induced analgesia, or analgesia by reducing hyperalgesia during opioid withdrawal. ${ }^{35}, 72$ In addition, NOP receptor blockade can have antidepressant effects. ${ }^{36}$ To determine the biased activity of NOP receptor ligands, reference ligands are used to compare its activity. These reference ligands are Ro65-6570 (Figure 9), but mainly nociceptin. Different biased nociceptin-opioid receptor ligands are listed and discussed briefly below. 

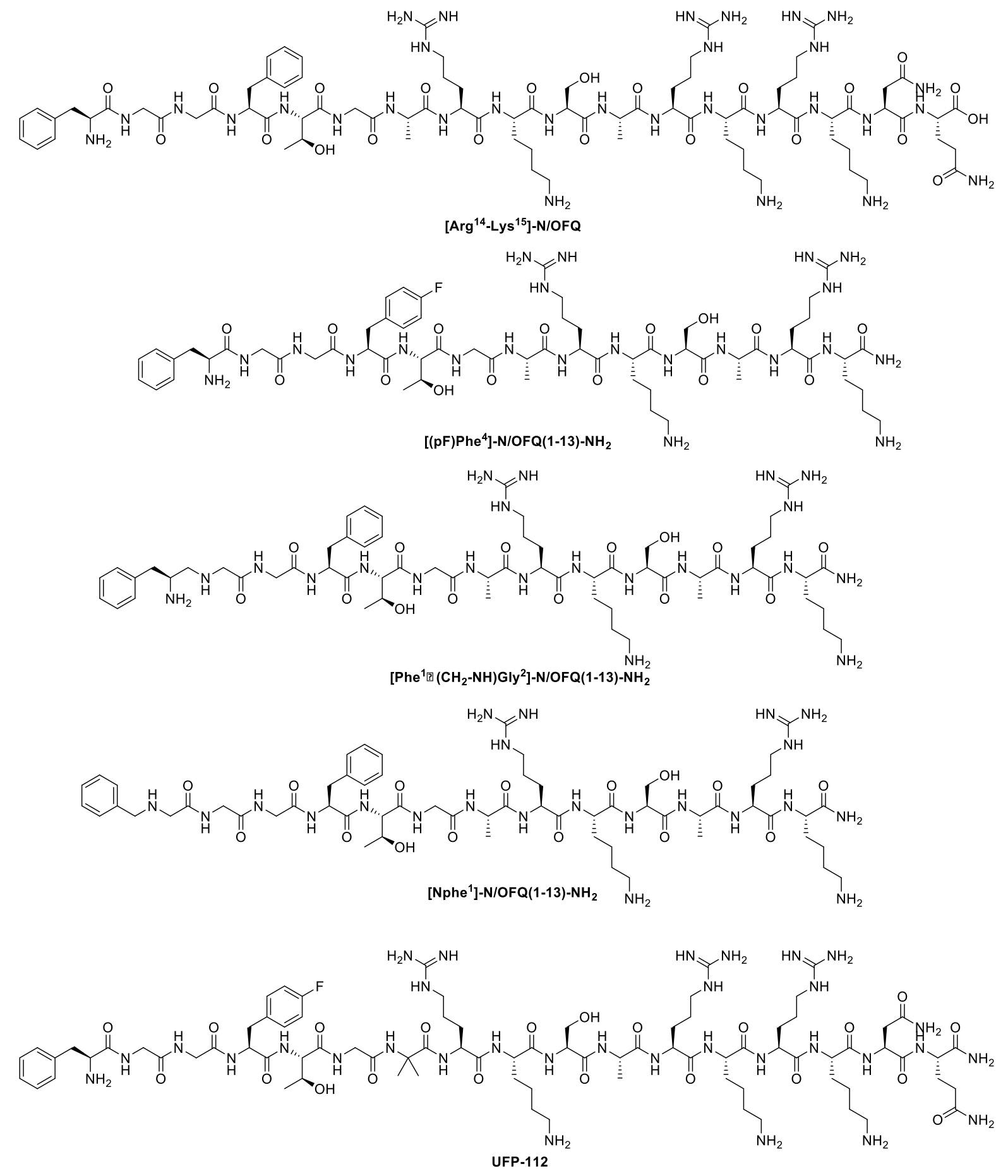

Figure 8: Structures of UFP-112 derivatives

\section{UFP-112}

UFP-112 (Figure 8) is a modified peptide analog of nociceptin that was developed by Arduin et al. in 2007. ${ }^{233}$ Prior to the discovery of UFP-112, a number of other modifications on the nociceptin peptide were experimentally validated: increased potency was seen in $\left[\mathrm{Arg}^{14}-\mathrm{Lys}^{15}\right]-\mathbf{N} / \mathbf{O F Q}^{234}$ and [(pF)Phe ${ }^{4}$ ]-N/OFQ(1-13)- $\mathrm{NH}_{2}{ }^{235}$ reduced efficacy on $\left[\mathrm{Phe}^{1} \Psi\left(\mathrm{CH}_{2}-\mathrm{NH}\right) \mathrm{Gly}^{2}\right]-\mathrm{N} / \mathrm{OFQ}(1-13)-\mathrm{NH}_{2}{ }^{236}$ or antagonism in the case of [Nphe ${ }^{1}$ ]-N/OFQ(1-13)- $\mathrm{NH}_{2}$ (Figure 8). ${ }^{237}$ When $\mathrm{C}_{\alpha, \alpha}$ dialkylated amino acids were used in place of $\mathrm{Ala}^{7}, \mathrm{Ala}^{11}$ and $\mathrm{Ala}^{15}$ promising results were obtained. As such, the substitution 
of $\mathrm{Ala}^{7}$ by Aib (2-aminoisobutyric acid) on N/OFQ led to a 7-fold more potent peptide than N/OFQ itself. Taking the previously described potency enhancing modifications into account, UFP-112 was obtained with the sequence [(pF)Phe ${ }^{4} \mathrm{Aib}^{7} \mathrm{Arg}^{14} \mathrm{Lys}^{15}$ ]-N/OFQ-NH 2 (Figure 8) developing full agonism on NOP receptor. ${ }^{233}$ In the same year, Rizzi et al. reported UFP-112 as a selective and potent full agonist for NOP receptor with long-lasting effects in vivo. ${ }^{238}$ On top of this, the long lasting effects of UFP-112, which are comparable to those of morphine, were shown in hyperalgesia and acute pain. Upon i.t. administration in primates, UFP-112 did not produce itch/scratching responses, with an exclusive NOP receptor activation. ${ }^{239}$ Additionally, the bias for UFP-112 was quantified in 2015 by Malfacini et al. using the operational model (Equation 2). The obtained bias factor for UFP-112 was 0.71 relative to nociceptin towards the $G$ protein pathway versus $\beta$-arrestin- 2 recruitment. ${ }^{240}$ 
Nociceptin (N/OFQ): H-Phe-Gly-Gly-Phe-Thr-Gly-Ala-Arg-Lys-Ser-Ala-Arg-Lys-Leu-Ala-Asn-GIn-OH

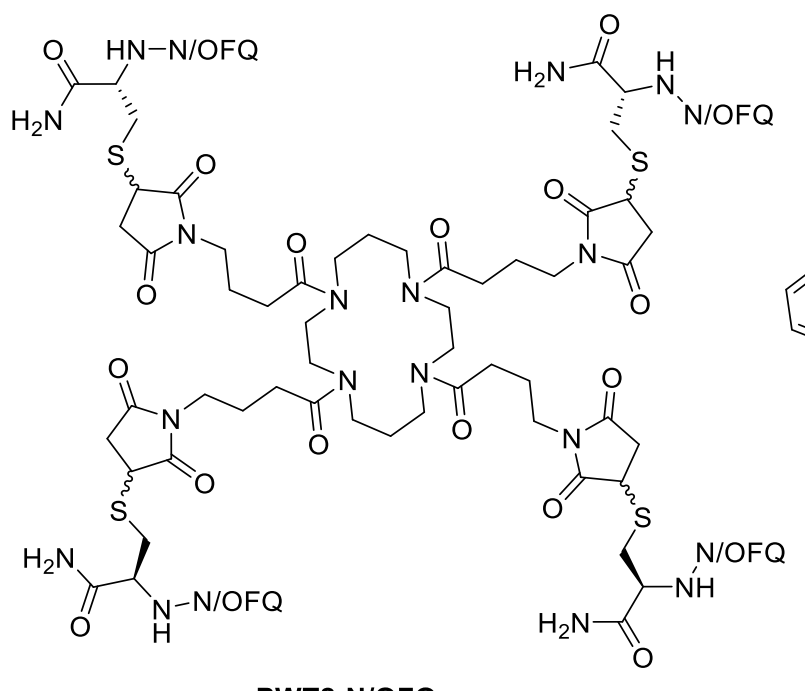

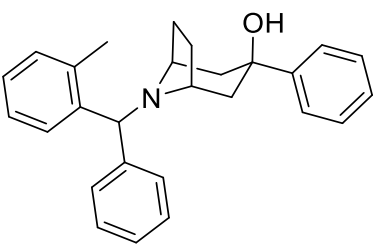

SCH 221510

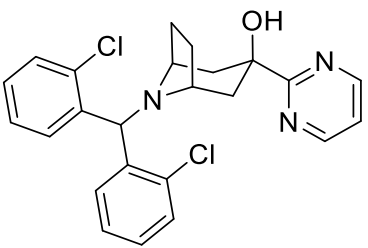

SCH 486757<smiles>COC(=O)N1CN(c2ccccc2)C2(CCN(Cc3cccc4ccccc34)CC2)C1=O</smiles>

NNC 63-0532

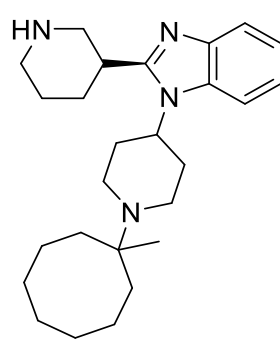

MCOPPB

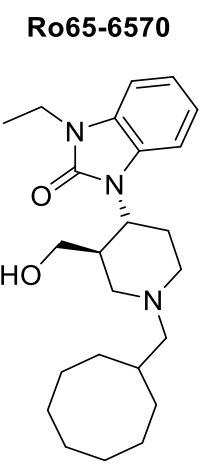

J-113397

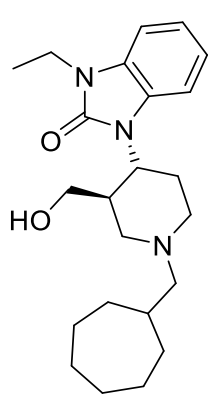

RTI-816
Ro2q

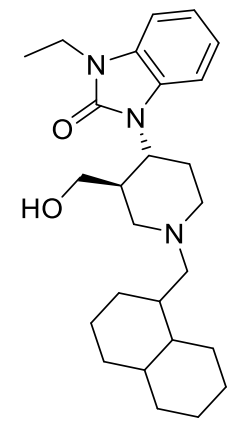

RTI-819

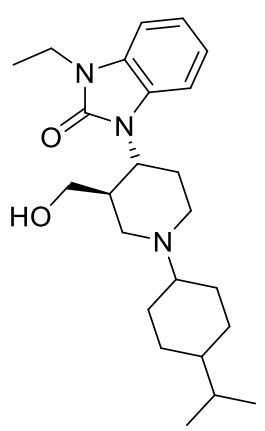

RTI-856

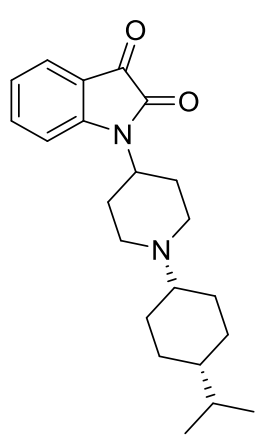

AT-090

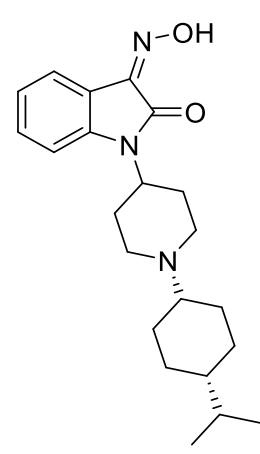

AT-127

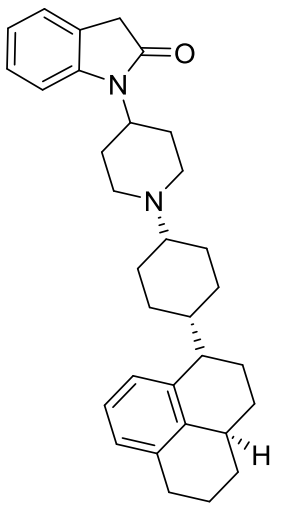

AT-202

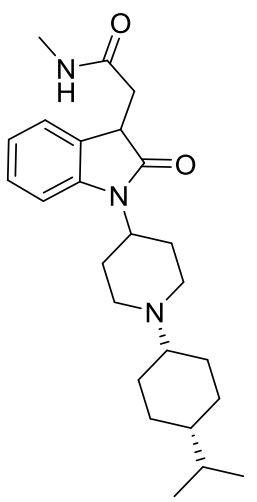

AT -403 


\section{PWT2-N/OFQ}

PWT2-N/OFQ (Figure 9) is a branched derivative of N/OFQ with four-fold symmetry, where PWT stands for peptide-welding technology. The first examples of homotetravalent PWT-N/OFQ were described by Guerrini et al. in 2014. The PWT core (a cyclam in the case of PWT2) is linked to maleimido moieties, and then linked to $\left[\mathrm{Cys}^{18}\right]-\mathrm{N} / \mathrm{OFQ}-\mathrm{NH}_{2}$ via a thiol-Michael reaction. ${ }^{241}$ PWT2N/OFQ was found to be 40-times more potent than the native N/OFQ peptide with longer lasting effects. ${ }^{241}$ This PWT technique was later applied on other opioid ligands (e.g. dermorphin, N/OFQ analogs, UPF-101). ${ }^{242}$ In 2015, Rizzi et al. demonstrated the spinal antinociceptive effects of PWT2N/OFQ for both neuropathic and nociceptive pain in mice and primates, exhibiting a duration of action of more than 24 hours in primates and 40 -fold more potency than N/OFQ. ${ }^{243}$ Moreover, PWT2-N/OFQ displayed a biased action towards $G$ protein-signaling, since the calculated bias factor was 1.09 quantified with the operational model relative to N/OFQ (Equation 2). ${ }^{240}$

\section{SCH 221510}

SCH 221510 (Figure 9) is an orally-available NOP receptor agonist with anxiolytic-like effects and a high affinity $\left(\mathrm{K}_{\mathrm{i}}=0.3 \mathrm{nM}\right)$ towards NOP receptor and selectivity for the NOP receptor over MOR, KOR, and DOR (217-, 437- and > 9500-fold, respectively). The anxiolytic-like effects were established through preclinical animal models, showing similar effects than CDP (chlordiazepoxide), but no disruption of overt behavior, such as locomotor activity, was observed, as is the case for CDP. SCH 221510 is also capable of attenuating vocalizations in guinea pig pups and, even upon chronic administration, the effects did not decrease. Whereas benzodiazepines are associated with sedation, muscle relaxation, amnesia, tolerance and dependence, $\mathbf{S C H} 221510$ is not. ${ }^{244}$ More recent studies on SCH 221510 have shown that SCH 221510 can attenuate the reinforcing effects of MOR agonists and does not function as a reinforcer in rats. Whenever an organism's future behavior is preceded by a specific antecedent stimulus, reinforcement is a consequence applied that will strengthen that behavior. For this reason, SCH $\mathbf{2 2 1 5 1 0}$ is now considered a potential drug candidate against addiction. ${ }^{245}$ Additionally, Sobczak et al. reported the anti-inflammatory and antinociceptive effects of SCH 221510 in mice with acute inflammation, thereby suggesting a potential therapeutic strategy for the treatment of inflammatory bowel diseases. ${ }^{246}$ The same research group also stated antitransit and antinociceptive effects. In mice, SCH 221510 inhibited the gastrointestinal tract contractibility both in vitro and in vivo. ${ }^{247}$ Regarding biased signaling, Malfacini et al. determined a bias factor of 0.77 relative to N/OFQ with a preference for the G protein pathway. ${ }^{240} \mathrm{~N} / \mathrm{OFQ}$ is the endogenous peptide ligand for NOP receptor. A few years later, Ferrari et al. reported a bias factor for SCH 221510 using the operational model for the calculation (Equation 2). A bias factor of 1.10 was obtained towards $G$ protein-signaling over $\beta$-arrestin-2 recruitment, in comparison with N/OFQ. ${ }^{248}$

\section{4. $\mathrm{SCH} 486757$}

SCH 486757 (Figure 9) is a non-peptidic, orally bioavailable agonist for NOP receptor with a selectivity of 211-, 128- and 3206-fold over the 'classical' opioid receptors (MOR, KOR, and DOR, respectively). SCH $\mathbf{4 8 6 7 5 7}$ was first shown to be a potent and efficacious antitussive agent in coughing models; ${ }^{249}$ it inhibited capsaicin-induced coughing in both acute and chronic dosing regimens by $46 \pm 9 \%$ and $40 \pm 11 \%$ respectively (as compared to codeine). In guinea pig, rat, dog and 
cat models, SCH 486757 is well tolerated without overt behavioral effects and it was also demonstrated that SCH $\mathbf{4 8 6 7 5 7}$ had a high affinity for human, guinea pig, dog, cat and rat NOP receptor. ${ }^{249}$ SCH 486757 was tested in phase I clinical trials for subacute cough in 2010, which was the first randomized placebo-controlled study of a NOP receptor agonist. The studies showed that virtually no difference in cough was observed for both $\mathbf{S C H} \mathbf{4 8 6 7 5 7}$ and codeine when compared to placebo. Additionally, patients treated with SCH 486757 reported sedation, however less gastrointestinal effects compared to codeine were reported. ${ }^{250}$ Due to lack of efficacy, the somnolence of patients and sedation, the continued clinical development of SCH 486757 was abandoned. ${ }^{250-251}$ Nevertheless, years later the biased character of SCH $\mathbf{4 8 6 7 5 7}$ was determined by calculating the factor, compared to N/OFQ, of 0.81 , calculated with the operational model (Equation 2), resulting in a $\mathrm{G}$ protein-biased ligand. ${ }^{248}$

\section{Ro compounds}

Ro64-6198 (Figure 9) is a small molecule spirocycle synthesized by Wichmann and colleagues. ${ }^{252}$ Ro64-6198 is a full agonist, displaying high affinity for NOP receptor and a more than 100-fold selectivity over MOR, DOR, and KOR, eliciting anxiolytic-like effects upon i.p. injection in an elevated plus-maze test. ${ }^{252-253}$ Furthermore, Ro64-6198 produced anxiolytic effects similar to benzodiazepines in rats. ${ }^{254}$ Even though Ro64-6198 showed limited bioavailability (around 4\%), it exhibited excellent brain penetration following parenteral administration. Upon high dosage of Ro64-6198 $(10 \mathrm{mg} / \mathrm{kg}$ i.p.), the forced motor behaviors and panic escape latencies in rats were disrupted. ${ }^{253}$ These effects were entirely absent in NOP receptor KO mice. ${ }^{255}$ After daily administration of Ro64-6198 for 15 days in rats, no tolerance to the anxiolytic-like effects was observed upon chronic administration and did not interfere with sensorimotor functions. Additionally, Ro64-6198 desensitized CAMP responses and downregulated the number of cell-surface NOP receptors in NOP receptor-expressing cells preexposed to Ro64-6198. ${ }^{256}$ In primates, it did not produce respiratory depression, pruritic or reinforcing effects in the same way as alfentanil. ${ }^{257}$

Ro65-6570 (Figure 9) is a small molecule with close structural similarities to Ro64-6198. Ro65-6570 was synthesized by Wichmann et al. in 1999 and was identified as a non-peptide agonist with high affinity for NOP receptor and modest selectivity over the 'classical' opioid receptors. ${ }^{258}$ In CHO h NOP receptor cells, Ro65-6570 acted as a full agonist with a 7-fold higher potency than N/OFQ. ${ }^{259}$ In 2002, Kotlinska et al. demonstrated that Ro65-6570 did not change the effect of cocaine upon i.c.v. administration, in contrast to N/OFQ which suppressed the cocaine effects. However, acute administration of Ro65-6570 increased the time spent in the drug-associated compartment of the conditioned place preference (CPP) apparatus in control rats. ${ }^{260}$ On the other hand, when Ro65-6570 was co-administered with opioid drugs - such as heroin, morphine, oxycodone etc. - it reduced the acquisition of place preference induced by opioid drugs. ${ }^{261}$ The bias for Ro65-6570 was quantified by the calculation of the bias factor using the Black \& Leff operational model (Equation 2), resulting in a bias factor of 1.07 towards the $G$ protein pathway versus the $\beta$-arrestin-2 recruitment, and relative to N/OFQ. ${ }^{240}$ The bias factor for Ro65-6570 was also calculated by Ferrari et al. and appeared to be 1.00 towards the $\mathrm{G}$ protein pathway (with N/OFQ as reference ligand). ${ }^{262}$ But in a later study, a different bias factor was obtained, resulting in a value of $1.64 .{ }^{248}$ Surprisingly, significant different bias factors were obtained, even though the same method was used in both studies.

Ro2q (Figure 9) is a small molecule, structurally similar to Ro64-6198 and Ro65-6570, discovered by Röver et al. coming out of their SAR studies around the central core 8-cycloalkyl-1-phenyl-1,3,8- 
triaza-spiro[4.5]decan-4-one. The cis-isomer of Ro2q is an agonist which is 40-fold more potent at NOP receptor than its trans-counterpart. Additionally, Ro2q is 40 -fold and more than 200 -fold more selective towards NOP receptor over MOR and KOR, respectively. ${ }^{263}$ The bias factor for Ro2q was later calculated using the operational model (Equation 2), resulting in a value of 0.93 towards the $G$ protein cascade in comparison with N/OFQ. ${ }^{248}$

\section{NNC 63-0532}

NNC 63-0532 (Figure 9) was first synthesized by Thomson and Hohlweg in $2000^{264}$ and is structurally similar to the Ro-compounds (vide supra). NNC 63-0532 showed a high affinity towards NOR (both human and rat receptor, $\mathrm{K}_{\mathrm{i}}=7.3 \mathrm{nM}$ and $11 \mathrm{nM}$, respectively). Additionally, it demonstrated a selectivity of 20-fold over MOR and KOR and 14-fold over dopamine $D_{2 S}, D_{3}$ and $D_{4.4}$ receptors upon radioligand binding displacement. ${ }^{264}$ On top of its NOP receptor selectivity, NNC 63-0532 showed an efficacy of $72 \%$, making it a partial agonist relative to N/OFQ in a cAMP inhibition assay, together with insufficiently promoting $\beta$-arrestin-1 and 2, also relative to N/OFQ. This latter fact made it impossible to calculate a bias factor. ${ }^{265}$ Another study was able to prove the lack of induced phosphorylation by NNC 63-0532 at NOP receptor, which is linked to the $\beta$-arrestin pathway. ${ }^{266}$ Since NNC 63-0532 was not able to produce sufficient $\beta$-arrestin-2, and lacked induced phosphorylation at NOP receptor, it could be considered as a G protein-biased NOP receptor ligand.

\section{MCOPPB}

MCOPPB (Figure 9) is a small molecule agonist of NOP receptor. It was developed by Hayashi et al. ${ }^{267}$ and has a high affinity for hNOP receptor as well as exhibiting high selectivity over the other opioid receptors (12-, 270- and $>1000$-fold over MOR, KOR, and DOR respectively). ${ }^{268}$ MCOPPB is a full agonist of NOP receptor with an $\mathrm{EC}_{50}$ of $0.39 \mathrm{nM}$, contrary to MOR, DOR, and KOR, where weak or partial agonism was observed. ${ }^{267}$ In the one-trial passive avoidance test, MCOPPB, unlike diazepam, did not produce amnesia. In addition, MCOPPB is effective upon oral administration and acceptable penetration of the blood-brain barrier penetration were observed. ${ }^{268}$ In later studies, MCOPPB was described as a biased NOP receptor agonist towards the G protein pathway relative to N/OFQ and 10 -fold more potent than the latter one. The bias factor was calculated using the operational model of Black and Leff (Equation 2), resulting in a value of 1.52 and 1.55 for $G$ protein over $\beta$-arrestin-1 and $\beta$-arrestin-2 respectively. This makes MCOPPB significantly biased towards the $G$ protein cascade over both $\beta$-arrestins. ${ }^{265}$ In another study, the bias factor was calculated for MCOPPB, also relative to N/OFQ using the same equation, with the obtained value of 0.97 , a bias towards $G$ protein over $\beta$-arrestin-2, but using the GTPYS assay instead of the cAMP assay used by Chang et $a .^{248}$

\section{RTI-compounds}

RTI-819 and RTI-856 (Figure 9) are both small molecules, derived from J-113397 (Figure 9), a potent and selective NOP receptor antagonist. The synthesis of J-113397 was first described in 1999 by Kawamoto et al. ${ }^{269}$ Later, RTI-816 (Figure 9), RTI-819 and RTI-856 were synthesized starting from the un- $N$-substituted piperidine ring, by performing a reductive alkylation. Upon performing a cAMP assay, RTI-816 showed weak inverse agonist activity at NOP receptor. RTI-819 and RTI-856 on the other hand demonstrated both partial agonism towards the $\mathrm{G}$ protein pathway with an efficacy of $75 \%$ and $77 \%$ respectively. Besides their partial agonism at $\mathrm{G}$ protein, they only induced very weak $\beta$ arrestin-1 and 2 recruitment. Consequently, no bias factor was calculated and RTI-819 and RTI-856 were both considered as G protein-biased ligand at NOP receptor. ${ }^{265}$ 


\section{AT compounds}

Different AT compounds, e.g. AT-001, AT-004, AT-035, AT-090, AT-127, AT-202 and AT-403, were synthesized at Astraea Therapeutics, all consisting of a piperidine ring and a 2-indolone moiety.

AT-090 and AT-127 (Figure 9) behaved as potent partial agonists for NOP receptor in the functional assays performed, being the GTP $Y$ S binding, calcium mobilization and BRET assays. Additionally, both compounds showed a higher selectivity over NOP receptor than Ro65-6570. The whole set of AT compounds displayed a moderate selectivity for NOP receptor over the other opioid receptors MOR, KOR, and DOR, whereas AT-090 and AT-127 showed the highest selectivity (17-fold and 61-fold over MOR, and 42-fold and 126-fold over KOR, respectively), similar to Ro65-6570. Upon calculation of the bias factor, AT-090 was demonstrated to be bias towards $\beta$-arrestin-2 recruitment with a bias factor of - -0.78 , though AT-127 had a bias factor of 0.27 showing a bias slightly towards the $\mathrm{G}$ protein pathway. ${ }^{262}$

An additional two AT compounds were explored for their bias were AT-202 and AT-403 (Figure 9), both of which contain a piperidine and dihydroindole core. The synthesis of AT-202 was described in 2004. ${ }^{270}$ AT-202, also described as SR16835, is a full agonist for NOP receptor and showed a binding affinity similar to that of SCH 221510 and SCH 486757. ${ }^{74}$ In a mouse spinal nerve ligation model for neuropathic pain, AT-202 displayed anti-allodynic activity with Von Frey monofilaments upon systemic administration. No thermal antinociceptive activity in tail-flick test was observed in mice for acute pain. ${ }^{74-75}$ Even though AT-202 proved to be 50-fold less potent than N/OFQ in a GTPYS binding assay and 100 -fold less potent in a calcium mobilization assay, it showed to be a G protein-biased agonist for the NOP receptor with a bias factor of 0.46 in comparison with N/OFQ, and quantified using the operational model (Equation 2). Furthermore, AT-202 exhibited moderate selectivity over the other opioid receptors. In contrast to AT-202, AT-403 displayed a similar degree of potency as N/OFQ in both a GTPYS binding and calcium mobilization assays, but is also a potent full agonist. Additionally, AT-403 demonstrated excellent selectivity towards NOP receptor over MOR, KOR, and DOR, but its bias factor did not exceed 0.16 relative to N/OFQ. This value is not statistically different from 0 and so AT-403 cannot be considered a biased NOP receptor ligand. ${ }^{248}$ Later studies on AT-403 demonstrated the induction of anti-Parkinsonian and anti-dyskinetic effects. At low doses in vivo, AT-403 improved Parkinsonian akinesia and disrupted motor activity as well as significantly reducing abnormal involuntary movements (AIMs). ${ }^{271}$ Based on these findings, it remains unclear whether AT403 functions as a biased agonist at NOP receptor or not, since the reduction of side effects were clearly observed, but no significant bias factor has so far been be calculated.

\section{Bifunctional biased opioid receptor ligands}

Bifunctional ligands can have the prospect of improved potency, whilst at the same time producing fewer harmful side effects compared to ligands only binding to a single target. Major advantages for bifunctional ligands over drug cocktails are the fact that their PK and PD properties are more predictable and there is less chance of drug-drug interactions. ${ }^{272}$ While the advantages of agonism or antagonism at one receptor are maintained, targeting a second receptor with a single molecule can bring along benefits such as attenuated side effects (e.g. MOR/DOR ligands, vide infra) or significantly lowered dosages for efficient analgesic responses due to synergistic effects induced through a simultaneous activation of distinct receptors involved in pain signaling (e.g., MOR/NOP 
ligands).[Guillemyn JMC and Starnowska Eur J Pharm Sci 2017] Different bifunctional biased opioid receptor ligands are listed and discussed briefly below. 


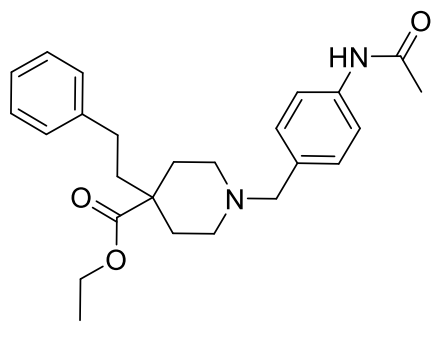

CYM51010<smiles>Cc1cc(O)cc(C)c1C[C@H](N)C(=O)N[C@@H](CCCCNC(=O)C[C@H](NC(=O)[C@H](Cc1ccccc1)NC(N)=O)C(=O)N[C@@H](Cc1ccccc1)C(N)=O)C(N)=O</smiles>

Dmt-c[D-Lys-Phe-Asp]-NH 2<smiles>CONCONC(CS)C(N)=O</smiles><smiles>COC(CN1CCC(C)(C)C1)c1ccccc1</smiles>

2S-LP2<smiles>Cc1cc(O)cc(C)c1C[C@H](N)C(=O)N1Cc2ccccc2CC1CNC(Cc1ccccc1)C(=O)N[C@@H](Cc1ccccc1)C(N)=O</smiles>

DIPP-NH2[psi]

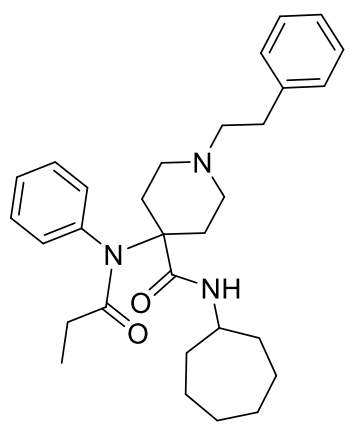

MP102

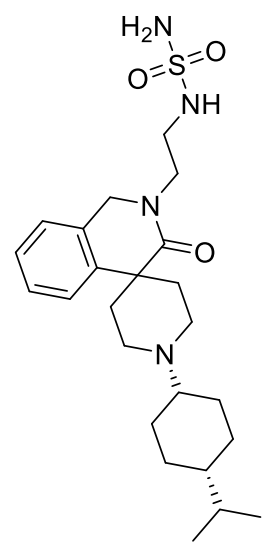

AT-121

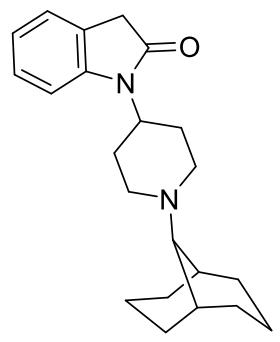

AT-201

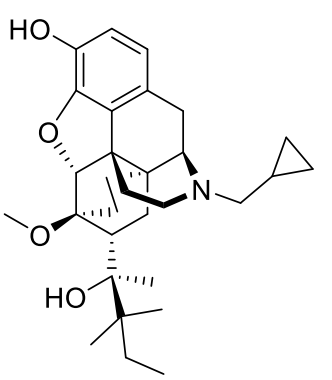

BU08028<smiles>CCONCONC(CO)C(N)=O</smiles>

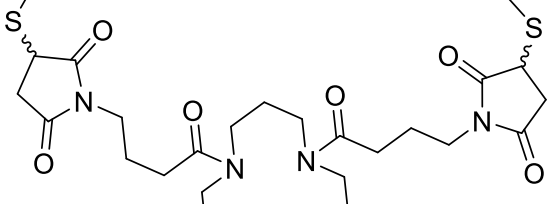<smiles>CCNC(=O)CCCNC(=O)CCCN1C(=O)C[C@H](S)C1=O</smiles>

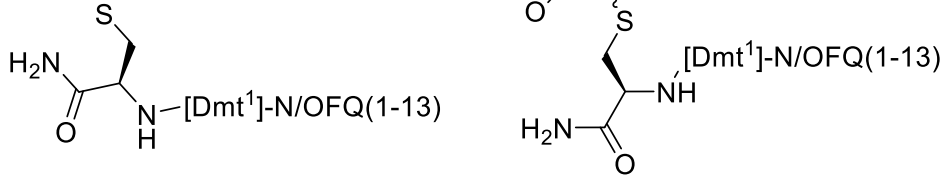

PWT2-[Dmt $\left.{ }^{1}\right]$ /OFQ(1-13) 


\section{A. MOR/DOR bifunctional ligands}

\section{CYM51010}

CYM51010 (Figure 10) is a small molecule biased agonist for the $\mu-\delta$ opioid receptor heterodimer discovered by Gomes et al. ${ }^{273}$ Its biased activity was discovered using the MOR-DOR heterodimerselective monoclonal antibody, since its activity was blocked by this antibody. Upon systemic administration, CYM51010 exerted antinociceptive effects comparable to morphine, but less antinociceptive tolerance. CYM51010 displayed a higher potency for G protein activation towards the heterodimer compared with MOR and DOR separately ( $E C_{50}$ of $54 \mathrm{nM}$ vs 210 and $300 \mathrm{nM}$ for $\mathrm{MOR}$ and DOR respectively) and a lower potency for $\beta$-arrestin recruitment ( $\mathrm{EC}_{50}$ of $8.3 \mu \mathrm{M}$ vs 1.8 and $2.7 \mu \mathrm{M}$ for MOR and DOR respectively), suggestive of biased activity towards the $\mathrm{G}$ protein pathway. ${ }^{273-274-275}$ Additionally, CYM51010 was found to remain active even in morphine-tolerant systems and is capable of reversing thermal hyperalgesia in rats, thereby acting as an inhibitor of neuropathic pain in rodents. Furthermore, CYM51010 produced significantly less internalization at MOR relative to DAMGO and at DOR relative to deltorphin I. ${ }^{275}$

2. Dmt-c[D-Lys-Phe-Asp]-NH $\mathrm{NH}_{2}$

Dmt-c[D-Lys-Phe-Asp] $-\mathrm{NH}_{2}$ (Figure 10) is a cyclic peptide, derived from the selective MOR ligand Tyr$c$ [D-Lys-Phe-Asp]- $\mathrm{NH}_{2}$ by the replacement of Tyr with 2',6'-dimethyltyrosine (Dmt). The sequence was derived from EM-2. Dmt-C[D-Lys-Phe-Asp]- $\mathrm{NH}_{2}$ displayed a high efficacy MOR/DOR agonist profile with a high affinity for both receptors. Furthermore, the ligand demonstrated improved antinociception in the hot-plate test when compared to its Tyr counterpart. In addition, it also showed a 5-fold higher antinociceptive effect in murine models than its Tyr-bearing analog. Nevertheless, Dmt-c[D-Lys-Phe-Asp]- $\mathrm{NH}_{2}$ was found to promote the $\mathrm{G}$ protein pathway at MOR similarly to EM-2, but it recruited $\beta$-arrestin in much higher extent, which resulted in in a bias factor of -1.16 relative to EM-2 (operational model; Equation 2). ${ }^{276}$

\section{DIPP- $-\mathrm{NH}_{2}[\psi]$}

TIPP- $\mathrm{NH}_{2}$ is a tetrapeptide Tyr-Tic-Phe-Phe- $\mathrm{NH}_{2}$ containing the constrained phenylalanine analog Tic and was discovered by Schiller et al. as a ligand with a higher selectivity to DOR over MOR (26fold). ${ }^{277}$ TIPP- $\mathrm{NH}_{2}$ showed a moderate degree of potency at MOR in guinea pig ileum (GPI) assays and extensive antagonism towards the DOR in mouse vas deferens (MVD) assays. This resulted in the first $\mu$-agonist/ $\delta$-antagonist bifunctional ligand with mixed MOR-agonist and DOR-antagonist properties. ${ }^{277}$ Subsequently, TIPP- $[\psi]$ was described as a highly potent and stable DOR antagonist, while showing no MOR or KOR antagonism, with high selectivity towards the DOR over the MOR, being $\mu / \delta=10500$-fold). TIPP-[ $\psi]$ is a pseudopeptide that is highly stable against enzymatic degradation. ${ }^{278}$ Through the substitution of Tyr with Dmt, Schiller was able to demonstrate enhanced potency towards DOR antagonism, but decreased DOR selectivity. ${ }^{279}$ Subsequently, the modifications going from DIPP- $\mathrm{NH}_{2}$ to DIPP- $\mathrm{NH}_{2}[\psi]$ (Figure 10) led to a better opioid profile. After i.c.v. administration, DIPP- $\mathrm{NH}_{2}[\psi]$ produced three-fold more potent analgesic effects in a rat tail flick test, though at the same time producing less acute tolerance, relative to morphine. Chronic tolerance was produced by DIPP- $\mathrm{NH}_{2}[\psi]$, but still less pronounced than morphine. Additionally, no physical dependence was observed upon administration of much higher doses needed to induce analgesic responses. ${ }^{280}$ 


\section{2S-LP2}

2S-LP2 (Figure 10) is a N-substituted 6,7-benzomorphan compound, synthesized by Pasquinucci et al. that acts as a G protein-biased agonist for both MOR and DOR using DADLE as a reference ligand. 25 LP2 displayed a high affinity for MOR and DOR ( $\mathrm{K}_{\mathrm{i}}=0.5 \mathrm{nM}$ and $2.59 \mathrm{nM}$ respectively), with a 53-fold selectivity of MOR over KOR. In comparison to the racemic LP2 compound, which is also biased for the G protein pathway, 2S-LP2 has a higher biased factor (0.82 vs 0.57 for MOR and 2.31 vs 2.03 for DOR) calculated using the operational model (Equation 2). 2S-LP2 is hence a compound with more preference to $G$ protein than its racemic mixture, and consequently it could provide a safer treatment oppurtunity. ${ }^{281}$

\section{MP102}

MP102 (Figure 10) is a fentanyl-like compound synthesized by Váradi et al. using an Ugi multicomponent reaction. It serves as a mixed MOR agonist/DOR partial agonist with respect to DAMGO and DPDPE respectively, in addition with in vivo analgesic potency upon s.c. administration. Importantly, no physical dependence or constipation was observed in mice, together with a lower production of respiratory depression compared to morphine. ${ }^{282}$ Consequently, MP102 is a G proteinbiased ligand with preference towards DOR and showed a reduced alcohol intake. ${ }^{283}$

\section{B. MOR/ NOP receptor bifunctional ligands}

1. PWT2-[Dmt $\left.{ }^{1}\right] \mathrm{N} / \mathrm{OFQ}(1-13)$

PWT2-[Dmt $\left.{ }^{1}\right]$ N/OFQ(1-13) (Figure 10) is an analog of the previously described compound PWT2N/OFQ(1-13), reported as a G protein-biased NOP receptor agonist. ${ }^{284}\left[\mathrm{Dmt}^{1}\right] \mathbf{N} / \mathrm{OFQ}(1-13)-\mathrm{NH}_{2}$ was first described in 2013 by Molinari et al. as a potent full agonist behaving as a universal agonist, since it showed high affinity towards all four opioid receptors $\left(K_{i}=10.48 n M, 9.43 n M, 9.83 n M\right.$ and 10.59 $\mathrm{nM}$ for MOR, DOR, KOR and NOP receptor respectively). Additionally, [Dmt $\left.{ }^{1}\right] \mathrm{N} / \mathrm{OFQ}(1-13)$ displayed a selectivity for NOP receptor over MOR (26-fold). ${ }^{285}$ Upon linking [Dmt $\left.{ }^{1}\right] \mathrm{N} / \mathrm{OFQ}(1-13)-\mathrm{NH}_{2}$ to PWT2, the tetrabranched molecule (vide supra), the ligand became a $\mathrm{G}$ protein-biased agonist compared to both [Dmt ${ }^{1}$ N/OFQ(1-13)-NH $\mathrm{NH}_{2}$ and N/OFQ on NOP receptor, and as compared to both [Dmt $\left.{ }^{1}\right] \mathbf{N} / \mathrm{OFQ}(1-13)-\mathrm{NH}_{2}$ and dermorphin on MOR. Yet, it was still a potent agonist with long-lasting action. ${ }^{284}$ Since PWT2-[Dmt ${ }^{1}$ N/OFQ(1-13) activated the $G$ protein pathway over the $\beta$-arrestin-2 recruitment for both NOP receptor and MOR, PWT2-[Dmt $\left.{ }^{1}\right]$ N/OFQ(1-13) can be classified as a $G$ protein-biased bifunctional ligand.

\section{BU08028}

BU08028 (Figure 10) is an orvinol compound with structural similarity to buprenorphine, discovered as the first "universal opioid ligand" with a high affinity at all four opioid receptors (MOR, KOR, DOR and NOP receptor affinities of 2.14, 5.63, 1.59 and $8.46 \mathrm{nM}$ respectively). BU08028 was shown to have long-lasting effects on tail-flick latency, but is liable to the development tolerance in thermal antinociception at a faster rate than for morphine. In addition, BU08028 was shown to have high-tomoderate activity at both MOR and NOP receptor, low activity at DOR, and no activity at KOR. Furthermore, no doses caused respiratory depression or dependence. ${ }^{35,274,286}$ Later studies by Ding et al. showed that BU08028 to be safe in primates with an improved side effect profile. Following s.c. administration, it elicited longer-lasting antinociceptive and anti-allodynic effects than buprenorphine. In addition, BU08028 lacked reinforcing effects together with no production of acute physical dependence. ${ }^{35,274,287}$ 


\section{BPR1M97}

BPR1M97 (Figure 10) is a small molecule containing a tetrahydro-isoquinoline core, discovered by Chen et al. on the basis of SAR studies. The authors showed that BPR1M97 is a potent, high affinity MOR agonist whilst also being a medium-strength KOR agonist, which can be explained by the formation of hydrogen bonds between $\mathrm{His}^{54}, \mathrm{Asp}^{147}$ and $\mathrm{Tyr}^{148}$ observed in molecular docking simulations. In tail-flick tests, BPR1M97 exhibited strong antinociceptive effects. ${ }^{288}$ More recently, BPR1M97 was shown to be a bifunctional full agonist at both MOR and NOP receptor. Its high potency and efficacy were qualified, in addition to causing less cardiovascular, respiratory and gastrointestinal dysfunction (as compared to morphine as a reference ligand). On top of this, BPR1M97 induced CAMP inhibition on NOP receptor, while not recruiting $\beta$-arrestin- 2 , making it a $G$ protein-biased NOP receptor agonist. For MOR, it behaved as a full agonist for the $G$ protein pathway and a partial agonist for $\beta$-arrestin-2 recruitment. ${ }^{289}$ As a result, BPR1M97 can be classified as a bifunctional $G$ protein-biased ligand at MOR and NOP receptor.

\section{AT-compounds}

AT-121 (Figure 10) is a sulfamide-containing derivative of the other AT-compounds previously discussed (vide supra). It was recently developed by Ding et al. in 2018 as a bifunctional NOP receptor /MOR agonist using a combination of receptor structure-guided drug design and SAR analysis. AT-121 served as a potent analgesic partial agonist, without inducing hyperalgesia or physical dependence. Additionally, it evoked 100 -fold more potent antinociceptive effects relative to morphine, together with antiallodynic activity and the lack of reinforcing effects in monkeys (as would be seen with oxycodone and cocaine), while buprenorphine produced mild reinforcing effects. ${ }^{290}$ Currently, however, only limited pharmacologic data about AT-121 is available.

AT-201 (Figure 10), previously named SR 16435, was first described by Zaveri et al. It consists of a 2indolone and piperidine moiety, ${ }^{270}$ and was one of the first non-peptidic NOP receptor /MOR bifunctional agonists to be characterized. It has a high affinity for both NOP receptor and MOR, viz. 7.49 and $2.70 \mathrm{nM}$ respectively. ${ }^{270,} 291$ In a GTPyS functional assay, AT-201 was demonstrated to be a partial agonist for both MOR $^{291}$ and NOP receptor. ${ }^{270}$ Following acute administration of AT-201, increased latency of the tail-flick in the mouse tail-flick assay was observed, resulting in an antinociceptive effect. Since naloxone was able to block this effect, it was suggested that the antinociceptive effect was mediated by the MOR. ${ }^{291}$ Additionally, a significant decrease in the onset tolerance was confirmed relative to morphine. ${ }^{71,291}$

AT-212 (Figure 10), previously named SR 16507, was also described by Zaveri et al. and is structurally very similar to AT-201. ${ }^{270}$ It has been described as a NOP receptor /MOR bifunctional agonist with a high affinity for both receptors, viz. 5.22 and $1.07 \mathrm{nM}$. Additionally, AT-212 was experimentally proven to be a potent full agonist for the NOP receptor and a very potent partial agonist for the MOR in a GTPyS functional assay. ${ }^{292}$ Even though AT-212 was able to produce modest conditioned place preference (CPP), it was able to attenuate morphine CPP. ${ }^{71,293}$

Since only limited studies on the bias of both AT-201 and AT-212 are available, their biased activity is still to be fully determined.

\section{Cebranopadol}

Cebranopadol (Figure 10) is a spiro[cyclohexane-dihydropyrano[3.4-b]indole]-amine derivative first reported by Schunk et al. in 2014. Cebranopadol acts as an effective analgesic at all four opioid 
receptors. Different functional in vitro tests are displayed in Table 4. Upon in vivo PK experiments in mice, cebranopadol displayed good oral bioavailability $(\mathrm{F}=44 \%)$, low clearance $(\mathrm{Cl}=0.96 \mathrm{~L} / \mathrm{h} \cdot \mathrm{kg})$, medium distribution volume $\left(\mathrm{V}_{\mathrm{c}}=2.96 \mathrm{~L} / \mathrm{kg}\right)$ and moderate half-life $\left(\mathrm{t}_{1 / 2}=2.57 \mathrm{~h}\right)$. Cebranopadol is equipotent to fentanyl and is highly effective in acute nociceptive animal pain models. ${ }^{294}$ In several rat models of both acute and chronic pain - including tail-flick, spinal nerve ligation, bone cancer, rheumatoid arthritis and diabetic neuropathy - cebranopadol showed highly potent, efficacious antinociceptive and antihypersensitive activity. Additionally, the duration of action was long for both i.v. and oral administration ( 7 and more than 9 hours, respectively). The first indications of bias were observed when cebranopadol was not able to disrupt respiration and motor coordination, which is the case for morphine. ${ }^{295}$ For both $\mathrm{G}$ protein and $\beta$-arrestin activity, cebranopadol remained a full agonist for the MOR in these studies, unlike NOP receptor for which cebranopadol completely lost efficacy towards $\beta$-arrestin recruitment. This makes cebranopadol a $G$ protein-biased ligand for NOP receptor, but with a 10 -fold higher potency for MOR over NOP receptor towards $\mathrm{G}$ proteinsignaling. ${ }^{296}$ Currently, cebranopadol is in phase II clinical trials, since it showed lower abuse potential than hydromorphine..$^{297-298}$

Table 4: In vitro data of cebranopadol at all four opioid receptors

\begin{tabular}{c|c|cc}
\multirow{2}{*}{ Receptor } & Radioligand binding & \multicolumn{2}{|c}{$\left[{ }^{35}\right.$ S]GTPyS binding } \\
\cline { 2 - 4 } & $\mathrm{K}_{\mathrm{i}}(\mathrm{nM})$ & $\mathrm{EC}_{50}(\mathrm{nM})$ & Relative efficacy (\%) $^{\mathrm{a} M}$ \\
\hline MOR & 0.7 & 1.2 & 103.5 \\
DOR & 18.0 & 110.0 & 105.0 \\
KOR & 2.6 & 17.0 & 67.2 \\
NOR & 0.9 & 13.0 & 88.9 \\
\hline
\end{tabular}

${ }^{a}$ The reference ligands used: DAMGO (MOR), U69,593 (DOR), SNC-80 (KOR), N/OFQ (NOR)

\section{Conclusion: Past challenges, future perspectives}

The interest in the field of biased agonism at the opioid receptors has exponentially increased over the last decade. This review shows the results of tremendous research efforts in the search for biased ligands, particularly on all four opioid receptors. They each have their own unique properties which makes them a singularly and collectively interesting basis for the development of new and improved biased agonists, preferentially towards the $\mathrm{G}$ protein pathway. The calculation of bias is already well established in vitro by the use of the equiactive or the operational model equations, whereas in vivo testing deals rather with the comparison of certain effects between ligands, making the latter more difficult to determine.

The most significant challenge faced by researchers in this field, though, is the selection, and subsequent development of the most appropriate systems in which to study the effects of functional selectivity, since the observed effects are heavily context dependent: the qualitative measurement and quantification of the biased signaling can be influenced by nuanced experimental kinetics, readout bias, variations related to the cell or tissue cultures employed in the studies, as well as by the dependency of the system on the observed pharmacological effects. ${ }^{98}$ The first goal for the development of biased ligands is the identification of agonists exerting their effects through functionally selective mechanisms, which consequently provides opportunities to understand ligand 
bias and the means for its quantification, in addition to high-throughput screening to distinguish $G$ protein and $\beta$-arrestin efficacy. Despite the range of available possibilities for identification, there is still a limited understanding between in vitro and in vivo profiles of biased ligands. Furthermore, the cost and complexity of ligand screening as a part of the ligand development process is another substantial challenge to be overcome, as is determining which measure of bias is needed to obtain a change in physiological responses. ${ }^{91}$ It is not straightforward to identify the signaling pathways responsible for therapeutic effects and the pathways responsible for the detrimental side effects, and only limited cases were confidently determined. ${ }^{44,112-113,299-300}$ On the other hand, the means to quantify and illuminate biased agonism are already elaborated to a significant extent. ${ }^{301}$ As a consequence, there appears to be a worrying lack of correlation between different studies of calculated bias factors (vide supra): the bias of a given agonist has been shown to depend upon the signaling output used for the calculation. ${ }^{81}$ This lack of consistency can perhaps be ascribed to insufficiently rigorous data collection or the fact that current methods are not always able to distinguish between system and ligand bias. ${ }^{302}$ Caution should be therefore exerted in any transposition from in vitro efficacy to in vivo biological responses. ${ }^{91,303}$

Earlier this year, Machelska and Chelik described five potential strategies that are being actively utilized in the design and development of new opioid analgesics. ${ }^{304}$ These include the biased activation of opioid receptors, the $\mathrm{pH}$-dependent activation of receptors in peripheral tissue and the targeting of opioid heterodimers. The multifunctional (biased) ligands remain the subject of considerable scientific attention, especially if we consider that a number of studies have shown that DOR is able to heterodimerize with both MOR and KOR. The resulting MOR/DOR and DOR/KOR heterodimers represent novel pharmacological targets with distinct receptor-binding properties. ${ }^{305-}$ ${ }^{307}$ Although the (patho)physiological function of these heterodimeric opioid receptors remains to be fully elucidated, initial studies indicate that targeting the MOR/DOR heterodimer specifically may lead to improved analgesics with reduced side effects. ${ }^{308} \mathrm{~A}$ critical goal of research in this area, therefore, is to fully understand these complex, higher-order receptor interactions, particularly in terms of biased agonism, and to harness this knowledge towards the development of novel opioid analgesics devoid of side-effects.

Numerous GPCR crystal structures have been resolved over the past decade in a variety of active conformations and now serve as the most common source of data for structure-based drug design. ${ }^{309}$ Some groups have already been able to demonstrate the utility of the approach. On the basis of the crystal structure of MOR, Manglik and coworkers were able to generate a potent small molecule $G_{i}$ activator by screening more than three million lead-like compounds in the ZINC database. ${ }^{109}$ The authors' optimization work yielded the first-in-class molecule PZM21 (vide supra) that, thanks to its MOR selectivity and significant bias, showed long-lasting analgesia devoid of both respiratory depression and morphine-like reinforcing activity. The authors also note that their general approach is able to find scaffolds that stabilize as yet unprobed receptor conformations. Others have also enjoyed success with structure-based design approaches (including ${ }^{64,} 310$ and featuring in ${ }^{311}$ ), and it is expected that more will follow in the future. As our structural understanding of biased signaling and its manipulation improves - for example following the first active crystal structure of the $\delta$ opioid receptor by Claff and coworkers in $2019^{312}$ - there will be increased opportunities available for structure-based design approaches including (virtual) fragment screening and NMR-based methods. ${ }^{313}$ Furthermore, Che and coworkers state molecular insights on mechanistic properties of biased signaling at the $\mathrm{k}$ opioid receptor by using the active-state structure 
of the receptor stabilized with nanobodies. ${ }^{314}$ When considering multi-functional selectivity towards the opioid receptors, structure-guided approaches can also be used. Very recently, Uprety et al. demonstrated this for MOR and KOR, but further investigation in this field is needed. ${ }^{315}$

Finally, the issues faced before the approval of oliceridine (TRV-130, OLINVYK ${ }^{\mathrm{TM}}$ ) suggests that a better understanding of the signaling pathways, as well as a more rigorous analysis of the signaling data, may prevent potentially costly drug attrition rates in the future. The approval of OLINVYK ${ }^{\mathrm{TM}}$, the first functionally selective opioid analgesic, has opened up new avenues for future molecules in the development towards better, superior analgesics. Since TRV-130 has only limited applications, there is an extensive window for potential improvement, especially in terms of its administration. This provides ample opportunity to develop orally bioavailable molecules, as well as new medicines that can overcome the commonly experienced side effects seen with TRV-130: nausea, vomiting, dizziness, headache, constipation, pruritus, and hypoxia. ${ }^{316}$ TRV-130 is now heralded as a paragon that has shown the possibilities of biased GPCR agonism. Even with the FDA approval, however, the purported clinical benefits of these agents remain to be demonstrated. ${ }^{317}$ That being said, TRV-130 can, in any case, serve as a means of comparison for the next generation of biased ligands at MOR and even the other opioid receptors, and shows the development potential that can be reached within this area of research, especially when one considers how much remains undiscovered within the field.

In this review, many biased ligands were described both in vitro and in vivo, but only a few have been or are ready to be tested in clinical trials, e.g. TRV734, CYT-1010, PN6047, ADL5747, ADL5859, TRV250, SCH 486757, and cebranopadol. There is still a big need for $\mathrm{G}$ protein-biased agonists on the opioid receptors to be tested on humans and a better understanding on how the bias exactly works on the signaling pathways, as evidenced by the extent of efforts undertaken to bring TRV130 to the market. It is important to mention that even though many biased ligands have been described in this review, none of them represent a profound bias. To fully address the term 'biased ligand', extremely biased ligands, e.g. an infinite bias factor (in vitro bias) or zero side effects (in vivo bias) will ultimately be needed.

Further down the line, of course, this leads, in turn, to the ongoing need for better and safer analgesics, since the major opioid still used in clinical use is morphine, which even today is associated with a number of severe and dangerous side effects. To overcome this problem, and after discovering the role of the signaling pathways of the opioid receptors, the discovery of $G$ proteinbiased ligands will have great impact on both drug design and medicine. This will have long lasting effects on the way new therapeutics are designed, the way they work and the way they are prescribed.

\section{Acknowledgements}

This work was financially supported by the Research Foundation Flanders (FWO), the Research Council of VUB for support through the Strategic Research Program SRP50 and the Flemish Government's Industrial Research Fund (IOF). 


\section{References}

1. Hauser, A. S.; Attwood, M. M.; Rask-Andersen, M.; Schiöth, H. B.; Gloriam, D. E., Trends in GPCR drug discovery: new agents, targets and indications. Nature Reviews Drug Discovery 2017, 16, 829.

2. Rosenbaum, D. M.; Rasmussen, S. G. F.; Kobilka, B. K., The structure and function of Gprotein-coupled receptors. Nature 2009, 459, 356.

3. Waldhoer, M.; Bartlett, S. E.; Whistler, J. L., Opioid receptors. Annual review of biochemistry 2004, 73 (1), 953-990.

4. $\quad$ Brownstein, M. J., A brief history of opiates, opioid peptides, and opioid receptors. Proceedings of the National Academy of Sciences of the United States of America 1993, 90 (12), 5391.

5. Janecka, A.; Fichna, J.; Janecki, T., Opioid receptors and their ligands. Current topics in medicinal chemistry 2004, 4 (1), 1-17.

6. Buenaventura, R.; Adlaka, R.; Sehgal, N., Opioid complications and side effects. Pain physician 2008, 11, S105-S120.

7. Guillemyn, K.; Kleczkowska, P.; Novoa, A.; Vandormael, B.; Van den Eynde, I.; Kosson, P.; Asim, M. F.; Schiller, P. W.; Spetea, M.; Lipkowski, A. W., In vivo antinociception of potent mu opioid agonist tetrapeptide analogues and comparison with a compact opioid agonist-neurokinin 1 receptor antagonist chimera. Molecular brain 2012, 5 (1), 4.

8. Matthes, H. W. D.; Maldonado, R.; Simonin, F.; Valverde, O.; Slowe, S.; Kitchen, I.; Befort, K.; Dierich, A.; Le Meur, M.; Dollé, P.; Tzavara, E.; Hanoune, J.; Roques, B. P.; Kieffer, B. L., Loss of morphine-induced analgesia, reward effect and withdrawal symptoms in mice lacking the $\mu$-opioidreceptor gene. Nature 1996, 383 (6603), 819-823.

9. Stevens, C.; Aravind, S.; Das, S.; Davis, R., Pharmacological characterization of LPS and opioid interactions at the toll-like receptor 4. British Journal of Pharmacology 2013, 168 (6), 1421-1429.

10. Zhang, J.; Ferguson, S. S. G.; Barak, L. S.; Bodduluri, S. R.; Laporte, S. A.; Law, P.-Y.; Caron, M. G., Role for $\mathrm{G}$ protein-coupled receptor kinase in agonist-specific regulation of $\mu$-opioid receptor responsiveness. Proceedings of the National Academy of Sciences 1998, 95 (12), 7157-7162.

11. Feng, Y.; He, X.; Yang, Y.; Chao, D.; H Lazarus, L.; Xia, Y., Current research on opioid receptor function. Current drug targets 2012, 13 (2), 230-246.

12. Corbett, A. D.; Henderson, G.; McKnight, A. T.; Paterson, S. J., 75 years of opioid research: the exciting but vain quest for the Holy Grail. British journal of pharmacology 2006, 147 (S1), S153S162.

13. Patrick, G. L., The opioid analgesics. In An introduction to medicinal chemistry, Sixth ed.; Oxford University Press: Oxford, 2017; pp 678-704.

14. Koneru, A.; Satyanarayana, S.; Rizwan, S., Endogenous opioids: their physiological role and receptors. Global J Pharmacol 2009, 3 (3), 149-153.

15. Stein, C., New concepts in opioid analgesia. Expert opinion on investigational drugs 2018, 27 (10), 765-775.

16. Sobczak, M.; Sałaga, M.; Storr, M. A.; Fichna, J., Physiology, signaling, and pharmacology of opioid receptors and their ligands in the gastrointestinal tract: current concepts and future perspectives. Journal of gastroenterology 2014, 49 (1), 24-45.

17. Al-Hasani, R.; Bruchas, M. R., Molecular mechanisms of opioid receptor-dependent signaling and behavior. Anesthesiology: The Journal of the American Society of Anesthesiologists 2011, 115 (6), 1363-1381.

18. Stein, C.; Lang, L. J., Peripheral mechanisms of opioid analgesia. Current opinion in pharmacology 2009, 9 (1), 3-8.

19. Martínez, V.; Abalo, R., Peripherally acting opioid analgesics and peripherally-induced analgesia. Behavioural Pharmacology 2020, 31 (2\&3), 136-158.

20. Iwaszkiewicz, K.; Schneider, J.; Hua, S., Targeting peripheral opioid receptors to promote analgesic and anti-inflammatory actions. Frontiers in pharmacology 2013, 4, 132. 
21. Smith, J. S.; Lefkowitz, R. J.; Rajagopal, S., Biased signalling: from simple switches to allosteric microprocessors. Nature Reviews Drug Discovery 2018, 17, 243.

22. Hilger, D.; Masureel, M.; Kobilka, B. K., Structure and dynamics of GPCR signaling complexes. Nature Structural \& Molecular Biology 2018, 25 (1), 4-12.

23. Zhang, R.; Xie, X., Tools for GPCR drug discovery. Acta Pharmacologica Sinica 2012, 33, 372.

24. Rankovic, Z.; Brust, T. F.; Bohn, L. M., Biased agonism: An emerging paradigm in GPCR drug discovery. Bioorganic \& Medicinal Chemistry Letters 2016, 26 (2), 241-250.

25. Reiter, E.; Lefkowitz, R. J., GRKs and $\beta$-arrestins: roles in receptor silencing, trafficking and signaling. Trends in endocrinology \& metabolism 2006, 17 (4), 159-165.

26. Rajagopal, S.; Shenoy, S. K., GPCR desensitization: Acute and prolonged phases. Cellular Signalling 2018, 41, 9-16.

27. Violin, J. D.; Crombie, A. L.; Soergel, D. G.; Lark, M. W., Biased ligands at G-protein-coupled receptors: promise and progress. Trends in Pharmacological Sciences 2014, 35 (7), 308-316.

28. Clapp III, J. F.; Kett, A.; Olariu, N.; Omoniyi, A. T.; Wu, D.; Kim, H.; Szeto, H. H., Cardiovascular and metabolic responses to two receptor-selective opioid agonists in pregnant sheep. American journal of obstetrics and gynecology 1998, 178 (2), 397-401.

29. Perrine, S. A.; Hoshaw, B. A.; Unterwald, E. M., Delta opioid receptor ligands modulate anxiety-like behaviors in the rat. British journal of pharmacology 2006, 147 (8), 864-872.

30. Jutkiewicz, E. M.; Rice, K. C.; Traynor, J. R.; Woods, J. H., Separation of the convulsions and antidepressant-like effects produced by the delta-opioid agonist SNC80 in rats. Psychopharmacology 2005, 182 (4), 588-596.

31. Pradhan, A. A.; Smith, M. L.; Kieffer, B. L.; Evans, C. J., Ligand-directed signalling within the opioid receptor family. British journal of pharmacology 2012, 167 (5), 960-969.

32. Land, B. B.; Bruchas, M. R.; Lemos, J. C.; Xu, M.; Melief, E. J.; Chavkin, C., The dysphoric component of stress is encoded by activation of the dynorphin kappa-opioid system. $J$ Neurosci 2008, 28 (2), 407-14.

33. Mores, K. L.; Cummins, B. R.; Cassell, R. J.; Van Rijn, R. M., A Review of the Therapeutic Potential of Recently Developed G Protein-Biased Kappa Agonists. Frontiers in pharmacology 2019, $10,407$.

34. Dogra, S.; Yadav, P. N., Biased agonism at kappa opioid receptors: Implication in pain and mood disorders. European journal of pharmacology 2015, 763, 184-190.

35. Günther, T.; Dasgupta, P.; Mann, A.; Miess, E.; Kliewer, A.; Fritzwanker, S.; Steinborn, R.; Schulz, S., Targeting multiple opioid receptors-Improved analgesics with reduced side effects? British journal of pharmacology 2018, 175 (14), 2857-2868.

36. Redrobe, J. P.; Regoli, D.; Quirion, R., Nociceptin receptor antagonists display antidepressant-like properties in the mouse forced swimming test. Naunyn-Schmiedeberg's archives of pharmacology 2002, 365 (2), 164-167.

37. Chen, Y.; Mestek, A.; Liu, J.; Hurley, J. A.; Yu, L., Molecular cloning and functional expression of a mu-opioid receptor from rat brain. Molecular pharmacology 1993, 44 (1), 8-12.

38. Reisine, T.; Bell, G. I., Molecular biology of opioid receptors. Trends in neurosciences 1993, 16 (12), 506-510.

39. Snyder, S. H.; Pasternak, G. W., Historical review: opioid receptors. Trends in pharmacological sciences 2003, 24 (4), 198-205.

40. Pasternak, G. W.; Pan, Y.-X., Mu opioids and their receptors: evolution of a concept. Pharmacological reviews 2013, 65 (4), 1257-1317.

41. Stefano, G. B.; Hartman, A.; Bilfinger, T. V.; Magazine, H. I.; Liu, Y.; Casares, F.; Goligorsky, M. S., Presence of the $\mu 3$ opiate receptor in endothelial cells coupling to nitric oxide production and vasodilation. Journal of Biological Chemistry 1995, 270 (51), 30290-30293.

42. Satoh, M.; Minami, M., Molecular pharmacology of the opioid receptors. Pharmacology \& therapeutics 1995, 68 (3), 343-364. 
43. Dietis, N.; Rowbotham, D.; Lambert, D., Opioid receptor subtypes: fact or artifact? British journal of anaesthesia 2011, 107 (1), 8-18.

44. Raehal, K. M.; Walker, J. K.; Bohn, L. M., Morphine side effects in $\beta$-arrestin 2 knockout mice. Journal of Pharmacology and Experimental Therapeutics 2005, 314 (3), 1195-1201.

45. DeWire, S. M.; Yamashita, D. S.; Rominger, D. H.; Liu, G.; Cowan, C. L.; Graczyk, T. M.; Chen, X.-T.; Pitis, P. M.; Gotchev, D.; Yuan, C.; Koblish, M.; Lark, M. W.; Violin, J., A G protein-biased ligand at the $\mu$-opioid receptor is potently analgesic with reduced gastrointestinal and respiratory dysfunction compared with morphine. Journal of Pharmacology and Experimental Therapeutics 2013, 344 (3), 708-717.

46. Altarifi, A. A.; David, B.; Muchhala, K. H.; Blough, B. E.; Akbarali, H.; Negus, S. S., Effects of acute and repeated treatment with the biased mu opioid receptor agonist TRV130 (oliceridine) on measures of antinociception, gastrointestinal function, and abuse liability in rodents. Journal of Psychopharmacology 2017, 31 (6), 730-739.

47. Viscusi, E. R.; Skobieranda, F.; Soergel, D. G.; Cook, E.; Burt, D. A.; Singla, N., APOLLO-1: A randomized placebo and active-controlled phase III study investigating oliceridine (TRV130), a G protein-biased ligand at the $\mu$-opioid receptor, for management of moderate-to-severe acute pain following bunionectomy. Journal of pain research 2019, 12, 927.

48. FDA Briefing Document. Oct. $11^{\text {th }}, 2018$.

49. Evans, C. J.; Keith, D. E.; Morrison, H.; Magendzo, K.; Edwards, R. H., Cloning of a delta opioid receptor by functional expression. Science 1992, 258 (5090), 1952-1955.

50. Kieffer, B. L.; Befort, K.; Gaveriaux-Ruff, C.; Hirth, C. G., The delta-opioid receptor: isolation of a cDNA by expression cloning and pharmacological characterization. Proceedings of the National Academy of Sciences 1992, 89 (24), 12048-12052.

51. Gendron, L.; Cahill, C. M.; von Zastrow, M.; Schiller, P. W.; Pineyro, G., Molecular pharmacology of $\delta$-opioid receptors. Pharmacological reviews 2016, 68 (3), 631-700.

52. Commons, K. G., Translocation of presynaptic delta opioid receptors in the ventrolateral periaqueductal gray after swim stress. Journal of Comparative Neurology 2003, 464 (2), 197-207. 53. Pellissier, L.; Pujol, C.; Becker, J.; Le Merrer, J., Delta opioid receptors: learning and motivation. Delta Opioid Receptor Pharmacology and Therapeutic Applications 2016, 227-260.

54. Spahn, V.; Stein, C., Targeting delta opioid receptors for pain treatment: drugs in phase I and II clinical development. Expert Opin Investig Drugs 2017, 26 (2), 155-160.

55. Yasuda, K.; Raynor, K.; Kong, H.; Breder, C. D.; Takeda, J.; Reisine, T.; Bell, G. I., Cloning and functional comparison of kappa and delta opioid receptors from mouse brain. Proceedings of the National Academy of Sciences 1993, 90 (14), 6736-6740.

56. Zukin, R. S.; Eghbali, M.; Olive, D.; Unterwald, E. M.; Tempel, A., Characterization and visualization of rat and guinea pig brain kappa opioid receptors: evidence for kappa 1 and kappa 2 opioid receptors. Proceedings of the National Academy of Sciences 1988, 85 (11), 4061-4065. 57. Rothman, R. B.; Bykov, V.; Xue, B.; Xu, H.; De Costa, B. R.; Jacobson, A. E.; Rice, K. C.; Kleinman, J. E.; Brady, L. S., Interaction of opioid peptides and other drugs with multiple kappa receptors in rat and human brain. Evidence for species differences. Peptides 1992, 13 (5), 977-987. 58. Clark, J. A.; Liu, L.; Price, M.; Hersh, B.; Edelson, M.; Pasternak, G. W., Kappa opiate receptor multiplicity: evidence for two U50, 488-sensitive kappa 1 subtypes and a novel kappa 3 subtype. Journal of Pharmacology and Experimental Therapeutics 1989, 251 (2), 461-468.

59. Mansour, A.; Burke, S.; Pavlic, R.; Akil, H.; Watson, S., Immunohistochemical localization of the cloned k1 receptor in the rat CNS and pituitary. Neuroscience 1996, 71 (3), 671-690.

60. Mansour, A.; Khachaturian, H.; Lewis, M.; Akil, H.; Watson, S., Autoradiographic differentiation of $\mathrm{mu}$, delta, and kappa opioid receptors in the rat forebrain and midbrain. Journal of Neuroscience 1987, 7 (8), 2445-2464.

61. Britt, J. P.; McGehee, D. S., Presynaptic opioid and nicotinic receptor modulation of dopamine overflow in the nucleus accumbens. Journal of Neuroscience 2008, 28 (7), 1672-1681. 
62. Bruijnzeel, A. W., kappa-Opioid receptor signaling and brain reward function. Brain research reviews 2009, 62 (1), 127-146.

63. Phan, N. Q.; Lotts, T.; Antal, A.; Bernhard, J. D.; Ständer, S., Systemic kappa opioid receptor agonists in the treatment of chronic pruritus: a literature review. Acta dermato-venereologica 2012, $92(5), 555-560$.

64. Zheng, Z.; Huang, X.-P.; Mangano, T. J.; Zou, R.; Chen, X.; Zaidi, S. A.; Roth, B. L.; Stevens, R. C.; Katritch, V., Structure-Based Discovery of New Antagonist and Biased Agonist Chemotypes for the Kappa Opioid Receptor. Journal of Medicinal Chemistry 2017, 60 (7), 3070-3081.

65. Dykstra, L. A.; Gmerek, D. E.; Winger, G.; Woods, J. H., Kappa opioids in rhesus monkeys. I. Diuresis, sedation, analgesia and discriminative stimulus effects. Journal of Pharmacology and Experimental Therapeutics 1987, 242 (2), 413-420.

66. Knoll, A. T.; Carlezon Jr, W. A., Dynorphin, stress, and depression. Brain research 2010, 1314, 56-73.

67. Chavkin, C.; Sud, S.; Jin, W.; Stewart, J.; Zjawiony, J. K.; Siebert, D. J.; Toth, B. A.; Hufeisen, S. J.; Roth, B. L., Salvinorin A, an active component of the hallucinogenic sage Salvia divinorum is a highly efficacious k-opioid receptor agonist: structural and functional considerations. Journal of Pharmacology and Experimental Therapeutics 2004, 308 (3), 1197-1203.

68. Galeotti, N.; Mannelli, L. D. C.; Mazzanti, G.; Bartolini, A.; Ghelardini, C., Menthol: a natural analgesic compound. Neuroscience letters 2002, 322 (3), 145-148.

69. Mollereau, C.; Parmentier, M.; Mailleux, P.; Butour, J.-L.; Moisand, C.; Chalon, P.; Caput, D.; Vassart, G.; Meunier, J.-C., ORL1, a novel member of the opioid receptor family: cloning, functional expression and localization. FEBS letters 1994, 341 (1), 33-38.

70. Mogil, J. S.; Pasternak, G. W., The molecular and behavioral pharmacology of the orphanin FQ/nociceptin peptide and receptor family. Pharmacological reviews 2001, 53 (3), 381-415.

71. Toll, L.; Bruchas, M. R.; Cox, B. M.; Zaveri, N. T., Nociceptin/orphanin FQ receptor structure, signaling, ligands, functions, and interactions with opioid systems. Pharmacological reviews 2016, 68 (2), 419-457.

72. Pan, Z. Z.; Hirakawa, N.; Fields, H. L., A cellular mechanism for the bidirectional painmodulating actions of orphanin $\mathrm{FQ} /$ nociceptin. Neuron 2000, 26 (2), 515-522.

73. Marti, M.; Sarubbo, S.; Latini, F.; Cavallo, M.; Eleopra, R.; Biguzzi, S.; Lettieri, C.; Conti, C.; Simonato, M.; Zucchini, S.; Quatrale, R.; Sensi, M.; Candeletti, S.; Romualdi, P.; Morari, M., Brain interstitial nociceptin/orphanin FQ levels are elevated in Parkinson's disease. Movement Disorders 2010, 25 (11), 1723-1732.

74. Zaveri, N. T., Nociceptin Opioid Receptor (NOP) as a Therapeutic Target: Progress in Translation from Preclinical Research to Clinical Utility: Miniperspective. Journal of medicinal chemistry 2016, 59 (15), 7011-7028.

75. Khroyan, T. V.; Polgar, W. E.; Orduna, J.; Montenegro, J.; Jiang, F.; Zaveri, N. T.; Toll, L., Differential effects of nociceptin/orphanin FQ (NOP) receptor agonists in acute versus chronic pain: studies with bifunctional NOP/ $\mu$ receptor agonists in the sciatic nerve ligation chronic pain model in mice. Journal of Pharmacology and Experimental Therapeutics 2011, 339 (2), 687-693.

76. Thompson, G. L.; Lane, J. R.; Coudrat, T.; Sexton, P. M.; Christopoulos, A.; Canals, M., Biased Agonism of Endogenous Opioid Peptides at the $<$ em $>\mu</ e m>-O p i o i d$ Receptor. Molecular Pharmacology 2015, 88 (2), 335-346.

77. Winpenny, D.; Clark, M.; Cawkill, D., Biased ligand quantification in drug discovery: from theory to high throughput screening to identify new biased $\mu$ opioid receptor agonists. British Journal of Pharmacology 2016, 173 (8), 1393-1403.

78. Wisler, J. W.; Xiao, K.; Thomsen, A. R. B.; Lefkowitz, R. J., Recent developments in biased agonism. Current Opinion in Cell Biology 2014, 27, 18-24.

79. van der Westhuizen, E. T.; Breton, B.; Christopoulos, A.; Bouvier, M., Quantification of ligand bias for clinically relevant $\beta 2$-adrenergic receptor ligands: implications for drug taxonomy. Molecular pharmacology 2014, 85 (3), 492-509. 
80. Kenakin, T., Biased receptor signaling in drug discovery. Pharmacological reviews 2019, 71 (2), 267-315.

81. Conibear, A. E.; Kelly, E., A biased view of $\mu$-opioid receptors? Molecular pharmacology 2019, 96 (5), 542-549.

82. Allen, J. A.; Yost, J. M.; Setola, V.; Chen, X.; Sassano, M. F.; Chen, M.; Peterson, S.; Yadav, P. N.; Huang, X.-p.; Feng, B.; Jensen, N. H.; Che, X.; Bai, X.; Frye, S. V.; Wetsel, W. C.; Caron, M. G.; Javitch, J. A.; Roth, B. L.; Jin, J., Discovery of $\beta$-arrestin-biased dopamine D2 ligands for probing signal transduction pathways essential for antipsychotic efficacy. Proceedings of the National Academy of Sciences 2011, 108 (45), 18488-18493.

83. Luttrell, L. M., Minireview: More than just a hammer: ligand "bias" and pharmaceutical discovery. Mol Endocrinol 2014, 28 (3), 281-94.

84. Wisler, J. W.; DeWire, S. M.; Whalen, E. J.; Violin, J. D.; Drake, M. T.; Ahn, S.; Shenoy, S. K.; Lefkowitz, R. J., A unique mechanism of $\beta$-blocker action: carvedilol stimulates $\beta$-arrestin signaling. Proceedings of the National Academy of Sciences 2007, 104 (42), 16657-16662.

85. Whalen, E. J.; Rajagopal, S.; Lefkowitz, R. J., Therapeutic potential of $\beta$-arrestin-and G protein-biased agonists. Trends in molecular medicine 2011, 17 (3), 126-139.

86. Gillis, A.; Gondin, A. B.; Kliewer, A.; Sanchez, J.; Lim, H. D.; Alamein, C.; Manandhar, P.; Santiago, M.; Fritzwanker, S.; Schmiedel, F.; Katte, T. A.; Reekie, T.; Grimsey, N. L.; Kassiou, M.; Kellam, B.; Krasel, C.; Halls, M. L.; Connor, M.; Lane, J. R.; Schulz, S.; Christie, M. J.; Canals, M., Low intrinsic efficacy for $\mathrm{G}$ protein activation can explain the improved side effect profiles of new opioid agonists. Science Signaling 2020, 13 (625), eaaz3140.

87. Gillis, A.; Kliewer, A.; Kelly, E.; Henderson, G.; Christie, M. J.; Schulz, S.; Canals, M., Critical Assessment of $\mathrm{G}$ Protein-Biased Agonism at the $\mu$-Opioid Receptor. Trends in Pharmacological Sciences 2020.

88. Gillis, A.; Sreenivasan, V.; Christie, M. J., Intrinsic Efficacy of Opioid Ligands and Its Importance for Apparent Bias, Operational Analysis, and Therapeutic Window. Molecular Pharmacology 2020, 98 (4), 410-424.

89. Kliewer, A.; Gillis, A.; Hill, R.; Schmiedel, F.; Bailey, C.; Kelly, E.; Henderson, G.; Christie, M. J.; Schulz, S., Morphine-induced respiratory depression is independent of $\beta$-arrestin2 signalling. British Journal of Pharmacology 2020, 177 (13), 2923-2931.

90. Kliewer, A.; Schmiedel, F.; Sianati, S.; Bailey, A.; Bateman, J. T.; Levitt, E. S.; Williams, J. T.; Christie, M. J.; Schulz, S., Phosphorylation-deficient G-protein-biased $\mu$-opioid receptors improve analgesia and diminish tolerance but worsen opioid side effects. Nature Communications 2019, 10 (1), 367.

91. Luttrell, L. M.; Maudsley, S.; Bohn, L. M., Fulfilling the Promise of "Biased" G ProteinCoupled Receptor Agonism. Molecular Pharmacology 2015, 88 (3), 579-588.

92. Tso, P. H.; Wong, Y. H., Gz can mediate the acute actions of $\mu$-and $\mathrm{k}$-opioids but is not involved in opioid-induced adenylyl cyclase supersensitization. Journal of Pharmacology and Experimental Therapeutics 2000, 295 (1), 168-176.

93. Grundmann, M.; Kostenis, E., Temporal Bias: Time-Encoded Dynamic GPCR Signaling. Trends in Pharmacological Sciences 2017, 38 (12), 1110-1124.

94. Kenakin, T.; Christopoulos, A., Signalling bias in new drug discovery: detection, quantification and therapeutic impact. Nature reviews Drug discovery 2013, 12 (3), 205-216.

95. Furchgott, R., The use of $\beta$-haloalkylamines in the differentiation of receptors and in the determination of dissociation constants of receptor-agonist complexes. Adv. Drug Res. 1966, 3, 2155.

96. Rajagopal, S.; Ahn, S.; Rominger, D. H.; Gowen-MacDonald, W.; Lam, C. M.; DeWire, S. M.; Violin, J. D.; Lefkowitz, R. J., Quantifying ligand bias at seven-transmembrane receptors. Molecular pharmacology 2011, 80 (3), 367-377.

97. Black, J. W.; Leff, P., Operational models of pharmacological agonism. Proceedings of the Royal society of London. Series B. Biological sciences 1983, 220 (1219), 141-162. 
98. Kenakin, T.; Watson, C.; Muniz-Medina, V.; Christopoulos, A.; Novick, S., A simple method for quantifying functional selectivity and agonist bias. ACS chemical neuroscience 2012, 3 (3), 193-203.

99. Schmid, C. L.; Kennedy, N. M.; Ross, N. C.; Lovell, K. M.; Yue, Z.; Morgenweck, J.; Cameron, M. D.; Bannister, T. D.; Bohn, L. M., Bias factor and therapeutic window correlate to predict safer opioid analgesics. Cell 2017, 171 (5), 1165-1175. e13.

100. Chen, X.-T.; Pitis, P.; Liu, G.; Yuan, C.; Gotchev, D.; Cowan, C. L.; Rominger, D. H.; Koblish, M.; DeWire, S. M.; Crombie, A. L.; Violin, J. D.; Yamashita, D. S., Structure-Activity Relationships and Discovery of a $G$ Protein Biased $\mu$ Opioid Receptor Ligand,[(3-Methoxythiophen-2-yl) methyl](\{2-[(9 R)-9-(pyridin-2-yl)-6-oxaspiro-[4.5] decan-9-yl] ethyl\}) amine (TRV130), for the Treatment of Acute Severe Pain. Journal of medicinal chemistry 2013, 56 (20), 8019-8031.

101. Pedersen, M. F.; Wróbel, T. M.; Märcher-Rørsted, E.; Pedersen, D. S.; Møller, T. C.; Gabriele, F.; Pedersen, H.; Matosiuk, D.; Foster, S. R.; Bouvier, M.; Bräuner-Osborne, H., Biased agonism of clinically approved $\mu$-opioid receptor agonists and TRV130 is not controlled by binding and signaling kinetics. Neuropharmacology 2020, 166, 107718.

102. Burgueño, J.; Pujol, M.; Monroy, X.; Roche, D.; Varela, M. J.; Merlos, M.; Giraldo, J., A complementary scale of biased agonism for agonists with differing maximal responses. Scientific reports 2017, 7 (1), 1-11.

103. Soergel, D. G.; Ann Subach, R.; Sadler, B.; Connell, J.; Marion, A. S.; Cowan, C. L.; Violin, J. D.; Lark, M. W., First Clinical Experience With TRV130: Pharmacokinetics and Pharmacodynamics in Healthy Volunteers. The Journal of Clinical Pharmacology 2014, 54 (3), 351-357.

104. Soergel, D. G.; Subach, R. A.; Burnham, N.; Lark, M. W.; James, I. E.; Sadler, B. M.; Skobieranda, F.; Violin, J. D.; Webster, L. R., Biased agonism of the $\mu$-opioid receptor by TRV130 increases analgesia and reduces on-target adverse effects versus morphine: a randomized, doubleblind, placebo-controlled, crossover study in healthy volunteers. $P A I N^{\circledR}$ 2014, 155 (9), 1829-1835.

105. Singla, N.; Minkowitz, H. S.; Soergel, D. G.; Burt, D. A.; Subach, R. A.; Salamea, M. Y.; Fossler, M. J.; Skobieranda, F., A randomized, Phase Ilb study investigating oliceridine (TRV130), a novel $\mu$ receptor G-protein pathway selective ( $\mu$-GPS) modulator, for the management of moderate to severe acute pain following abdominoplasty. Journal of pain research 2017, 10, 2413-2424.

106. Viscusi, E. R.; Webster, L.; Kuss, M.; Daniels, S.; Bolognese, J. A.; Zuckerman, S.; Soergel, D. G.; Subach, R. A.; Cook, E.; Skobieranda, F., A randomized, phase 2 study investigating TRV130, a biased ligand of the $\mu$-opioid receptor, for the intravenous treatment of acute pain. PAIN 2016, 157 (1), 264-272.

107. Singla, N. K.; Skobieranda, F.; Soergel, D. G.; Salamea, M.; Burt, D. A.; Demitrack, M. A.; Viscusi, E. R., APOLLO-2: A Randomized, Placebo and Active-Controlled Phase III Study Investigating Oliceridine (TRV 130), a G Protein-Biased Ligand at the $\mu$-Opioid Receptor, for Management of Moderate to Severe Acute Pain Following Abdominoplasty. Pain Practice 2019, 19 (7), 715-731. 108. James, I. E.; Skobieranda, F.; Soergel, D. G.; Ramos, K. A.; Ruff, D.; Fossler, M. J., A First-inHuman Clinical Study With TRV734, an Orally Bioavailable G-Protein-Biased Ligand at the $\mu$-Opioid Receptor. Clinical pharmacology in drug development 2020, 9 (2), 256-266.

109. Manglik, A.; Lin, H.; Aryal, D. K.; McCorvy, J. D.; Dengler, D.; Corder, G.; Levit, A.; Kling, R. C.; Bernat, V.; Hubner, H.; Huang, X. P.; Sassano, M. F.; Giguere, P. M.; Lober, S.; Da, D.; Scherrer, G.; Kobilka, B. K.; Gmeiner, P.; Roth, B. L.; Shoichet, B. K., Structure-based discovery of opioid analgesics with reduced side effects. Nature 2016, 537 (7619), 185-190.

110. Irwin, J. J.; Sterling, T.; Mysinger, M. M.; Bolstad, E. S.; Coleman, R. G., ZINC: A Free Tool to Discover Chemistry for Biology. Journal of Chemical Information and Modeling 2012, 52 (7), 17571768.

111. Hill, R.; Disney, A.; Conibear, A.; Sutcliffe, K.; Dewey, W.; Husbands, S.; Bailey, C.; Kelly, E.; Henderson, $G$., The novel $\mu$-opioid receptor agonist PZM21 depresses respiration and induces tolerance to antinociception. British journal of pharmacology 2018, 175 (13), 2653-2661. 
112. Bohn, L. M.; Gainetdinov, R. R.; Lin, F.-T.; Lefkowitz, R. J.; Caron, M. G., $\mu$-Opioid receptor desensitization by $\beta$-arrestin- 2 determines morphine tolerance but not dependence. Nature 2000, 408 (6813), 720-723.

113. Bohn, L. M.; Lefkowitz, R. J.; Gainetdinov, R. R.; Peppel, K.; Caron, M. G.; Lin, F.-T., Enhanced morphine analgesia in mice lacking $\beta$-arrestin 2. Science 1999, 286 (5449), 2495-2498.

114. Siuda, E. R.; Carr III, R.; Rominger, D. H.; Violin, J. D., Biased mu-opioid receptor ligands: a promising new generation of pain therapeutics. Current opinion in pharmacology 2017, 32, 77-84.

115. Azzam, A. A.; McDonald, J.; Lambert, D. G., Hot topics in opioid pharmacology: mixed and biased opioids. British journal of anaesthesia 2019.

116. Lewis, J., Buprenorphine. Drug and alcohol dependence 1985, 14 (3-4), 363-372.

117. Elkader, A.; Sproule, B., Buprenorphine. Clinical pharmacokinetics 2005, 44 (7), 661-680.

118. Mustazza, C.; Bastanzio, G., Development of nociceptin receptor (NOP) agonists and antagonists. Medicinal research reviews 2011, 31 (4), 605-648.

119. Prommer, E., Levorphanol: the forgotten opioid. Supportive care in cancer 2007, 15 (3), 259-

264.

120. Atkinson, T. J.; Fudin, J.; Pandula, A.; Mirza, M., Medication pain management in the elderly: unique and underutilized analgesic treatment options. Clinical therapeutics 2013, 35 (11), 16691689.

121. Gudin, J.; Fudin, J.; Nalamachu, S., Levorphanol use: past, present and future. Postgraduate medicine 2016, 128 (1), 46-53.

122. Le Rouzic, V.; Narayan, A.; Hunkle, A.; Marrone, G. F.; Lu, Z.; Majumdar, S.; Xu, J.; Pan, Y.-X.; Pasternak, G. W., Pharmacological characterization of levorphanol, a G-protein biased opioid analgesic. Anesthesia \& Analgesia 2019, 128 (2), 365-373.

123. Groer, C. E.; Tidgewell, K.; Moyer, R. A.; Harding, W. W.; Rothman, R. B.; Prisinzano, T. E.; Bohn, L. M., An opioid agonist that does not induce $\mu$-opioid receptor-arrestin interactions or receptor internalization. Molecular pharmacology 2007, 71 (2), 549-557.

124. Harding, W. W.; Tidgewell, K.; Byrd, N.; Cobb, H.; Dersch, C. M.; Butelman, E. R.; Rothman, R. B.; Prisinzano, T. E., Neoclerodane diterpenes as a novel scaffold for $\mu$ opioid receptor ligands.

Journal of medicinal chemistry 2005, 48 (15), 4765-4771.

125. Roth, B. L.; Baner, K.; Westkaemper, R.; Siebert, D.; Rice, K. C.; Steinberg, S.; Ernsberger, P.;

Rothman, R. B., Salvinorin A: a potent naturally occurring nonnitrogenous $\mathrm{K}$ opioid selective agonist. Proceedings of the National Academy of Sciences 2002, 99 (18), 11934-11939.

126. Madariaga-Mazón, A.; Marmolejo-Valencia, A. F.; Li, Y.; Toll, L.; Houghten, R. A.; MartinezMayorga, K., Mu-Opioid receptor biased ligands: A safer and painless discovery of analgesics? Drug discovery today 2017, 22 (11), 1719-1729.

127. Lamb, K.; Tidgewell, K.; Simpson, D. S.; Bohn, L. M.; Prisinzano, T. E., Antinociceptive effects of herkinorin, a MOP receptor agonist derived from salvinorin $A$ in the formalin test in rats: new concepts in mu opioid receptor pharmacology: from a symposium on new concepts in mu-opioid pharmacology. Drug and alcohol dependence 2012, 121 (3), 181-188.

128. Rowan, M. P.; Bierbower, S. M.; Eskander, M. A.; Szteyn, K.; Por, E. D.; Gomez, R.; Veldhuis, N.; Bunnett, N. W.; Jeske, N. A., Activation of mu opioid receptors sensitizes transient receptor potential vanilloid type 1 (TRPV1) via $\beta$-arrestin-2-mediated cross-talk. PloS one 2014, 9 (4).

129. Yudin, Y.; Rohacs, T., The G-protein-biased agents PZM21 and TRV130 are partial agonists of $\mu$-opioid receptor-mediated signalling to ion channels. British journal of pharmacology 2019, 176 (17), 3110-3125.

130. Crowley, R. S.; Riley, A. P.; Sherwood, A. M.; Groer, C. E.; Shivaperumal, N.; Biscaia, M.; Paton, K.; Schneider, S.; Provasi, D.; Kivell, B. M.; Filizola, M.; Prisinzano, T. E., Synthetic Studies of Neoclerodane Diterpenes from Salvia divinorum: Identification of a Potent and Centrally Acting $\mu$ Opioid Analgesic with Reduced Abuse Liability. Journal of Medicinal Chemistry 2016, 59 (24), 1102711038. 
131. Tidgewell, K.; Groer, C. E.; Harding, W. W.; Lozama, A.; Schmidt, M.; Marquam, A.; Hiemstra, J.; Partilla, J. S.; Dersch, C. M.; Rothman, R. B.; Bohn, L. M.; Prisinzano, T. E., Herkinorin Analogues with Differential $\beta$-Arrestin-2 Interactions. Journal of Medicinal Chemistry 2008, 51 (8), 2421-2431. 132. Crowley, R. S.; Riley, A. P.; Alder, A. F.; Anderson, R. J.; Luo, D.; Kaska, S.; Maynez, P.; Kivell, B. M.; Prisinzano, T. E., Synthetic Studies of Neoclerodane Diterpenes from Salvia divinorum: Design, Synthesis, and Evaluation of Analogues with Improved Potency and G-protein Activation Bias at the $\mu$-Opioid Receptor. ACS Chemical Neuroscience 2020, 11 (12), 1781-1790.

133. Grewal, K. S., OBSERVATIONS OX THE PHARMACOLOGY OF MITRAGYNINE. 1932.

134. Prozialeck, W. C.; Jivan, J. K.; Andurkar, S. V., Pharmacology of kratom: an emerging botanical agent with stimulant, analgesic and opioid-like effects. The Journal of the American Osteopathic Association 2012, 112 (12), 792-799.

135. Warner, M. L.; Kaufman, N. C.; Grundmann, O., The pharmacology and toxicology of kratom: from traditional herb to drug of abuse. International journal of legal medicine 2016, 130 (1), 127138.

136. Váradi, A.; Marrone, G. F.; Palmer, T. C.; Narayan, A.; Szabó, M. R.; Le Rouzic, V.; Grinnell, S. G.; Subrath, J. J.; Warner, E.; Kalra, S.; Hunkele, A.; Pagirsky, J.; Eans, S. O.; Medina, J. M.; Xu, J.; Pan, Y.-X.; Borics, A.; Pasternak, G. W.; McLaughlin, J. P.; Majumdar, S., Mitragynine/corynantheidine pseudoindoxyls as opioid analgesics with mu agonism and delta antagonism, which do not recruit $\beta$ arrestin-2. Journal of medicinal chemistry 2016, 59 (18), 8381-8397.

137. Ya, K.; Tangamornsuksan, W.; Scholfield, C. N.; Methaneethorn, J.; Lohitnavy, M., Pharmacokinetics of mitragynine, a major analgesic alkaloid in kratom (Mitragyna speciosa): a systematic review. Asian journal of psychiatry 2019, 43, 73-82.

138. Kruegel, A. C.; Gassaway, M. M.; Kapoor, A.; Váradi, A. S.; Majumdar, S.; Filizola, M.; Javitch, J. A.; Sames, D., Synthetic and receptor signaling explorations of the Mitragyna alkaloids: mitragynine as an atypical molecular framework for opioid receptor modulators. Journal of the American Chemical Society 2016, 138 (21), 6754-6764.

139. Meijer, D.; Hovinga, G.; Versluis, A.; Bröring, J.; Van Aken, K.; Moolenaar, F.; Wesseling, H., Pharmacokinetics of the oral narcotic analgesic bezitramide and preliminary observations on its effect on experimentally induced pain. European journal of clinical pharmacology 1984, 27 (5), 615618.

140. Grim, T. W.; Schmid, C. L.; Stahl, E. L.; Pantouli, F.; Ho, J.-H.; Acevedo-Canabal, A.; Kennedy, N. M.; Cameron, M. D.; Bannister, T. D.; Bohn, L. M., A G protein signaling-biased agonist at the $\mu-$ opioid receptor reverses morphine tolerance while preventing morphine withdrawal.

Neuropsychopharmacology 2020, 45 (2), 416-425.

141. Pantouli, F.; Grim, T. W.; Schmid, C. L.; Acevedo-Canabal, A.; Kennedy, N. M.; Cameron, M. D.; Bannister, T. D.; Bohn, L. M., Comparison of morphine, oxycodone and the biased MOR agonist SR-17018 for tolerance and efficacy in mouse models of pain. Neuropharmacology 2021, 185, 108439.

142. Kennedy, N. M.; Schmid, C. L.; Ross, N. C.; Lovell, K. M.; Yue, Z.; Chen, Y. T.; Cameron, M. D.; Bohn, L. M.; Bannister, T. D., Optimization of a Series of Mu Opioid Receptor (MOR) Agonists with High G Protein Signaling Bias. Journal of Medicinal Chemistry 2018, 61 (19), 8895-8907.

143. Zadina, J. E.; Hackler, L.; Ge, L.-J.; Kastin, A. J., A potent and selective endogenous agonist for the $\mu$-opiate receptor. Nature 1997, 386 (6624), 499.

144. Goldberg, I. E.; Rossi, G. C.; Letchworth, S. R.; Mathis, J. P.; Ryan-Moro, J.; Leventhal, L.; Su, W.; Emmel, D.; Bolan, E. A.; Pasternak, G. W., Pharmacological characterization of endomorphin-1 and endomorphin-2 in mouse brain. Journal of Pharmacology and Experimental Therapeutics 1998, 286 (2), 1007-1013.

145. Kelly, E., Efficacy and ligand bias at the $\mu$-opioid receptor. British journal of pharmacology 2013, 169 (7), 1430-1446. 
146. Rivero, G.; Llorente, J.; McPherson, J.; Cooke, A.; Mundell, S. J.; McArdle, C. A.; Rosethorne, E. M.; Charlton, S. J.; Krasel, C.; Bailey, C. P.; Henderson, G.; Kelly, E., Endomorphin-2: a biased agonist at the $\mu$-opioid receptor. Molecular pharmacology 2012, 82 (2), 178-188.

147. Webster, L.; Schmidt, W. K., Dilemma of Addiction and Respiratory Depression in the Treatment of Pain: A Prototypical Endomorphin as a New Approach. Pain Medicine 2019.

148. Zadina, J. E.; Nilges, M. R.; Morgenweck, J.; Zhang, X.; Hackler, L.; Fasold, M. B., Endomorphin analog analgesics with reduced abuse liability, respiratory depression, motor impairment, tolerance, and glial activation relative to morphine. Neuropharmacology 2016, 105, 215-227.

149. Liu, X.; Zhao, L.; Wang, Y.; Zhou, J.; Wang, D.; Zhang, Y.; Zhang, X.; Wang, Z.; Yang, D.; Mou, L.; Wang, R., MEL-N16: a series of novel endomorphin analogs with good analgesic activity and a favorable side effect profile. ACS chemical neuroscience 2017, 8 (10), 2180-2193.

150. Dekan, Z.; Sianati, S.; Yousuf, A.; Sutcliffe, K. J.; Gillis, A.; Mallet, C.; Singh, P.; Jin, A. H.; Wang, A. M.; Mohammadi, S. A.; Stewart, M.; Rantnayake, R.; Fontaine, F.; Lacey, E.; Piggott, A. M.; Du, Y. P.; Canals, M.; Sessions, R. B.; Kelly, E.; Capon, R. J.; Alewood, P. F.; Christie, M. J., A tetrapeptide class of biased analgesics from an Australian fungus targets the $\mu$-opioid receptor. Proceedings of the National Academy of Sciences 2019, 116 (44), 22353-22358.

151. Stanley, T. H., The fentanyl story. The Journal of Pain 2014, 15 (12), 1215-1226.

152. Stanley, T. H., The history of opioid use in anesthetic delivery. In The Wondrous Story of Anesthesia, Springer: 2014; pp 641-659.

153. Varga, E. V.; Navratilova, E.; Stropova, D.; Jambrosic, J.; Roeske, W. R.; Yamamura, H. I., Agonist-specific regulation of the $\delta$-opioid receptor. Life sciences 2004, 76 (6), 599-612.

154. Pradhan, A. A.; Befort, K.; Nozaki, C.; Gavériaux-Ruff, C.; Kieffer, B. L., The delta opioid receptor: an evolving target for the treatment of brain disorders. Trends in Pharmacological Sciences 2011, 32 (10), 581-590.

155. Yang, S.; Yunden, J.; Sonoda, S.; Doyama, N.; Lipkowski, A. W.; Kawamura, Y.; Yoshikawa, M., Rubiscolin, a $\delta$ selective opioid peptide derived from plant Rubisco. FEBS letters 2001, 509 (2), 213-

217.

156. Chajra, H.; Amstutz, B.; Schweikert, K.; Auriol, D.; Redziniak, G.; Lefevre, F., Opioid receptor delta as a global modulator of skin differentiation and barrier function repair. International journal of cosmetic science 2015, 37 (4), 386-394.

157. Cassell, R. J.; Mores, K. L.; Zerfas, B. L.; Mahmoud, A. H.; Lill, M. A.; Trader, D. J.; van Rijn, R. M., Rubiscolins are naturally occurring $G$ protein-biased delta opioid receptor peptides. European Neuropsychopharmacology 2019, 29 (3), 450-456.

158. Conibear, A. E.; Asghar, J.; Hill, R.; Henderson, G.; Borbely, E.; Tekus, V.; Helyes, Z.; Palandri, J.; Bailey, C.; Starke, I.; von Mentzer, B.; Kendall, D.; Kelly, E., A Novel G Protein-Biased Agonist at the $\delta$ Opioid Receptor with Analgesic Efficacy in Models of Chronic Pain. Journal of Pharmacology and Experimental Therapeutics 2020, 372 (2), 224-236.

159. Fenalti, G.; Giguere, P. M.; Katritch, V.; Huang, X.-P.; Thompson, A. A.; Cherezov, V.; Roth, B. L.; Stevens, R. C., Molecular control of $\delta$-opioid receptor signalling. Nature 2014, 506 (7487), 191196.

160. Balboni, G.; Salvadori, S.; Guerrini, R.; Negri, L.; Giannini, E.; Jinsmaa, Y.; Bryant, S. D.; Lazarus, L. H., Potent $\delta$-Opioid Receptor Agonists Containing the Dmt- Tic Pharmacophore. Journal of medicinal chemistry 2002, 45 (25), 5556-5563.

161. Aguila, B.; Coulbault, L.; Boulouard, M.; Liveillı, F.; Davis, A.; Toth, G.; Borsodi, A.; Balboni, G.; Salvadori, S.; Jauzac, P.; Allouche, S., In vitro and in vivo pharmacological profile of UFP-512, a novel selective $\delta$-opioid receptor agonist; correlations between desensitization and tolerance. British journal of pharmacology 2007, 152 (8), 1312-1324.

162. Vergura, R.; Balboni, G.; Spagnolo, B.; Gavioli, E.; Lambert, D. G.; McDonald, J.; Trapella, C.; Lazarus, L. H.; Regoli, D.; Guerrini, R.; Salvadori, S.; Calo', G., Anxiolytic-and antidepressant-like activities of H-Dmt-Tic-NH-CH (CH2-COOH)-Bid (UFP-512), a novel selective delta opioid receptor agonist. Peptides 2008, 29 (1), 93-103. 
163. Charfi, I.; Audet, N.; Bagheri Tudashki, H.; Pineyro, G., Identifying ligand-specific signalling within biased responses: focus on $\delta$ opioid receptor ligands. British journal of pharmacology 2015, $172(2), 435-448$.

164. Charfi, I.; Nagi, K.; Mnie-Filali, O.; Thibault, D.; Balboni, G.; Schiller, P. W.; Trudeau, L.-E.; Pineyro, G., Ligand-and cell-dependent determinants of internalization and cAMP modulation by delta opioid receptor (DOR) agonists. Cellular and molecular life sciences 2014, 71 (8), 1529-1546. 165. Calderon, S. N.; Rothman, R. B.; Porreca, F.; Flippen-Anderson, J. L.; McNutt, R. W.; Xu, H.; Smith, L. E.; Bilsky, E. J.; Davis, P.; Rice, K. C., Probes for Narcotic Receptor Mediated Phenomena. 19. Synthesis of (+)-4-[(. alpha. R)-. alpha.-((2S, 5R)-4-Allyl-2, 5-dimethyl-1-piperazinyl)-3methoxybenzyl]-N, N-diethylbenzamide (SNC 80): A Highly Selective, Nonpeptide. delta. Opioid Receptor Agonist. Journal of Medicinal Chemistry 1994, 37 (14), 2125-2128.

166. Metcalf, M. D.; Yekkirala, A. S.; Powers, M. D.; Kitto, K. F.; Fairbanks, C. A.; Wilcox, G. L.; Portoghese, P. S., The $\delta$ Opioid Receptor Agonist SNC80 Selectively Activates Heteromeric $\mu-\delta$ Opioid Receptors. ACS Chemical Neuroscience 2012, 3 (7), 505-509.

167. Saitoh, A.; Kimura, Y.; Suzuki, T.; Kawai, K.; Nagase, H.; Kamei, J., Potential Anxiolytic and Antidepressant-Like Activities of SNC80, a Selective $\delta$-Opioid Agonist, in Behavioral Models in Rodents. Journal of Pharmacological Sciences 2004, 95 (3), 374-380.

168. Dripps, I. J.; Boyer, B. T.; Neubig, R. R.; Rice, K. C.; Traynor, J. R.; Jutkiewicz, E. M., Role of signalling molecules in behaviours mediated by the $\delta$ opioid receptor agonist SNC80. British Journal of Pharmacology 2018, 175 (6), 891-901.

169. PharmNovo SEARCH FOR NOVEL TREATMENT INITIATED 2008.

https://www.pharmnovo.com/about-us/our-history (accessed April $6^{\text {th }}$ ).

170. PharmNovo PN6047 - OUR CANDIDATE COMPOUND.

https://www.pharmnovo.com/therapeutic-focus/projects (accessed April $6^{\text {th }}$ ).

171. Wei, Z.-Y.; Brown, W.; Takasaki, B.; Plobeck, N.; Delorme, D.; Zhou, F.; Yang, H.; Jones, P.; Gawell, L.; Gagnon, H.; Schmidt, R.; Yue, S.-Y.; Walpole, C.; Payza, K.; St-Onge, S.; Labarre, M.; Godbout, C.; Jakob, A.; Butterworth, J.; Kamassah, A.; Morin, P.-E.; Projean, D.; Ducharme, J.; Roberts, E., N,N-Diethyl-4-(phenylpiperidin-4-ylidenemethyl)benzamide: A Novel, Exceptionally Selective, Potent $\delta$ Opioid Receptor Agonist with Oral Bioavailability and Its Analogues. Journal of Medicinal Chemistry 2000, 43 (21), 3895-3905.

172. Marie, N.; Landemore, G.; Debout, C.; Jauzac, P.; Allouche, S., Pharmacological characterization of AR-M1000390 at human delta opioid receptors. Life Sciences 2003, 73 (13), 16911704.

173. Pradhan, A. A. A.; Becker, J. A. J.; Scherrer, G.; Tryoen-Toth, P.; Filliol, D.; Matifas, A.; Massotte, D.; Gavériaux-Ruff, C.; Kieffer, B. L., In vivo delta opioid receptor internalization controls behavioral effects of agonists. PloS one 2009, 4 (5), e5425-e5425.

174. Pradhan, A. A. A.; Walwyn, W.; Nozaki, C.; Filliol, D.; Erbs, E.; Matifas, A.; Evans, C.; Kieffer, B. L., Ligand-Directed Trafficking of the $\delta$-Opioid Receptor $<$ em $>$ In Vivo</em>: Two Paths Toward Analgesic Tolerance. The Journal of Neuroscience 2010, 30 (49), 16459-16468.

175. Codd, E. E.; Carson, J. R.; Colburn, R. W.; Stone, D. J.; Van Besien, C. R.; Zhang, S.-P.; Wade, P. R.; Gallantine, E. L.; Meert, T. F.; Molino, L.; Pullan, S.; Razler, C. M.; Dax, S. L.; Flores, C. M., JNJ20788560 [9-(8-azabicyclo [3.2. 1] oct-3-ylidene)-9H-xanthene-3-carboxylic acid diethylamide], a selective delta opioid receptor agonist, is a potent and efficacious antihyperalgesic agent that does not produce respiratory depression, pharmacologic tolerance, or physical dependence. Journal of Pharmacology and Experimental Therapeutics 2009, 329 (1), 241-251.

176. Le Bourdonnec, B.; Windh, R. T.; Leister, L. K.; Zhou, Q. J.; Ajello, C. W.; Gu, M.; Chu, G.-H.; Tuthill, P. A.; Barker, W. M.; Koblish, M.; Wiant, D. D.; Graczyk, T. M.; Belanger, S.; Cassel, J. A.; Feschenko, M. S.; Brogdon, B. L.; Smith, S. A.; Derelanko, M. J.; Kutz, S.; Little, P. J.; DeHaven, R. N.; DeHaven-Hudkins, D. L.; Dolle, R. E., Spirocyclic Delta Opioid Receptor Agonists for the Treatment of Pain: Discovery of N,N-Diethyl-3-hydroxy-4-(spiro[chromene-2,4'-piperidine]-4-yl) Benzamide (ADL5747). Journal of Medicinal Chemistry 2009, 52 (18), 5685-5702. 
177. Nozaki, C.; Le Bourdonnec, B.; Reiss, D.; Windh, R. T.; Little, P. J.; Dolle, R. E.; Kieffer, B. L.; Gavériaux-Ruff, C., $\delta$-Opioid Mechanisms for ADL5747 and ADL5859 Effects in Mice: Analgesia, Locomotion, and Receptor Internalization. Journal of Pharmacology and Experimental Therapeutics 2012, 342 (3), 799-807.

178. Filizola, M., Insights from molecular dynamics simulations to exploit new trends for the development of improved opioid drugs. Neuroscience Letters 2019, 700, 50-55.

179. Fossler, M. J.; Schmith, V.; Greene, S. A.; Lohmer, L.; Kramer, M. S.; Arscott, K.; James, I. E.; Demitrack, M. A., A Phase I, Randomized, Single Blind, Placebo Controlled, Single Ascending Dose Study of the Safety, Tolerability, and Pharmacokinetics of Subcutaneous and Oral TRV250, a G Protein-Selective Delta Receptor Agonist, in Healthy Subjects. CNS Drugs 2020, 34 (8), 853-865. 180. Petrillo, P.; Angelici, O.; Bingham, S.; Ficalora, G.; Garnier, M.; Zaratin, P. F.; Petrone, G.; Pozzi, O.; Sbacchi, M.; Stean, T. O.; Upton, N.; Dondio, G. M.; Scheideler, M. A., Evidence for a selective role of the $\delta$-opioid agonist [8R-(4bS*, 8a $\alpha, 8 \mathrm{a} \beta, 12 \mathrm{~b} \beta)]$ 7, 10-Dimethyl-1-methoxy-11-(2methylpropyl) oxycarbonyl 5, 6, 7, 8, 12, 12b-hexahydro-(9H)-4, 8-methanobenzofuro [3, 2-e] pyrrolo $[2,3-\mathrm{g}]$ isoquinoline hydrochloride (SB-235863) in blocking hyperalgesia associated with inflammatory and neuropathic pain responses. Journal of Pharmacology and Experimental Therapeutics 2003, 307 (3), 1079-1089.

181. Nagase, H.; Kawai, K.; Hayakawa, J.; Wakita, H.; Mizusuna, A.; Matsuura, H.; Tajima, C.; Takezawa, Y.; Endoh, T., Rational Drug Design and Synthesis of a Highly Selective Nonpeptide \&delta;-Opioid Agonist, (4aS $<$ SUP $>*</ S U P>, 12 a R<S U P>*</ S U P>)-4 a-(3-H y d r o x y p h e n y l)-2-m e t h y l-1$, 2, 3, 4, 4a, 5, 12, 12a-octahydropyrido[3, 4-b]acridine (TAN-67). CHEMICAL \& PHARMACEUTICAL BULLETIN 1998, 46 (11), 1695-1702.

182. Bradbury, F. A.; Zelnik, J. C.; Traynor, J. R., G Protein independent phosphorylation and internalization of the $\delta$-opioid receptor. Journal of Neurochemistry 2009, 109 (5), 1526-1535. 183. van Rijn, R. M.; Whistler, J. L., The $\delta 1$ Opioid Receptor Is a Heterodimer That Opposes the Actions of the $\delta 2$ Receptor on Alcohol Intake. Biological Psychiatry 2009, 66 (8), 777-784.

184. van Rijn, R. M.; Brissett, D. I.; Whistler, J. L., Dual Efficacy of Delta Opioid Receptor-Selective Ligands for Ethanol Drinking and Anxiety. Journal of Pharmacology and Experimental Therapeutics 2010, 335 (1), 133-139.

185. Chiang, T.; Sansuk, K.; van Rijn, R. M., $\beta$-Arrestin 2 dependence of $\delta$ opioid receptor agonists is correlated with alcohol intake. British Journal of Pharmacology 2016, 173 (2), 332-343.

186. Robins, M. T.; Chiang, T.; Mores, K. L.; Alongkronrusmee, D.; van Rijn, R. M., Critical Role for Gi/o-Protein Activity in the Dorsal Striatum in the Reduction of Voluntary Alcohol Intake in C57BI/6 Mice. Frontiers in Psychiatry 2018, 9 (112).

187. Nagase, H.; Nemoto, T.; Matsubara, A.; Saito, M.; Yamamoto, N.; Osa, Y.; Hirayama, S.; Nakajima, M.; Nakao, K.; Mochizuki, H.; Fujii, H., Design and synthesis of KNT-127, a $\delta$-opioid receptor agonist effective by systemic administration. Bioorganic \& Medicinal Chemistry Letters 2010, 20 (21), 6302-6305.

188. Saitoh, A.; Sugiyama, A.; Nemoto, T.; Fujii, H.; Wada, K.; Oka, J.-I.; Nagase, H.; Yamada, M., The novel $\delta$ opioid receptor agonist KNT-127 produces antidepressant-like and antinociceptive effects in mice without producing convulsions. Behavioural Brain Research 2011, 223 (2), 271-279.

189. Nozaki, C.; Nagase, H.; Nemoto, T.; Matifas, A.; Kieffer, B. L.; Gaveriaux-Ruff, C., In vivo properties of KNT-127, a novel $\delta$ opioid receptor agonist: receptor internalization, antihyperalgesia and antidepressant effects in mice. British Journal of Pharmacology 2014, 171 (23), 5376-5386.

190. Burford, N. T.; Livingston, K. E.; Canals, M.; Ryan, M. R.; Budenholzer, L. M. L.; Han, Y.; Shang, Y.; Herbst, J. J.; O'Connell, J.; Banks, M.; Zhang, L.; Filizola, M.; Bassoni, D. L.; Wehrman, T. S.; Christopoulos, A.; Traynor, J. R.; Gerritz, S. W.; Alt, A., Discovery, Synthesis, and Molecular Pharmacology of Selective Positive Allosteric Modulators of the $\delta$-Opioid Receptor. Journal of Medicinal Chemistry 2015, 58 (10), 4220-4229. 
191. Shang, Y.; Yeatman, H. R.; Provasi, D.; Alt, A.; Christopoulos, A.; Canals, M.; Filizola, M., Proposed Mode of Binding and Action of Positive Allosteric Modulators at Opioid Receptors. ACS Chemical Biology 2016, 11 (5), 1220-1229.

192. Stanczyk, M. A.; Livingston, K. E.; Chang, L.; Weinberg, Z. Y.; Puthenveedu, M. A.; Traynor, J. R., The $\delta$-opioid receptor positive allosteric modulator BMS 986187 is a G-protein-biased allosteric agonist. British Journal of Pharmacology 2019, 176 (11), 1649-1663.

193. Wang, Y.-h.; Sun, J.-f.; Tao, Y.-m.; Chi, Z.-q.; Liu, J.-g., The role of k-opioid receptor activation in mediating antinociception and addiction. Acta Pharmacologica Sinica 2010, 31 (9), 1065-1070.

194. Chavkin, C., The therapeutic potential of $\mathrm{k}$-opioids for treatment of pain and addiction. Nature Publishing Group: 2010.

195. Brust, T. F.; Morgenweck, J.; Kim, S. A.; Rose, J. H.; Locke, J. L.; Schmid, C. L.; Zhou, L.; Stahl, E. L.; Cameron, M. D.; Scarry, S. M.; Aubé, J.; Jones, S. R.; Martin, T. J.; Bohn, L. M., Biased agonists of the kappa opioid receptor suppress pain and itch without causing sedation or dysphoria. Science Signaling 2016, 9 (456), ra117-ra117.

196. Sharma, S. K.; Jones, R. M.; Metzger, T. G.; Ferguson, D. M.; Portoghese, P. S., Transformation of a k-Opioid Receptor Antagonist to a k-Agonist by Transfer of a Guanidinium Group from the 5'- to 6'-Position of Naltrindole. Journal of Medicinal Chemistry 2001, 44 (13), 2073-2079.

197. Rives, M.-L.; Rossillo, M.; Liu-Chen, L.-Y.; Javitch, J. A., 6'-Guanidinonaltrindole (6'-GNTI) is a $\mathrm{G}$ protein-biased $\mathrm{k}$-opioid receptor agonist that inhibits arrestin recruitment. Journal of Biological Chemistry 2012, 287 (32), 27050-27054.

198. Waldhoer, M.; Fong, J.; Jones, R. M.; Lunzer, M. M.; Sharma, S. K.; Kostenis, E.; Portoghese, P. S.; Whistler, J. L., A heterodimer-selective agonist shows $<\mathrm{em}>$ in vivo</em $>$ relevance of $\mathrm{G}$ protein-coupled receptor dimers. Proceedings of the National Academy of Sciences of the United States of America 2005, 102 (25), 9050-9055.

199. Schmid, C. L.; Streicher, J. M.; Groer, C. E.; Munro, T. A.; Zhou, L.; Bohn, L. M., Functional selectivity of 6'-guanidinonaltrindole (6'-GNTI) at k-opioid receptors in striatal neurons. Journal of Biological Chemistry 2013, 288 (31), 22387-22398.

200. White, K. L.; Scopton, A. P.; Rives, M.-L.; Bikbulatov, R. V.; Polepally, P. R.; Brown, P. J.; Kenakin, T.; Javitch, J. A.; Zjawiony, J. K.; Roth, B. L., Identification of Novel Functionally Selective $<$ em $>\mathrm{k}<$ /em>-Opioid Receptor Scaffolds. Molecular Pharmacology 2014, 85 (1), 83-90.

201. Nagase, H.; Hayakawa, J.; Kawamura, K.; Kawai, K.; Takezawa, Y.; Matsuura, H.; Tajima, C.; Endo, T., DISCOVERY OF A STRUCTURALLY NOVEL OPIOID K-AGONIST DERIVED FROM 4, 5EPOXYMORPHINAN. CHEMICAL \& PHARMACEUTICAL BULLETIN 1998, 46 (2), 366-369.

202. Togashi, Y.; Umeuchi, H.; Okano, K.; Ando, N.; Yoshizawa, Y.; Honda, T.; Kawamura, K.; Endoh, T.; Utsumi, J.; Kamei, J.; Tanaka, T.; Nagase, H., Antipruritic activity of the K-opioid receptor agonist, TRK-820. European Journal of Pharmacology 2002, 435 (2), 259-264.

203. Kumagai, H.; Ebata, T.; Takamori, K.; Muramatsu, T.; Nakamoto, H.; Suzuki, H., Effect of a novel kappa-receptor agonist, nalfurafine hydrochloride, on severe itch in 337 haemodialysis patients: a Phase III, randomized, double-blind, placebo-controlled study. Nephrology Dialysis Transplantation 2009, 25 (4), 1251-1257.

204. Liu, J. J.; Chiu, Y.-T.; DiMattio, K. M.; Chen, C.; Huang, P.; Gentile, T. A.; Muschamp, J. W.; Cowan, A.; Mann, M.; Liu-Chen, L.-Y., Phosphoproteomic approach for agonist-specific signaling in mouse brains: mTOR pathway is involved in $\mathrm{k}$ opioid aversion. Neuropsychopharmacology 2019, 44 (5), 939-949.

205. Endoh, T.; Matsuura, H.; Tajima, A.; Izumimoto, N.; Tajima, C.; Suzuki, T.; Saitoh, A.; Suzuki, T.; Narita, M.; Tseng, L.; Nagase, H., Potent antinociceptive effects of TRK-820, a novel K-opioid receptor agonist. Life Sciences 1999, 65 (16), 1685-1694.

206. Ko, M.-C.; Husbands, S. M., Effects of Atypical k-Opioid Receptor Agonists on Intrathecal Morphine-Induced Itch and Analgesia in Primates. Journal of Pharmacology and Experimental Therapeutics 2009, 328 (1), 193-200. 
207. Schattauer, S. S.; Kuhar, J. R.; Song, A.; Chavkin, C., Nalfurafine is a G-protein biased agonist having significantly greater bias at the human than rodent form of the kappa opioid receptor. Cellular Signalling 2017, 32, 59-65.

208. Glick, S. D.; Maisonneuve, I. M., Mechanisms of Antiaddictive Actions of Ibogainea. Annals of the New York Academy of Sciences 1998, 844 (1), 214-226.

209. Maillet, E. L.; Milon, N.; Heghinian, M. D.; Fishback, J.; Schürer, S. C.; Garamszegi, N.; Mash, D. C., Noribogaine is a G-protein biased k-opioid receptor agonist. Neuropharmacology 2015, 99, 675-688.

210. Mash, D. C.; Staley, J. K.; Pablo, J. P.; Holohean, A. M.; Hackman, J. C.; Davidoff, R. A., Properties of ibogaine and its principal metabolite (12-hydroxyibogamine) at the MK-801 binding site of the NMDA receptor complex. Neuroscience Letters 1995, 192 (1), 53-56.

211. Glick, S. D.; Maisonneuve, I. M.; Pearl, S. M., Evidence for roles of $\mathrm{K}$-opioid and NMDA receptors in the mechanism of action of ibogaine. Brain Research 1997, 749 (2), 340-343.

212. Frankowski, K. J.; Hedrick, M. P.; Gosalia, P.; Li, K.; Shi, S.; Whipple, D.; Ghosh, P.; Prisinzano, T. E.; Schoenen, F. J.; Su, Y.; Vasile, S.; Sergienko, E.; Gray, W.; Hariharan, S.; Milan, L.; Heynen-Genel, S.; Mangravita-Novo, A.; Vicchiarelli, M.; Smith, L. H.; Streicher, J. M.; Caron, M. G.; Barak, L. S.; Bohn, L. M.; Chung, T. D. Y.; Aubé, J., Discovery of Small Molecule Kappa Opioid Receptor Agonist and Antagonist Chemotypes through a HTS and Hit Refinement Strategy. ACS Chemical Neuroscience 2012, 3 (3), 221-236.

213. Zhou, L.; Lovell, K. M.; Frankowski, K. J.; Slauson, S. R.; Phillips, A. M.; Streicher, J. M.; Stahl, E.; Schmid, C. L.; Hodder, P.; Madoux, F.; Cameron, M. D.; Prisinzano, T. E.; Aubé, J.; Bohn, L. M., Development of functionally selective, small molecule agonists at kappa opioid receptors. Journal of Biological Chemistry 2013, 288 (51), 36703-36716.

214. Bohn, L. M.; Aubé, J., Seeking (and Finding) Biased Ligands of the Kappa Opioid Receptor. ACS Medicinal Chemistry Letters 2017, 8 (7), 694-700.

215. Lovell, K. M.; Frankowski, K. J.; Stahl, E. L.; Slauson, S. R.; Yoo, E.; Prisinzano, T. E.; Aubé, J.; Bohn, L. M., Structure-Activity Relationship Studies of Functionally Selective Kappa Opioid Receptor Agonists that Modulate ERK 1/2 Phosphorylation While Preserving G Protein Over $\beta$ Arrestin2 Signaling Bias. ACS Chemical Neuroscience 2015, 6 (8), 1411-1419.

216. Simonson, B.; Morani, A.; Ewald, A.; Walker, L.; Kumar, N.; Simpson, D.; Miller, J.; Prisinzano, T.; Kivell, B., Pharmacology and anti-addiction effects of the novel $\mathrm{k}$ opioid receptor agonist $\mathrm{M}$ esyl $\mathrm{S}$ al B, a potent and long-acting analogue of salvinorin A. British journal of pharmacology 2015, 172 (2), 515-531.

217. Kivell, B. M.; Paton, K. F.; Kumar, N.; Morani, A. S.; Culverhouse, A.; Shepherd, A.; Welsh, S. A.; Biggerstaff, A.; Crowley, R. S.; Prisinzano, T. E., Kappa opioid receptor agonist mesyl Sal B attenuates behavioral sensitization to cocaine with fewer aversive side-effects than salvinorin $A$ in Rodents. Molecules 2018, 23 (10), 2602.

218. Yan, F.; Bikbulatov, R. V.; Mocanu, V.; Dicheva, N.; Parker, C. E.; Wetsel, W. C.; Mosier, P. D.; Westkaemper, R. B.; Allen, J. A.; Zjawiony, J. K.; Roth, B. L., Structure-Based Design, Synthesis, and Biochemical and Pharmacological Characterization of Novel Salvinorin A Analogues as Active State Probes of the k-Opioid Receptor. Biochemistry 2009, 48 (29), 6898-6908.

219. White, K. L.; Robinson, J. E.; Zhu, H.; DiBerto, J. F.; Polepally, P. R.; Zjawiony, J. K.; Nichols, D. E.; Malanga, C. J.; Roth, B. L., The G Protein-Biased <em>k</em>-Opioid Receptor Agonist RB-64 Is Analgesic with a Unique Spectrum of Activities In Vivo. Journal of Pharmacology and Experimental Therapeutics 2015, 352 (1), 98-109.

220. Bui, A. M.; Cavé, A.; Janot, M. M.; Parello, J.; Potier, P.; Scheidegger, U., Isolement et analyse structurale du collybolide, nouveau sesquiterpene extrait de Collybia maculata alb. et sch. ex fries (basidiomycetes). Tetrahedron 1974, 30 (11), 1327-1336.

221. Gupta, A.; Gomes, I.; Bobeck, E. N.; Fakira, A. K.; Massaro, N. P.; Sharma, I.; Cavé, A.; Hamm, H. E.; Parello, J.; Devi, L. A., Collybolide is a novel biased agonist of K-opioid receptors with potent antipruritic activity. Proceedings of the National Academy of Sciences 2016, 113 (21), 6041-6046. 
222. Naylor, A.; Judd, D. B.; Lloyd, J. E.; Scopes, D. I. C.; Hayes, A. G.; Birch, P. J., A potent new class of .kappa.-receptor agonist: 4-substituted 1-(arylacetyl)-2-[(dialkylamino)methyl]piperazines. Journal of Medicinal Chemistry 1993, 36 (15), 2075-2083.

223. Brissett, D. I.; Whistler, J. L.; van Rijn, R. M., Contribution of mu and delta opioid receptors to the pharmacological profile of kappa opioid receptor subtypes. European Journal of Pain 2012, 16 (3), 327-337.

224. Kenakin, T., The Effective Application of Biased Signaling to New Drug Discovery. Molecular Pharmacology 2015, 88 (6), 1055-1061.

225. Von Voigtlander, P. F.; Collins, R. J.; Lewis, R. A.; Neff, G. L., U-50,488 H (trans-3,4-dichloro- $N$ methyl- $N$-[2-(1-pyrrolidinyl) cyclohexyl]-benzeneacetamide): Prototype for a new class of opioid analgesics. Pharmacologist 1981, 23, 134.

226. Kamei, J.; Tanihara, H.; Kasuya, Y., Antitussive effects of two specific k-opioid agonists, U50,488H and U-62,066E, in rats. European Journal of Pharmacology 1990, 187 (2), 281-286.

227. Dunn, A. D.; Reed, B.; Guariglia, C.; Dunn, A. M.; Hillman, J. M.; Kreek, M. J., Structurally Related Kappa Opioid Receptor Agonists with Substantial Differential Signaling Bias: Neuroendocrine and Behavioral Effects in C57BL6 Mice. International Journal of Neuropsychopharmacology 2018, 21 (9), 847-857.

228. Spetea, M.; Berzetei-Gurske, I. P.; Guerrieri, E.; Schmidhammer, H., Discovery and Pharmacological Evaluation of a Diphenethylamine Derivative (HS665), a Highly Potent and Selective к Opioid Receptor Agonist. Journal of Medicinal Chemistry 2012, 55 (22), 10302-10306.

229. Spetea, M.; Eans, S. O.; Ganno, M. L.; Lantero, A.; Mairegger, M.; Toll, L.; Schmidhammer, H.; McLaughlin, J. P., Selective $\mathrm{k}$ receptor partial agonist HS666 produces potent antinociception without inducing aversion after i.c.v. administration in mice. British Journal of Pharmacology 2017, 174 (15), 2444-2456.

230. Frankowski, K. J.; Ghosh, P.; Setola, V.; Tran, T. B.; Roth, B. L.; Aubé, J., N-Alkyloctahydroisoquinolin-1-one-8-carboxamides: Selective and Nonbasic K-Opioid Receptor Ligands. ACS Medicinal Chemistry Letters 2010, 1 (5), 189-193.

231. Frankowski, K. J.; Hirt, E. E.; Zeng, Y.; Neuenswander, B.; Fowler, D.; Schoenen, F.; Aubé, J., Synthesis of N-Alkyl-octahydroisoquinolin-1-one-8-carboxamide Libraries Using a Tandem DielsAlder/Acylation Sequence. Journal of Combinatorial Chemistry 2007, 9 (6), 1188-1192.

232. Bedini, A.; Di Cesare Mannelli, L.; Micheli, L.; Baiula, M.; Vaca, G.; De Marco, R.; Gentilucci, L.; Ghelardini, C.; Spampinato, S., Functional Selectivity and Antinociceptive Effects of a Novel KOPr Agonist. Frontiers in Pharmacology 2020, 11 (188).

233. Arduin, M.; Spagnolo, B.; Calò, G.; Guerrini, R.; Carrà, G.; Fischetti, C.; Trapella, C.; Marzola, E.; McDonald, J.; Lambert, D. G.; Regoli, D.; Salvadori, S., Synthesis and biological activity of nociceptin/orphanin FQ analogues substituted in position 7 or 11 with $\mathrm{C} \alpha, \alpha$-dialkylated amino acids. Bioorganic \& medicinal chemistry 2007, 15 (13), 4434-4443.

234. Okada, K.; Sujaku, T.; Chuman, Y.; Nakashima, R.; Nose, T.; Costa, T.; Yamada, Y.; Yokoyama, M.; Nagahisa, A.; Shimohigashi, Y., Highly potent nociceptin analog containing the Arg-Lys triple repeat. Biochemical and biophysical research communications 2000, 278 (2), 493-498.

235. Guerrini, R.; Caló, G.; Bigoni, R.; Rizzi, D.; Rizzi, A.; Zucchini, M.; Varani, K.; Hashiba, E.; Lambert, D. G.; Toth, G.; Borea, P. A.; Salvadori, S.; Regoli, D., Structure- activity studies of the Phe4 residue of nociceptin (1-13)-NH2: Identification of highly potent agonists of the nociceptin/orphanin FQ receptor. Journal of medicinal chemistry 2001, 44 (23), 3956-3964.

236. Guerrini, R.; Calo, G.; Rizzi, A.; Bigoni, R.; Bianchi, C.; Salvadori, S.; Regoli, D., A new selective antagonist of the nociceptin receptor. British journal of pharmacology 1998, 123 (2), 163-165.

237. Guerrini, R.; Calo', G.; Bigoni, R.; Rizzi, A.; Varani, K.; Toth, G.; Gessi, S.; Hashiba, E.; Hashimoto, Y.; Lambert, D. G.; Borea, P. A.; Tomatis, R.; Salvadori, S.; Regoli, D., Further studies on nociceptin-related peptides: discovery of a new chemical template with antagonist activity on the nociceptin receptor. Journal of medicinal chemistry 2000, 43 (15), 2805-2813. 
238. Rizzi, A.; Spagnolo, B.; Wainford, R. D.; Fischetti, C.; Guerrini, R.; Marzola, G.; Baldisserotto, A.; Salvadori, S.; Regoli, D.; Kapusta, D. R.; Calo', G., In vitro and in vivo studies on UFP-112, a novel potent and long lasting agonist selective for the nociceptin/orphanin FQ receptor. Peptides 2007, 28 (6), 1240-1251.

239. Hu, E.; Calò, G.; Guerrini, R.; Ko, M.-C., Long-lasting antinociceptive spinal effects in primates of the novel nociceptin/orphanin FQ receptor agonist UFP-112. Pain 2010, 148 (1), 107-113.

240. Malfacini, D.; Ambrosio, C.; MC, G.; Sbraccia, M.; Trapella, C.; Guerrini, R.; Bonora, M.; Pinton, P.; Costa, T.; Calo, G., Pharmacological profile of nociceptin/orphanin FQ receptors interacting with $\mathrm{G}$-proteins and $\beta$-arrestins 2. PloS one 2015, 10 (8).

241. Guerrini, R.; Marzola, E.; Trapella, C.; Molinari, S.; Cerlesi, M. C.; Malfacini, D.; Rizzi, A.; Salvadori, S.; Calo', G., A novel and facile synthesis of tetra branched derivatives of nociceptin/orphanin FQ. Bioorganic \& medicinal chemistry 2014, 22 (14), 3703-3712.

242. Calo', G.; Rizzi, A.; Ruzza, C.; Ferrari, F.; Pacifico, S.; Gavioli, E. C.; Salvadori, S.; Guerrini, R., Peptide welding technology - A simple strategy for generating innovative ligands for $G$ protein coupled receptors. Peptides 2018, 99, 195-204.

243. Rizzi, A.; Sukhtankar, D.; Ding, H.; Hayashida, K.; Ruzza, C.; Guerrini, R.; Calo, G.; Ko, M., Spinal antinociceptive effects of the novel NOP receptor agonist PWT2-nociceptin/orphanin FQ in mice and monkeys. British journal of pharmacology 2015, 172 (14), 3661-3670.

244. Varty, G. B.; Lu, S. X.; Morgan, C. A.; Cohen-Williams, M. E.; Hodgson, R. A.; Smith-Torhan, A.; Zhang, H.; Fawzi, A. B.; Graziano, M. P.; Ho, G. D.; Matasi, J.; Tulshian, D.; Coffin, V. L.; Carey, G. J., The anxiolytic-like effects of the novel, orally active nociceptin opioid receptor agonist 8-[bis (2methylphenyl) methyl]-3-phenyl-8-azabicyclo [3.2. 1] octan-3-ol (SCH 221510). Journal of Pharmacology and Experimental Therapeutics 2008, 326 (2), 672-682.

245. Sukhtankar, D. D.; Lagorio, C. H.; Ko, M.-C., Effects of the NOP agonist SCH221510 on producing and attenuating reinforcing effects as measured by drug self-administration in rats. European journal of pharmacology 2014, 745, 182-189.

246. Sobczak, M.; Mokrowiecka, A.; Cygankiewicz, A. I.; Zakrzewski, P. K.; Sałaga, M.; Storr, M.; Kordek, R.; Małecka-Panas, E.; Krajewska, W. M.; Fichna, J., Anti-inflammatory and antinociceptive action of an orally available nociceptin receptor agonist SCH 221510 in a mouse model of inflammatory bowel diseases. Journal of Pharmacology and Experimental Therapeutics 2014, 348 (3), 401-409.

247. Fichna, J.; Sobczak, M.; Mokrowiecka, A.; Cygankiewicz, A.; Zakrzewski, P.; Cenac, N.; Sałaga, M.; Timmermans, J. P.; Vergnolle, N.; Małecka-Panas, E.; Krajewska, W. M.; Storr, M., Activation of the endogenous nociceptin system by selective nociceptin receptor agonist SCH 221510 produces antitransit and antinociceptive effect: a novel strategy for treatment of diarrhea-predominant IBS. Neurogastroenterology \& Motility 2014, 26 (11), 1539-1550.

248. Ferrari, F.; Malfacini, D.; Journigan, B. V.; Bird, M. F.; Trapella, C.; Guerrini, R.; Lambert, D. G.; Calo', G.; Zaveri, N. T., In vitro pharmacological characterization of a novel unbiased NOP receptorselective nonpeptide agonist AT-403. Pharmacology research \& perspectives 2017, 5 (4), e00333.

249. McLeod, R. L.; Tulshian, D. B.; Bolser, D. C.; Varty, G. B.; Baptista, M.; Fernandez, X.; Parra, L. E.; Zimmer, J. C.; Erickson, C. H.; Ho, G. D.; Jia, Y.; Ng, F. W.; Korfmacher, W.; Xu, X.; Veals, J.; SmithTorhan, A.; Wainhaus, S.; Fawzi, A. B.; Austin, T. M.; van Heek, M.; Hey, J. A., Pharmacological profile of the NOP agonist and cough suppressing agent SCH 486757 (8-[Bis (2-Chlorophenyl) Methyl]-3-(2Pyrimidinyl)-8-Azabicyclo [3.2. 1] Octan-3-OI) in preclinical models. European journal of pharmacology 2010, 630 (1-3), 112-120.

250. Woodcock, A.; McLeod, R. L.; Sadeh, J.; Smith, J. A., The efficacy of a NOP1 agonist (SCH486757) in subacute cough. Lung 2010, 188 (1), 47-52.

251. McLeod, R. L.; Tulshian, D. B.; Sadeh, J., Where are the new cough treatments: a debriefing of recent clinical proof-of-concept trials with the NOP agonist SCH 486757. Pharmacology 2011, 88 (1-2), 50-54. 
252. Wichmann, J.; Adam, G.; Röver, S.; Hennig, M.; Scalone, M.; Cesura, A. M.; Dautzenberg, F. M.; Jenck, F., Synthesis of (1S, 3aS)-8-(2, 3, 3a, 4, 5, 6-hexahydro-1H-phenalen-1-yl)-1-phenyl-1, 3, 8triaza-spiro [4.5] decan-4-one, a potent and selective orphanin FQ (OFQ) receptor agonist with anxiolytic-like properties. European journal of medicinal chemistry 2000, 35 (9), 839-851.

253. Jenck, F.; Wichmann, J.; Dautzenberg, F. M.; Moreau, J.-L.; Ouagazzal, A. M.; Martin, J. R.; Lundstrom, K.; Cesura, A. M.; Poli, S. M.; Roever, S.; Kolczewski, S.; Adam, G.; Kilpatrick, G., A synthetic agonist at the orphanin $\mathrm{FQ} /$ nociceptin receptor ORL1: anxiolytic profile in the rat. Proceedings of the National Academy of Sciences 2000, 97 (9), 4938-4943.

254. Varty, G.; Hyde, L.; Hodgson, R.; Lu, S.; McCool, M.; Kazdoba, T.; Del Vecchio, R.; Guthrie, D.; Pond, A.; Grzelak, M.; Xu, X.; Korfmacher, W.; Tulshian, D.; Parker, E.; Higgins, G., Characterization of the nociceptin receptor (ORL-1) agonist, Ro64-6198, in tests of anxiety across multiple species. Psychopharmacology 2005, 182 (1), 132-143.

255. Higgins, G.; Grottick, A.; Ballard, T.; Richards, J.; Messer, J.; Takeshima, H.; Pauly-Evers, M.; Jenck, F.; Adam, G.; Wichmann, J., Influence of the selective ORL1 receptor agonist, Ro64-6198, on rodent neurological function. Neuropharmacology 2001, 41 (1), 97-107.

256. Dautzenberg, F. M.; Wichmann, J.; Higelin, J.; Py-Lang, G.; Kratzeisen, C.; Malherbe, P.; Kilpatrick, G. J.; Jenck, F., Pharmacological characterization of the novel nonpeptide orphanin FQ/nociceptin receptor agonist Ro 64-6198: rapid and reversible desensitization of the ORL1 receptor in vitro and lack of tolerance in vivo. Journal of Pharmacology and Experimental Therapeutics 2001, 298 (2), 812-819.

257. Ko, M.-C.; Woods, J. H.; Fantegrossi, W. E.; Galuska, C. M.; Wichmann, J.; Prinssen, E. P., Behavioral effects of a synthetic agonist selective for nociceptin/orphanin FQ peptide receptors in monkeys. Neuropsychopharmacology 2009, 34 (9), 2088-2096.

258. Wichmann, J.; Adam, G.; Röver, S.; Cesura, A. M.; Dautzenberg, F. M.; Jenck, F., 8acenaphthen-1-yl-1-phenyl-1, 3, 8-triaza-spiro [4.5] decan-4-one derivatives as orphanin FQ receptor agonists. Bioorganic \& medicinal chemistry letters 1999, 9 (16), 2343-2348.

259. Hashiba, E.; Harrison, C.; Calo, G.; Guerrini, R.; Rowbotham, D.; Smith, G.; Lambert, D., Characterisation and comparison of novel ligands for the nociceptin/orphanin FQ receptor. NaunynSchmiedeberg's archives of pharmacology 2001, 363 (1), 28-33.

260. Kotlinska, J.; Wichmann, J.; Legowska, A.; Rolka, K.; Silberring, J., Orphanin FQ/nociceptin but not Ro 65-6570 inhibits the expression of cocaine-induced conditioned place preference. Behavioural pharmacology 2002, 13 (3), 229-235.

261. Rutten, K.; De Vry, J.; Bruckmann, W.; Tzschentke, T. M., Effects of the NOP receptor agonist Ro65-6570 on the acquisition of opiate-and psychostimulant-induced conditioned place preference in rats. European journal of pharmacology 2010, 645 (1-3), 119-126.

262. Ferrari, F.; Cerlesi, M. C.; Malfacini, D.; Asth, L.; Gavioli, E. C.; Journigan, B. V.; Kamakolanu, U. G.; Meyer, M. E.; Yasuda, D.; Polgar, W. E.; Rizzi, A.; Guerrini, R.; Ruzza, C.; Zaveri, N. T.; Calo, G., In vitro functional characterization of novel nociceptin/orphanin FQ receptor agonists in recombinant and native preparations. European journal of pharmacology 2016, 793, 1-13.

263. Röver, S.; Wichmann, J.; Jenck, F.; Adam, G.; Cesura, A. M., ORL1 receptor ligands: Structureactivity relationships of 8-cycloalkyl-1-phenyl-1, 3, 8-triaza-spiro [4.5] decan-4-ones. Bioorganic \& medicinal chemistry letters 2000, 10 (8), 831-834.

264. Thomsen, C.; Hohlweg, R., (8-Naphthalen-1-ylmethyl-4-oxo-1-phenyl-1,3,8-triazaspiro[4.5]dec-3-yl)-acetic acid methyl ester (NNC 63-0532) is a novel potent nociceptin receptor agonist. British Journal of Pharmacology 2000, 131 (5), 903-908.

265. Chang, S. D.; Mascarella, S. W.; Spangler, S. M.; Gurevich, V. V.; Navarro, H. A.; Carroll, F. I.; Bruchas, M. R., Quantitative signaling and structure-activity analyses demonstrate functional selectivity at the nociceptin/orphanin FQ opioid receptor. Molecular pharmacology 2015, 88 (3), 502-511.

266. Mann, A.; Moulédous, L.; Froment, C.; O’Neill, P. R.; Dasgupta, P.; Günther, T.; Brunori, G.; Kieffer, B. L.; Toll, L.; Bruchas, M. R.; Zaveri, N. T.; Schulz, S., Agonist-selective NOP receptor 
phosphorylation correlates in vitro and in vivo and reveals differential post-activation signaling by chemically diverse agonists. Science Signaling 2019, 12 (574), eaau8072.

267. Hayashi, S.; Hirao, A.; Imai, A.; Nakamura, H.; Murata, Y.; Ohashi, K.; Nakata, E., Novel NonPeptide Nociceptin/Orphanin FQ Receptor Agonist, 1-[1-(1-Methylcyclooctyl)-4-piperidinyl]-2-[(3 R)3-piperidinyl]-1 H-benzimidazole: Design, Synthesis, and Structure- Activity Relationship of Oral Receptor Occupancy in the Brain for Orally Potent Antianxiety Drug. Journal of medicinal chemistry 2009, 52 (3), 610-625.

268. Hirao, A.; Imai, A.; Sugie, Y.; Yamada, Y.; Hayashi, S.; Toide, K., Pharmacological characterization of the newly synthesized nociceptin/orphanin FQ-receptor agonist 1-[1-(1Methylcyclooctyl)-4-piperidinyl]-2-[(3R)-3-piperidinyl]-1H-benzimidazole as an anxiolytic agent. Journal of pharmacological sciences 2008, 106 (3), 361-368.

269. Kawamoto, H.; Ozaki, S.; Itoh, Y.; Miyaji, M.; Arai, S.; Nakashima, H.; Kato, T.; Ohta, H.; Iwasawa, Y., Discovery of the first potent and selective small molecule opioid receptor-like (ORL1) antagonist: 1-[(3 R, 4 R)-1-cyclooctylmethyl-3-hydroxymethyl-4-piperidyl]-3-ethyl-1, 3-dihydro-2 Hbenzimidazol-2-one (J-113397). Journal of medicinal chemistry 1999, 42 (25), 5061-5063.

270. Zaveri, N. T.; Jiang, F.; Olsen, C. M.; Deschamps, J. R.; Parrish, D.; Polgar, W.; Toll, L., A novel series of piperidin-4-yl-1, 3-dihydroindol-2-ones as agonist and antagonist ligands at the nociceptin receptor. Journal of medicinal chemistry 2004, 47 (12), 2973-2976.

271. Arcuri, L.; Novello, S.; Frassineti, M.; Mercatelli, D.; Pisanò, C. A.; Morella, I.; Fasano, S.; Journigan, B. V.; Meyer, M. E.; Polgar, W. E.; Brambilla, R.; Zaveri, N. T.; Morari, M., AntiParkinsonian and anti-dyskinetic profiles of two novel potent and selective nociceptin/orphanin FQ receptor agonists. British journal of pharmacology 2018, 175 (5), 782-796.

272. Schiller, P. W., Bi-or multifunctional opioid peptide drugs. Life sciences 2010, 86 (15-16), 598603.

273. Gomes, I.; Fujita, W.; Gupta, A.; Saldanha, S. A.; Negri, A.; Pinello, C. E.; Eberhart, C.; Roberts, E.; Filizola, M.; Hodder, P.; Devi, L. A., Identification of a $\mu-\delta$ opioid receptor heteromer-biased agonist with antinociceptive activity. Proceedings of the National Academy of Sciences 2013, 110 (29), 12072-12077.

274. Cunningham, C. W.; Elballa, W. M.; Vold, S. U., Bifunctional opioid receptor ligands as novel analgesics. Neuropharmacology 2019.

275. Tiwari, V.; He, S.-Q.; Huang, Q.; Liang, L.; Yang, F.; Chen, Z.; Tiwari, V.; Fujita, W.; Devi, L. A.; Dong, X.; Guan, Y.; Raja, S. N., Activation of $\mu-\delta$ opioid receptor heteromers inhibits neuropathic pain behavior in rodents. Pain 2020, 161 (4), 842-855.

276. Gach-Janczak, K.; Piekielna-Ciesielska, J.; Adamska-Bartłomiejczyk, A.; Wtorek, K.; Ferrari, F.; Szymaszkiewicz, A.; Piasecka-Zelga, J.; Janecka, A., In vitro and in vivo activity of cyclopeptide Dmt-c [d-Lys-Phe-Asp] NH2, a mu opioid receptor agonist biased toward $\beta$-arrestin. Peptides 2018, 105, 5157.

277. Schiller, P. W.; Nguyen, T.; Weltrowska, G.; Wilkes, B. C.; Marsden, B. J.; Lemieux, C.; Chung, N. N., Differential stereochemical requirements of mu vs. delta opioid receptors for ligand binding and signal transduction: development of a class of potent and highly delta-selective peptide antagonists. Proceedings of the National Academy of Sciences 1992, 89 (24), 11871-11875.

278. Schiller, P. W.; Weltrowska, G.; Nguyen, T. M.; Wilkes, B. C.; Chung, N. N.; Lemieux, C., TIPP [. psi.]: a highly potent and stable pseudopeptide. delta. opioid receptor antagonist with extraordinary. delta. selectivity. Journal of medicinal chemistry 1993, 36 (21), 3182-3187.

279. Schiller, P.; Weltrowska, G.; NGUYEN, T.-D.; Chung, N.; Lemieux, C., Tipp analogs: highly selective $\delta$ opioid antagonists with subnanomolar potency and first known compounds with mixed $\mu$ agonist/ $\delta$ antagonist properties. Regulatory peptides 1994, S63-S64.

280. Schiller, P. W.; Weltrowska, G.; Berezowska, I.; Nguyen, T. M. D.; Wilkes, B. C.; Lemieux, C.; Chung, N. N., The TIPP opioid peptide family: development of $\delta$ antagonists, $\delta$ agonists, and mixed $\mu$ agonist/ $\delta$ antagonists. Peptide Science 1999, 51 (6), 411-425. 
281. Pasquinucci, L.; Turnaturi, R.; Calò, G.; Pappalardo, F.; Ferrari, F.; Russo, G.; Arena, E.; Montenegro, L.; Chiechio, S.; Prezzavento, O.; Parenti, C., (2S)-N-2-methoxy-2-phenylethyl-6,7benzomorphan compound (2S-LP2): Discovery of a biased mu/delta opioid receptor agonist. European Journal of Medicinal Chemistry 2019, 168, 189-198.

282. Váradi, A.; Palmer, T. C.; Haselton, N.; Afonin, D.; Subrath, J. J.; Le Rouzic, V.; Hunkele, A.; Pasternak, G. W.; Marrone, G. F.; Borics, A.; Majumdar, S., Synthesis of Carfentanil Amide Opioids Using the Ugi Multicomponent Reaction. ACS Chemical Neuroscience 2015, 6 (9), 1570-1577.

283. Gutridge, A. M.; Robins, M. T.; Cassell, R. J.; Uprety, R.; Mores, K. L.; Ko, M. J.; Pasternak, G. W.; Majumdar, S.; van Rijn, R. M., G protein-biased kratom-alkaloids and synthetic carfentanil-amide opioids as potential treatments for alcohol use disorder. British Journal of Pharmacology 2020, 177 (7), 1497-1513.

284. Cerlesi, M. C.; Ding, H.; Bird, M. F.; Kiguchi, N.; Ferrari, F.; Malfacini, D.; Rizzi, A.; Ruzza, C.; Lambert, D. G.; Ko, M.-C.; Calo, G.; Guerrini, R., Pharmacological studies on the NOP and opioid receptor agonist PWT2-[Dmt1] N/OFQ (1-13). European journal of pharmacology 2017, 794, 115126.

285. Molinari, S.; Camarda, V.; Rizzi, A.; Marzola, G.; Salvadori, S.; Marzola, E.; Molinari, P.; McDonald, J.; Ko, M.; Lambert, D.; Calo', G.; Guerrini, R., [Dmt1] N/OFQ (1-13)-NH2: a potent nociceptin/orphanin FQ and opioid receptor universal agonist. British journal of pharmacology 2013, 168 (1), 151-162.

286. Khroyan, T. V.; Polgar, W. E.; Cami-Kobeci, G.; Husbands, S. M.; Zaveri, N. T.; Toll, L., The first universal opioid ligand,(2S)-2-[(5R, 6R, 7R, 14S)-N-cyclopropylmethyl-4, 5-epoxy-6, 14-ethano-3hydroxy-6-methoxymorphinan-7-yl]-3, 3-dimethylpentan-2-ol (BU08028): characterization of the in vitro profile and in vivo behavioral effects in mouse models of acute pain and cocaine-induced reward. Journal of Pharmacology and Experimental Therapeutics 2011, 336 (3), 952-961.

287. Ding, H.; Czoty, P. W.; Kiguchi, N.; Cami-Kobeci, G.; Sukhtankar, D. D.; Nader, M. A.; Husbands, S. M.; Ko, M.-C., A novel orvinol analog, BU08028, as a safe opioid analgesic without abuse liability in primates. Proceedings of the National Academy of Sciences 2016, 113 (37), E5511E5518.

288. Chen, S.-R.; Ke, Y.-Y.; Yeh, T.-K.; Lin, S.-Y.; Ou, L.-C.; Chen, S.-C.; Chang, W.-T.; Chang, H.-F.; Wu, Z.-H.; Hsieh, C.-C.; Law, P.-Y.; Loh, H. H.; Shih, C.; Lai, Y.-K.; Yeh, S.-H.; Ueng, S.-H., Discovery, structure-activity relationship studies, and anti-nociceptive effects of $\mathrm{N}-(1,2,3$, 4-tetrahydro-1isoquinolinylmethyl) benzamides as novel opioid receptor agonists. European journal of medicinal chemistry 2017, 126, 202-217.

289. Chao, P.-K.; Chang, H.-F.; Chang, W.-T.; Yeh, T.-K.; Ou, L.-C.; Chuang, J.-Y.; Hsu, J. T.-A.; Tao, P.-L.; Loh, H. H.; Shih, C.; Ueng, S.-H.; Yeh, S.-H., BPR1M97, a dual mu opioid receptor/nociceptinorphanin FQ peptide receptor agonist, produces potent antinociceptive effects with safer properties than morphine. Neuropharmacology 2020, 166, 107678.

290. Ding, H.; Kiguchi, N.; Yasuda, D.; Daga, P. R.; Polgar, W. E.; Lu, J. J.; Czoty, P. W.; Kishioka, S.; Zaveri, N. T.; Ko, M.-C., A bifunctional nociceptin and mu opioid receptor agonist is analgesic without opioid side effects in nonhuman primates. Science translational medicine 2018, 10 (456).

291. Khroyan, T. V.; Zaveri, N. T.; Polgar, W. E.; Orduna, J.; Olsen, C.; Jiang, F.; Toll, L., SR 16435 [1(1-(bicyclo [3.3. 1] nonan-9-yl) piperidin-4-yl) indolin-2-one], a novel mixed nociceptin/orphanin $\mathrm{FQ} / \mu$-opioid receptor partial agonist: analgesic and rewarding properties in mice. Journal of Pharmacology and Experimental Therapeutics 2007, 320 (2), 934-943.

292. Khroyan, T. V.; Polgar, W. E.; Jiang, F.; Zaveri, N. T.; Toll, L., Nociceptin/orphanin FQ receptor activation attenuates antinociception induced by mixed nociceptin/orphanin $\mathrm{FQ} / \mu$-opioid receptor agonists. Journal of Pharmacology and Experimental Therapeutics 2009, 331 (3), 946-953.

293. Toll, L.; Khroyan, T. V.; Polgar, W. E.; Jiang, F.; Olsen, C.; Zaveri, N. T., Comparison of the antinociceptive and antirewarding profiles of novel bifunctional nociceptin receptor/ $\mu$-opioid receptor ligands: Implications for therapeutic applications. Journal of Pharmacology and Experimental Therapeutics 2009, 331 (3), 954-964. 
294. Schunk, S.; Linz, K.; Hinze, C.; Frormann, S.; Oberbörsch, S.; Sundermann, B.; Zemolka, S.; Englberger, W.; Germann, T.; Christoph, T.; Kögel, B. Y.; Schröder, W.; Harlfinger, S.; Saunders, D.; Kless, A.; Schick, H.; Sonnenschein, H., Discovery of a potent analgesic NOP and opioid receptor agonist: cebranopadol. ACS medicinal chemistry letters 2014, 5 (8), 857-862.

295. Linz, K.; Christoph, T.; Tzschentke, T. M.; Koch, T.; Schiene, K.; Gautrois, M.; Schröder, W.; Kögel, B. Y.; Beier, H.; Englberger, W.; Schunk, S.; De Vry, J.; Jahnel, U.; Frosch, S., Cebranopadol: a novel potent analgesic nociceptin/orphanin FQ peptide and opioid receptor agonist. Journal of Pharmacology and Experimental Therapeutics 2014, 349 (3), 535-548.

296. Rizzi, A.; Cerlesi, M. C.; Ruzza, C.; Malfacini, D.; Ferrari, F.; Bianco, S.; Costa, T.; Guerrini, R.; Trapella, C.; Calo', G., Pharmacological characterization of cebranopadol a novel analgesic acting as mixed nociceptin/orphanin FQ and opioid receptor agonist. Pharmacology research \& perspectives 2016, 4 (4), e00247.

297. Grünenthal Fueling our pipeline with innovation. https://www.grunenthal.com/en/r-dvision-mission/pipeline (accessed April $17^{\text {th }}$ ).

298. Göhler, K.; Sokolowska, M.; Schoedel, K. A.; Nemeth, R.; Kleideiter, E.; Szeto, I.; Eerdekens, M.-H., Assessment of the Abuse Potential of Cebranopadol in Nondependent Recreational Opioid Users: A Phase 1 Randomized Controlled Study. Journal of Clinical Psychopharmacology 2019, 39 (1), 46-56.

299. Li, Y.; Liu, X.; Liu, C.; Kang, J.; Yang, J.; Pei, G.; Wu, C., Improvement of morphine-mediated analgesia by inhibition of $\beta$-arrestin 2 expression in mice periaqueductal gray matter. International journal of molecular sciences 2009, 10 (3), 954-963.

300. Yang, C.-H.; Huang, H.-W.; Chen, K.-H.; Chen, Y.-S.; Sheen-Chen, S.-M.; Lin, C.-R., Antinociceptive potentiation and attenuation of tolerance by intrathecal $\beta$-arrestin 2 small interfering RNA in rats. British journal of anaesthesia 2011, 107 (5), 774-781.

301. Thompson, G. L.; Kelly, E.; Christopoulos, A.; Canals, M., Novel GPCR paradigms at the $\mu$ opioid receptor. British Journal of Pharmacology 2015, 172 (2), 287-296.

302. Onaran, H. O.; Ambrosio, C.; Uğur, Ö.; Madaras Koncz, E.; Grò, M. C.; Vezzi, V.; Rajagopal, S.; Costa, T., Systematic errors in detecting biased agonism: Analysis of current methods and development of a new model-free approach. Scientific Reports 2017, 7 (1), 44247.

303. Kenakin, T., Is the Quest for Signaling Bias Worth the Effort? Molecular Pharmacology 2018, 93 (4), 266-269.

304. Machelska, H.; Celik, M. Ö., Opioid Receptors in Immune and Glial Cells-Implications for Pain Control. Front Immunol 2020, 11, 300-300.

305. Kabli, N.; Martin, N.; Fan, T.; Nguyen, T.; Hasbi, A.; Balboni, G.; O'Dowd, B.; George, S., Agonists at the $\delta$-opioid receptor modify the binding of $\mu$-receptor agonists to the $\mu-\delta$ receptor hetero-oligomer. British journal of pharmacology 2010, 161 (5), 1122-1136.

306. Rozenfeld, R.; Devi, L. A., Receptor heterodimerization leads to a switch in signaling: $\beta$ arrestin2-mediated ERK activation by $\mu-\delta$ opioid receptor heterodimers. The FASEB Journal 2007, 21 (10), 2455-2465.

307. Wang, D.; Sun, X.; Bohn, L. M.; Sadee, W., Opioid receptor homo-and heterodimerization in living cells by quantitative bioluminescence resonance energy transfer. Molecular pharmacology 2005, 67 (6), 2173-2184.

308. Olson, K. M.; Lei, W.; Keresztes, A.; LaVigne, J.; Streicher, J. M., Novel Molecular Strategies and Targets for Opioid Drug Discovery for the Treatment of Chronic Pain. Yale J Biol Med 2017, 90 (1), 97-110.

309. Tan, L.; Yan, W.; McCorvy, J. D.; Cheng, J., Biased Ligands of G Protein-Coupled Receptors (GPCRs): Structure-Functional Selectivity Relationships (SFSRs) and Therapeutic Potential. Journal of Medicinal Chemistry 2018, 61 (22), 9841-9878.

310. McCorvy, J. D.; Butler, K. V.; Kelly, B.; Rechsteiner, K.; Karpiak, J.; Betz, R. M.; Kormos, B. L.; Shoichet, B. K.; Dror, R. O.; Jin, J.; Roth, B. L., Structure-inspired design of $\beta$-arrestin-biased ligands for aminergic GPCRs. Nature chemical biology 2018, 14 (2), 126-134. 
311. Zhao, B.; Li, W.; Sun, L.; Fu, W., The Use of Computational Approaches in the Discovery and Mechanism Study of Opioid Analgesics. Front Chem 2020, 8, 335-335.

312. Claff, T.; Yu, J.; Blais, V.; Patel, N.; Martin, C.; Wu, L.; Han, G. W.; Holleran, B. J.; Van der Poorten, O.; White, K. L.; Hanson, M. A.; Sarret, P.; Gendron, L.; Cherezov, V.; Katritch, V.; Ballet, S.; Liu, Z.-J.; Müller, C. E.; Stevens, R. C., Elucidating the active $\delta$-opioid receptor crystal structure with peptide and small-molecule agonists. Science Advances 2019, 5 (11), eaax9115.

313. Congreve, M.; Marshall, F., The impact of GPCR structures on pharmacology and structurebased drug design. British Journal of Pharmacology 2010, 159 (5), 986-996.

314. Che, T.; Majumdar, S.; Zaidi, S. A.; Ondachi, P.; McCorvy, J. D.; Wang, S.; Mosier, P. D.; Uprety, R.; Vardy, E.; Krumm, B. E.; Han, G. W.; Lee, M.-Y.; Pardon, E.; Steyaert, J.; Huang, X.-P.; Strachan, R. T.; Tribo, A. R.; Pasternak, G. W.; Carroll, F. I.; Stevens, R. C.; Cherezov, V.; Katritch, V.; Wacker, D.; Roth, B. L., Structure of the nanobody-stabilized active state of the kappa opioid receptor. Cell 2018, 172 (1-2), 55-67. e15.

315. Uprety, R.; Che, T.; Zaidi, S. A.; Grinnell, S. G.; Varga, B. R.; Faouzi, A.; Slocum, S. T.; Allaoa, A.; Varadi, A.; Nelson, M.; Bernhard, S. M.; Kulko, E.; Le Rouzic, V.; Eans, S. O.; Simons, C. A.; Hunkele, A.; Subrath, J.; Pan, Y. X.; Javitch, J. A.; McLaughlin, J. P.; Roth, B. L.; Pasternak, G. W.; Katritch, V.; Majumdar, S., Controlling opioid receptor functional selectivity by targeting distinct subpockets of the orthosteric site. Elife 2021, 10, e56519.

316. Trevena Olinvyk ${ }^{\mathrm{TM}}$ is now approved. https://olinvyk.com/ (accessed October $28^{\text {th }}$ ).

317. Mullard, A., FDA approves first GPCR biased agonist. Nature reviews. Drug Discovery 2020. 